Universidad de Lima

Escuela de Posgrado

Maestría en Tributación y Política Fiscal

\title{
ANÁLISIS COMPARATIVO DE LA \\ REGULACIÓN DEL PROGRAMA DE \\ OPERADOR ECONÓMICO AUTORIZADO EN \\ LOS PAÍSES DE LA ALIANZA DEL \\ PACÍFICO Y UNA PROPUESTA DE MEJORA \\ PARA EL PERÚ RESPECTO AL ALCANCE \\ DE LA CERTIFICACIÓN Y LOS BENEFICIOS \\ OTORGADOS
}

Trabajo de investigación para optar el Grado Académico de Maestro en

Tributación y Política Fiscal

Iván Genaro Ledesma Vilchez

Código 20031581

Asesor: Silvia León Pinedo

Julio de 2019 


\begin{abstract}
ANÁLISIS COMPARATIVO DE LA REGULACIÓN DEL PROGRAMA DE OPERADOR ECONÓMICO AUTORIZADO EN LOS PAÍSES DE LA ALIANZA DEL PACÍFICO Y UNA PROPUESTA DE MEJORA PARA EL PERÚ RESPECTO AL ALCANCE DE LA CERTIFICACIÓN Y LOS BENEFICIOS OTORGADOS
\end{abstract}

COMPARATIVE ANALYSIS OF THE REGULATION OF THE PROGRAM OF AUTHORIZED ECONOMIC OPERATORS IN COUNTRIES BELONGING TO THE PACIFIC ALLIANCE AND A PROPOSAL OF IMPROVEMENT FOR PERU WITH RESPECT TO THE REACH OF CERTIFICATION AND BENEFITS GRANTED 


\section{TABLA DE CONTENIDOS}

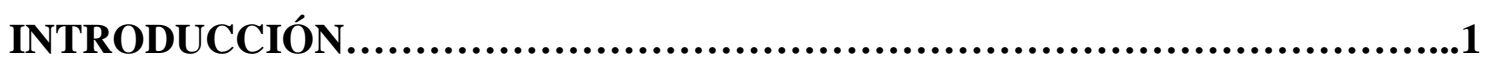

CAPÍTULO I: LAS AMENAZAS A LA CADENA INTERNACIONAL DE SUMINISTRO .............................................................3

$1.1 \quad$ Visión general....................................................... 3

1.2 Las nuevas amenazas a la cadena de suministro y el rol de las aduanas..........5

CAPÍTULO II: LA PROTECCIÓN DE LA CADENA INTERNACIONAL DE SUMINISTRO: EL PROGRAMA DE OPERADOR ECONÓMICO

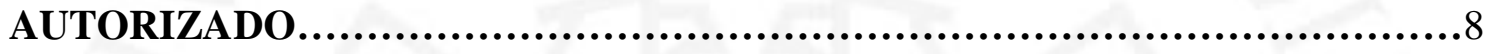

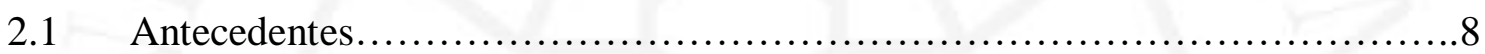

2.2 El Marco normativo SAFE de la Organización Mundial de Aduanas..............9

2.3 El operador económico autorizado ........................................ 12

2.4 El operador económico autorizado supranacional: Los acuerdos de reconocimiento mutuo de los programas OEA .................................. 14

2.5 Panorama general de los programas de operador económico autorizado en los países de la región...................................................... 17

CAPÍTULO III: EL OPERADOR ECONÓMICO AUTORIZADO EN EL PERÚ...................................................................... 20

$3.1 \quad$ Marco regulatorio general............................................ 20

3.1 Condiciones y requisitos para la certificación OEA ..........................22

3.2 Procedimiento de certificación como operador económico autorizado..........25

3.3 Beneficios otorgados al operador económico autorizado....................26

CAPÍTULO IV: EL PROGRAMA DE OPERADOR ECONÓMICO AUTORIZADO EN EL MARCO DE LA ALIANZA DEL PACÍFICO........... 28

$4.1 \quad$ Visión General....................................................... 28

4.2 El Programa del operador económico autorizado en México................. 30

4.3 El Programa del operador económico autorizado en Colombia................ 32

4.3 El Programa del operador económico autorizado en Chile....................34 
4.4 Comparación de la regulación de los programas de operador económico autorizado del Perú, México, Colombia y Chile, respecto al alcance de la certificación y los beneficios otorgados................................................... 36

4.4.1 Justificación del alcance de la comparación............................. 36

4.4.2 Análisis comparativo del marco regulatorio OEA en Colombia y México..........38

CAPÍTULO V: PROPUESTAS DE MEJORA DEL MARCO REGULATORIO EN EL PERÚ RESPECTO AL ALCANCE DE LA CERTIFICACIÓN Y BENEFICIOS DEL PROGRAMA DE OPERADOR ECONÓMICO AUTORIZADO...............59

5.1 Necesidad de mejorar el marco regulatorio ante las nuevas amenazas..........60

5.1.1 Los delitos informáticos en las cadenas de suministro.......................60

5.1.2 La renovación tecnológica permanente en materia aduanera..................60

5.1.3 La prevención de las amenazas sanitarias y agrícolas........................61

5.2 Mejoras propuestas del marco regulatorio................................62

5.2.1 Participación de las entidades gubernamentales que intervienen en el control de mercancías que ingresan o salen del territorio nacional.............................62

5.2.2 Nuevos actores en el programa del operador económico autorizado.............64

5.2.3 Nuevos beneficios en materia de simplificación y atención preferente...........66

5.2.4 Beneficios en materia de servicios tributarios............................. 70

5.2.5 Beneficios otorgados por otras entidades gubernamentales de control...........71

PROYECTO DE LEY QUE CREA EL COMITÉ DE COORDINACION MULTISECTORIAL DEL OPERADOR ECONÓMICO AUTORIZADO, APRUEBA LINEAMIENTOS PARA EL OTORGAMIENTO DE FACILIDADES Y ESTABLECE EL TRATAMIENTO PREFERENCIAL AL OPERADOR ECONÓMICO AUTORIZADO EN LOS PROCEDIMIENTOS Y SERVICIOS TRIBUTARIOS BRINDADOS POR SUNAT ...................................74

CONCLUSIONES..............................................................78

REFERENCIAS .......................................................................80 


\section{ÍNDICE DE ANEXOS}

Anexo 1: Cuadro comparativo de los requisitos generales OEA de los países miembros de la Alianza del Pacifico ............................................... 84 Anexo 2: Cuadro comparativo de los beneficios otorgados en los programas OEA de los países miembros de la Alianza del Pacifico.................................... 116

Anexo 3: Cuadro de beneficios otorgados en el programa OEA del Perú..............137 


\section{RESUMEN}

En el presente estudio se muestra la importancia de la figura del operador económico autorizado (OEA) para la protección de la cadena internacional de suministro, por lo que resulta necesario el fortalecimiento de los programas OEA a nivel mundial, a fin de crear cadenas globales seguras. En el caso del Perú, se demuestra en el estudio que dicho fortalecimiento requiere de la mejora constante de su marco regulatorio y de la implementación de medidas destinadas a incrementar la adhesión al programa. Para tal fin, se realiza el análisis comparativo del marco regulatorio de los países de la Alianza del Pacifico por tratarse de un modelo de mejores prácticas en materia de OEA, proponiéndose como resultado de este análisis un proyecto de ley que regula la participación en el Perú de otras entidades gubernamentales de control a través de la creación de un comité multisectorial, establece los lineamientos para las facilidades que otorguen, y permita a la SUNAT establecer beneficios en materia de servicios tributarios; además del establecimiento de nuevas categorías OEA vinculadas a este esquema de certificación único y la incorporación de nuevos operadores al programa; todo esto con el objetivo de incrementar la adhesión al programa, la participación de los OEA en el comercio exterior del país y la seguridad de la cadena logística internacional.

Palabras clave: cadena de suministro, Alianza del Pacífico, OEA 


\begin{abstract}
In the following study we will put forth the importance of the figure of the authorized economic operator (AEO) in the protection of the international chain of supply, for which it is necessary the strengthening of AEO programs on a worldwide scale, with the purpose of creating safe global chains. In the case of Peru, we will show in the study that said strengthening requires a constant improvement of its regulatory framework, and the implementation of actions destined to increment the adhesion to the program. For said purpose, we will conduct a comparative analysis of the regulatory framework of countries belonging to the Pacific Alliance (Alianza del Pacifico) due to it being a model of better practices in matters of AEO, proposing as a result of this analysis a bill that regulates the participation of Peru in other government control entities through the creation of a multisectoral committee, establishing the guidelines for facilities they grant, and enabling SUNAT establish benefits in matter of tax services; in addition to the establishment of new AEO categories linked to this scheme of unique certification and the incorporation of new operators to the program; all of this with the objective of increasing the adhesion to the program, the participation of AEO in foreign trade of the country and the security of the international logistics chain.
\end{abstract}

Keywords: Supply chain, Pacific Alliance, AEO 


\section{INTRODUCCIÓN}

Como resultado del incremento de las amenazas globales a la cadena internacional de suministro, surge el programa del Operador Económico Autorizado (OEA) como una iniciativa destinada a establecer un estándar de seguridad internacional, basado en la participación de los actores del comercio exterior considerados confiables, sistema que fue adoptado por el Perú en el año 2013.

Sin embargo, y al igual que los distintos programas OEA implementados a nivel mundial, en el Perú dicho programa se encuentra en un proceso de fortalecimiento e innovación permanente, por cuanto su participación en las operaciones de importación y exportación de bienes, en función al número de empresas certificados y el volumen total de las operaciones realizadas por estos, es aún reducida, por lo que se requiera hacer más atractivo el programa en base a un marco normativo ágil, una mayor base de operadores que incorpore distintos tipos de actores y un esquema de beneficios tangibles.

Por otro lado, con la globalización del comercio y la innovación tecnológica, las amenazas a la cadena de suministro han evolucionado, así la prevención de las amenazas relacionadas a la seguridad informática, la seguridad sanitaria o agrícola, la protección ambiental, entre otras vulnerabilidades y riesgos actuales, deben incorporarse en los estándares de seguridad de los Programas OEA.

Del mismo modo, la existencia de cadenas logísticas que involucran varios países, obliga a repensar el rol de las aduanas, sustituyendo el control fronterizo en cada país, por la gestión integrada de todas las fronteras comprometidos en dicha cadena, así como incentivar la participación de los socios confiables, como es el caso de los operadores económicos autorizados.

En ese escenario, el Programa OEA del Perú no solo requiere de su fortalecimiento local, sino también de su reconocimiento internacional mediante la suscripción de acuerdos de reconocimiento mutuo con los programas OEA de otros países, siendo uno de los más importantes el acuerdo suscrito el 2018 con los países de la Alianza del Pacifico: México, Colombia y Chile. 
Las ventajas obtenidas por el Perú con este acuerdo son indudables, y si bien es cierto que se ha demostrado la compatibilidad de los respectivos Programas OEA en el proceso de negociación del citado Acuerdo, la evaluación comparativa del marco regulatorio de estos programas, en particular sobre el alcance y los requisitos de certificación, así como los beneficios otorgados, constituye una valiosa oportunidad de mejora, a fin de identificar las soluciones implementadas por cada uno de los países respecto a las nuevas amenazas globales, los nuevos roles de la Aduana respecto a la gestión coordinada en fronteras, los esquemas de beneficios otorgados y el éxito obtenido, así como cualquier otro aspecto que potencie y haga más atractivos sus respectivos programas; todo esto a fin de evaluar su eventual incorporación en el Programa OEA en el Perú.

En suma, consideramos justificada la realización del análisis comparativo materia del presente trabajo, así como las conclusiones que se obtengan respecto a las compatibilidades o diferencias de los respectivos Programas OEA y las mejores prácticas verificadas, en lo referido al alcance de la certificación y los beneficios otorgados a las empresas que la obtienen, las cuales servirán de sustento para la elaboración de una propuesta de mejora del marco regulatorio del Programa OEA en el Perú que se incluye en el presente trabajo. 


\section{CAPÍTULO I: LAS AMENAZAS A LA CADENA INTERNACIONAL DE SUMINISTRO}

\subsection{Visión general}

El suministro entendido como abastecimiento, es una actividad económica fundamental para cubrir las necesidades de una persona, familia, empresa o cualquier otra unidad social o empresarial.

Dicha actividad económica ha evolucionado desde el mercado tradicional al traslado de bienes para su intercambio dentro o fuera de las fronteras de un país. En ese sentido, la dimensión física del suministro, desde su inicio (fabricación del bien destinado al intercambio) hasta su conclusión (consumo del bien), se ha vuelto más compleja, por cuanto ha incorporado otras actividades complementarias, como por ejemplo el embalaje, la consolidación de mercancías, el transporte local e internacional, la gestión aduanera, etc. que permiten que el suministro se realice en forma efectiva.

Esa serie de actividades es precisamente una cadena de suministro, que incorpora una red de empresas u operadores, que van desde el proveedor de la materia prima hasta la entrega del producto final. A través de esta fluyen todos los materiales, recursos, servicios y productos, pudiendo extenderse a otros países, en cuyo caso estaremos hablando de una cadena internacional o global de suministro, que puede atravesar una o varias fronteras e incorporar cadenas subsidiarias (como por ejemplo la provisión de materias primas para la producción del bien suministrado).

En suma, si bien es cierto que el suministro y las cadenas que lo componen, existen como actividad económica desde los albores de la humanidad, no existió hasta hace un tiempo una visión integral u holística del suministro como un todo, o, mejor dicho, como una "cadena global de suministro". Este concepto se ha desarrollado recién en los últimos 30 años y ha predominado como el marco conceptual de toda actividad comercial, sea cual fuere el nivel (fabricante, comercializador, etc.) o la extensión de la cadena (minorista, mayorista, proveedor de servicios, etc.).

En ese orden de ideas, una definición completa del término "cadena de suministro" es la postulada por David Blanchard como "La secuencia de eventos que 
cubren el ciclo de vida entero de un producto o servicio desde que es concebido hasta que es consumido"1.

Ahora bien, esa red de suministro como un todo, tiene como objetivo principal asegurar que los bienes lleguen a destino, en el tiempo más breve y al menor costo posible; esta dependencia de la eficacia de una cadena de suministro ha hecho que cualquier vulneración o interrupción de esta genere mucho daño, lo que, sumado a la natural fragilidad de una cadena extensa, como es el caso de una cadena global o internacional, agrava su impacto en el comercio exterior y la economía.

De este modo, el impacto de estas vulnerabilidades en los costos es mayor en el caso de proveedores o países riesgosos, por lo que cualquier ventaja en los precios que pudiera tener determinado país, no tendría efecto alguno si hay un mayor riesgo de vulnerabilidad, afectando en forma directa la competitividad. Este problema se presenta en cierta medida en América Latina, con la presencia del narcotráfico, el terrorismo y los delitos financieros vinculados a estas actividades ${ }^{2}$.

Por otro lado, y tal como se explicó respecto a la evolución del concepto de cadena de suministro, el concepto de seguridad de la cadena global tiene un antes y después con los atentados del 11 de setiembre de 2001 en las Torres Gemelas de Manhattan, New York; este terrible evento generó la aparición de varias iniciativas gubernamentales, que si bien es cierto estaban orientadas a reforzar la seguridad de la cadena de suministro, impactaron inicialmente en sus tiempos y costos, habiéndose requerido de todo un proceso para integrarlas en un sistema único de estándares de seguridad que no entorpeciese el comercio internacional, sino más bien que se apoyase en la participación de operadores confiables y en el conocimiento de todos los eslabones de la cadena. Es el caso del programa del gobierno de los Estados Unidos de América "Customs-Trade Program Against Terrorism" (C-TPAT), el cual constituye el modelo de estándar de seguridad de la cadena global de suministro más exitoso a nivel mundial, el cual sirvió de inspiración para el marco internacional de seguridad de la Organización Mundial de Aduanas, que a su vez impulsó el programa del operador económico autorizado.

\footnotetext{
${ }^{1}$ David Blanchard (2010), Supply Chain Management Best Practices, 2nd. Edition, John Wiley \& Sons, ISBN 9780470531884

${ }^{2}$ Young, Richard R.; Esqueda, Paul, Vulnerabilidades de la cadena de suministros: consideraciones para el caso de América Latina. Academia. Revista latinoamericana de Administración (en línea) 2005, (primer semestre)
} 
Cabe señalar sobre este punto, que las amenazas a la cadena global de suministro que motivaron el establecimiento de iniciativas y estándares de seguridad, no solo han provenido del terrorismo internacional, sino también del tráfico de drogas, el comercio de mercancías prohibidas o peligrosas, el robo de mercancías o infraestructura, el blanqueo de dinero o lavado de activos, los delitos contra la propiedad intelectual, entre otros, cometidos por organizaciones criminales igualmente globales; sin embargo, la evolución del comercio ha dado lugar a la aparición de nuevos amenazas, como veremos en el siguiente acápite.

\subsection{Las nuevas amenazas a la cadena de suministro y el rol de las aduanas} En los últimos años, el comercio internacional de mercancías se ha incrementado en volumen y complejidad. De acuerdo con el Informe de Perspectivas de la Economía Mundial (2019), del Fondo Monetario Internacional, el volumen del comercio mundial de mercancías, medido por el promedio de las exportaciones e importaciones de bienes y servicios, mostró un crecimiento del $4 \%$ en 2018, con una proyección igual para el $2019^{3}$.

Este incremento del comercio mundial exige que las aduanas ejerzan sus funciones sin entorpecer el flujo del comercio. En tal sentido, el rol tradicional de las aduanas de controlar la circulación de mercancías para asegurar los intereses del Estado, y garantizar la percepción de ingresos, no es suficiente para ejercer en forma oportuna y eficiente la función de protección y seguridad de la cadena de suministro.

En tal sentido, el control aduanero convencional en las fronteras debe recurrir al uso intensivo de la gestión de riesgo en base a la información anticipada trasmitida desde el país de exportación por la aduana de origen, o por los mismos operadores; del mismo modo, deberá impulsarse la gestión coordinada en fronteras de tal forma que exista un solo control (o por lo menos la menor cantidad posible de estos) en toda la extensión de la cadena de suministro, de tal forma que el control efectuado en una aduana de salida, por ejemplo, sea suficiente para permitir el ingreso de las mercancías en la aduana de ingreso, sin que sea necesario un nuevo control. Por último, la aduana deberá recurrir a los operadores considerados como socios confiables, para cuyo fin puede establecer calificaciones de confianza a dichos operadores a cambio del otorgamiento de beneficios

\footnotetext{
${ }^{3}$ https://www.imf.org/es/Publications/WEO/Issues/2019/01/11/weo-update-january-2019
} 
que aseguren su participación en la seguridad y cumplimiento; esto lo veremos más adelante cuando desarrollemos la figura del operador económico autorizado.

Por otro lado, a medida que la cadena global de suministro se va integrando digitalmente y es administrada mediante el uso intensivo de tecnologías de información, se incrementa el riesgo de ataques cibernéticos, vulneraciones de datos y otras formas de interrupción de la cadena. Las razones son complejas y variadas: puede ser la obtención de secretos comerciales o industriales, o información financiera de clientes, la extorsión, la generación de trastornos económicos como parte de una guerra comercial, etc.

Del mismo modo, la seguridad sanitaria o agrícola cobra protagonismo ante la existencia de cadenas globales de suministro muy vulnerables a riesgos vinculados a la contaminación agrícola o sanitaria.

La Organización de las Naciones Unidas para la Alimentación y la Agricultura (FAO) informa que una de cada diez personas, sufre de enfermedad por contaminación alimentaria y 420000 mueren por esa razón. El 70 por ciento de las nuevas enfermedades tienen origen animal y el 30\% de la producción agrícola mundial se pierde cada año por enfermedades de las plantas que pueden propagarse a otros países ${ }^{4}$.

En ese orden de ideas, las cadenas globales de suministro incrementan la posibilidad de que estas amenazas se transfieran a otros países con efectos muy dañinos. La contaminación de un alimento o producto agrícola en la fase de elaboración o producción, por ejemplo, que generalmente se realiza en un país distinto al de consumo, hace difícil identificar el origen de la contaminación. En consecuencia, resulta necesario que los estándares de seguridad incorporen medidas de prevención de la contaminación sanitaria o agrícola, los cuales deben respetarse en toda la cadena de suministro

A manera de conclusión de esta sección, queda claro que las amenazas existentes a la cadena global de suministro, así como los nuevos peligros que la acechan, no pueden ser enfrentadas por las aduanas mediante un control convencional, por lo que además del uso intensivo de la gestión de riesgo y la integración de los controle, se requerirá además de la implementación de estándares de seguridad que garanticen la participación de actores seguros y confiables en toda la extensión de la cadena y que incorporen las medidas de prevención necesarias para. En este punto surge la pregunta si los modelos de

\footnotetext{
${ }^{4}$ http://www.fao.org/news/story/es/item/469315/icode/
} 
estándares de seguridad vigentes en nuestro país cumplen con esta función. Esa pregunta es la que trataremos de resolver en los siguientes acápites. 


\section{CAPÍTULO II: LA PROTECCIÓN DE LA CADENA INTERNACIONAL DE SUMINISTRO: EL PROGRAMA DE OPERADOR ECONÓMICO AUTORIZADO}

\subsection{Antecedentes}

Como se ha comentado anteriormente, el atentado del 11 de setiembre en New York fue el punto de quiebre respecto a la necesidad de utilizar esquemas o iniciativas de seguridad de la cadena internacional de suministro por parte de las autoridades aduaneras, a fin de prevenir o combatir las amenazas globales. Esto no significa que antes no hayan existido otras iniciativas en materia de seguridad, siendo las principales las siguientes:

- Carrier Iniciative Program - CIP (1984)

El Programa Iniciativa del Transportista fue establecido en 1984 por los transportistas aéreos y marítimos para prevenir la contaminación de carga con narcóticos.

- $\quad$ ACSI (1997)

La Iniciativa contra el contrabando en las Américas (ACSI) surgió para frenar el tráfico de drogas en los embarques comerciales, fortaleciendo los programas de seguridad del sector privado en los centros de manufactura y de exportación de los países productores y tránsito de drogas.

- $\operatorname{BASC}(1996)$

El programa Business Anti-Smuggling Coalition o Coalición Empresarial Anticontrabando constituyó como un programa de cooperación entre el sector privado y organismos nacionales y extranjeros, orientado al comercio internacional seguro, el cual se inició en 1996 como una iniciativa de lucha contra el tráfico de drogas bajo la iniciativa de la Aduana de Estados Unidos de América.

Sin embargo, el principal esfuerzo en materia de seguridad sigue siendo el programa Customs-Trade Partnership Against Terrorism (C-TPAT), implementado por el gobierno de Estados Unidos de América en noviembre de 2001 con solo 7 participantes y que para el año 2014 ya contaba con 10,854 miembros. Este programa constituye una asociación voluntaria entre la aduana y el sector privado con el objetivo de cooperar en 
el fortalecimiento de la cadena de suministro; para dicho fin, las empresas deben cumplir con los estándares que fortalezcan sus prácticas de seguridad y conocer a sus asociados de negocios en toda la cadena de suministro, entre otros compromisos, siendo reconocidos como operadores de bajo riesgo con menos posibilidades de ser seleccionados a control en la aduana de ingreso de Estados Unidos, entre otros beneficios otorgados

De acuerdo con el portal del CTPAT, ${ }^{5}$ existen a la fecha más de 11,400 socios confiables certificados que incluyen importadores, exportadores, transportistas de carreteras, ferroviarios o marítimos; agentes de aduana, operadores portuarios, consolidadores de carga, entre otros, todos los cuales representan más del 52 por ciento de la carga que ingresa a EE. UU.

Las empresas que participan del programa CTPAT, a cambio de cumplir con los compromisos de seguridad mencionados, reciben una serie de beneficios exclusivos, entre ellos:

- Menor selección a exámenes por parte de la aduana

- Atención preferente en las inspecciones aduaneras

- Reducción de tiempos de espera en los controles de frontera.

- Asignación de un especialista en seguridad de la cadena de suministro

- Acceso a carriles de atención preferente en las fronteras

- Beneficios adicionales otorgados por las aduanas de otros países con los que Estados Unidos haya suscrito acuerdos de reconocimiento mutuo

Como resultado de la implementación del programa CTPAT, el entorno regulatorio mundial evolucionó totalmente, apareciendo iniciativas a cargo de organizaciones gubernamentales o privadas, de alcance local o internacional, destinadas a dotar de mayor seguridad a las cadenas globales de suministro. Es en ese escenario que surge el Marco Normativo SAFE establecido por la Organización Mundial de Aduanas, el cual describiremos a continuación.

\subsection{El Marco normativo SAFE de la Organización Mundial de Aduanas}

Teniendo en cuenta los antecedentes comentados en los anteriores acápites, en junio de 2005 la Organización Mundial de Aduanas (OMA) adoptó el Marco Normativo para

\footnotetext{
${ }^{5}$ https://www.cbp.gov/border-security/ports-entry/cargo-security/ctpat
} 
Asegurar y Facilitar el Comercio Global, Marco SAFE (de sus siglas en inglés "Security and Facilitation in a Global Environment") con el objetivo de establecer normas que garanticen la seguridad de la cadena logística y faciliten el comercio a nivel mundial, aumentando de este modo la certidumbre y predictibilidad, así como la fluidez del movimiento de mercancías a través de las cadenas logísticas internacionales.

Este documento internacional constituye el hito principal para la adopción de normas modernas de seguridad de la cadena logística a nivel mundial, estableciendo una serie de enfoques innovadores, como es el caso del reconocimiento de la importancia de la asociación entre la aduana y la empresa privada mediante la figura del operador económico autorizado, la gestión integrada y coordinada de las fronteras, la previsión de la continuidad y reanudación del comercio, la información anticipada sobre la carga, entre otros estándares. Cabe señalar que la OMA agrupa al 99\% de las aduanas a nivel mundial, por lo que constituye la plataforma ideal para la implementación global de esta iniciativa de seguridad.

En ese orden de ideas, el Marco SAFE incorpora disposiciones en lo referido a la cooperación aduanera (intercambio de información, reconocimiento mutuo de controles, asistencia administrativa, etc.), la cooperación con otros organismos que intervienen en el control de mercancías (control fitosanitario o zoosanitario, control de armas, explosivos u otras mercancías peligrosas) y los estándares aplicables a los operadores económicos autorizados (beneficios sugerido según el tipo de operador de comercio exterior certificado como OEA). Todas estas medidas tienen por objeto mantener un equilibrio entre seguridad y facilitación del comercio, es decir, que no se vean incrementados los costos para las aduanas y operadores del comercio ${ }^{6}$.

En tal sentido, el Marco SAFE tiene como objetivos principales:

- Establecer normas que aseguren y faciliten la cadena logística global.

- Permitir la gestión de la cadena logística para todos los modos de transporte.

- Mejorar las capacidades de las Aduanas.

- Fortalecer la cooperación entre las administraciones aduaneras, así como la cooperación con otras autoridades que intervienen en el control.

- Fortalecer la cooperación entre Aduanas y empresas.

\footnotetext{
${ }^{6}$ La versión de junio 2018 incorpora las mejoras referidas en el presente párrafo sobre la cooperación entre las autoridades aduaneras y otras agencias gubernamentales y la lista sugerida de beneficios OEA.
} 
Por otro lado, el Marco SAFE consta de cuatro elementos de acción básicos:

- El uso de la información anticipada al ingreso o salida de mercancías.

- El uso de la gestión de riesgo para la prevención de amenazas.

- El control o inspección en salida.

- Otorgamiento de beneficios a las empresas asociadas con la aduana.

Finalmente, y en base a los elementos antes mencionados orientados al cumplimiento de los objetivos del sistema, el Marco SAFE se asienta sobre tres pilares de colaboración:

- Pilar 1: La asociación Aduanas-Aduanas. Esta asociación entre las administraciones aduaneras busca que se efectúe la transmisión previa de información sobre las mercancías por medios electrónicos, y así poder identificar cargas riesgosas para cualquier país, siendo necesario para ello la utilización intensiva de tecnologías de información. Comprende un total de once estándares.

- Pilar 2: La asociación Aduanas- Empresas. Las administraciones aduaneras a nivel internacional implementan el segundo pilar a través de los denominados programas de operador económico autorizado, los cuales promueven la introducción de mejores prácticas y estándares internacionales que contribuyan a la seguridad de la cadena logística, la facilitación del comercio seguro y a la reducción del fraude fiscal. Este pilar está compuesto de seis estándares, siendo el lineamiento fundamental del Marco SAFE.

- Pilar 3: La cooperación de las Aduanas con otras autoridades públicas. Este pilar constituido por once estándares tiene como objetivo garantizar que las autoridades públicas respondan a los desafíos de seguridad de la cadena logística, evitando la duplicación de controles, simplificando los mismos y estableciendo normas internacionales que aseguren el flujo de mercancías. Es el caso, por ejemplo, de la cooperación entre las Aduanas y las autoridades de seguridad interna y de transporte (caso de la policía), los servicios que actúan en fronteras (agricultura, sanidad animal, etc.) y los organismos emisores de licencias (mercancías restringidas o protegidas).

Conforme a lo expuesto, la asociación Aduanas - Empresa, expresada a través del programa del operador económico autorizado (OEA), constituye la principal herramienta 
para el aseguramiento de la cadena global de suministro, cuyas principales características describiremos a continuación.

\subsection{El operador económico autorizado}

El concepto del Operador Económico Autorizado (OEA) tiene su origen en el Pilar 2 del Marco Normativo $\mathrm{SAFE}^{7}$, el cual lo define como:

Una parte que interviene en el traslado internacional de mercancías con cualquier capacidad que le haya sido reconocida por o en nombre de una administración nacional aduanera que cumple con las normas de la OMA o las normas de seguridad equivalentes de la cadena logística. Los OEA pueden ser fabricantes, importadores, exportadores, agentes aduaneros, transportistas, agentes de grupaje de carga, intermediarios, operadores de puertos, aeropuertos o terminales, operadores de transporte integrado, operadores de almacenes, distribuidores o transitarios (p. 43)

El objetivo del programa OEA es identificar a las empresas privadas que ofrezcan una alta garantía de seguridad respecto a la cadena logística, las cuales recibirán beneficios tangibles en materia de celeridad de sus operaciones, inmediatez de los controles y otras medidas. De este modo, constituyen el primer y más confiable filtro de prevención de amenazas, reduciendo los riesgos que deben enfrentar las aduanas y facilitando el ejercicio de sus funciones de seguridad y facilitación del comercio legítimo.

El Marco SAFE establece los criterios que deben cumplir las empresas para ser reconocidas como socios autorizados en cuestiones de seguridad, como por ejemplo la evaluación de amenazas, la existencia de un plan de seguridad, la seguridad física de los ambientes de carga o almacenamiento, la seguridad de los medios de transporte, el control del personal y la protección de la información.

Del mismo modo, las aduanas o los entes administradores de los programas OEA deben establecer los beneficios tangibles que obtendrán los OEA, como puede ser una menor selección a control aduanero, el trato preferente para sus despachos, la simplificación de trámites, una comunicación más efectiva con la administración

\footnotetext{
${ }^{7}$ Marco Normativo SAFE para asegurar y facilitar el comercio mundial. Organización Mundial de Aduanas, junio 2018. http://www.wcoomd.org/-/media/wco/public/es/pdf/topics/facilitation/instruments-andtools/tools/safe-package/safe-framework.pdf?la=en
} 
aduanera y en general el prestigio que otorga contar con dicha certificación oficial para las relaciones de negocios y la competitividad de las empresas.

Con relación a las obligaciones que deben ser cumplidas por un actor para ser reconocido como un operador económico autorizado, el Anexo IV del Marco de Normas SAFE establece el estándar recomendado para los programas OEA que se implementen. Dichas obligaciones se agrupan en los siguientes rubros:

- Comprobación del cumplimiento de las disposiciones aduaneras

Esto significa que se debe verificar que el actor no tenga antecedentes de incumplimiento de sus obligaciones y que no haya cometido las infracciones seleccionadas por la aduana, en un plazo determinado

- Sistema de seguimiento de sus operaciones

Este requisito implica mantener los archivos de sus operaciones y asegurar el acceso de la aduana a los mismos, los cuales deben contar con sistemas de seguimiento y control protegidos de cualquier uso indebido

- Solvencia financiera

Demostrar que cuenta con la solidez financiera suficiente para cumplir con sus compromisos.

- Consulta, cooperación y comunicación; acceso a la información y confidencialidad

Las aduanas y las empresas OEA deben interactuar en forma permanente, para lo cual se deben designar corresponsales, a fin de suministrar información oportunamente, la cual deberá tener la estructura necesaria y cumplir con las reglas de seguridad de la información.

- Educación, formación e información

Estas obligaciones se refieren al conocimiento sobre la cultura de seguridad que deben tener todos los integrantes de una organización, a fin de detectar cualquier desviación u oportunidad de mejora y proponer las alternativas de solución.

- Seguridad de la carga, de los medios de transporte, de las instalaciones y del personal y los socios comerciales 
Estas obligaciones constituyen el corazón del sistema, por cuanto se trata de las actividades destinadas específicamente a garantizar la integridad de la carga, la protección de las instalaciones y áreas sensibles, así como la participación de colaboradores y socios de negocios confiables, comprometidos con el mantenimiento y mejoramiento de las medidas de seguridad.

En suma, la adopción de los estándares del Pilar 2 del Marco de Normas SAFE por parte de los países que implementen sus programas OEA, refuerza efectivamente la seguridad de la cadena global de suministro, a la vez que logra el equilibrio entre facilitación y control aduanero.

\subsection{El operador económico autorizado supranacional: Los acuerdos de reconocimiento mutuo de los programas OEA}

De acuerdo a lo expuesto en el acápite anterior, la certificación como operador económico autorizado garantiza ante la aduana la participación de un actor confiable en la cadena global de suministro, lo cual redunda en la seguridad de las operaciones de comercio exterior; sin embargo, hemos visto que las cadenas de suministro globales involucran varios países y administraciones aduaneras, en cuyo caso el reconocimiento de un operador económico autorizado dentro de las fronteras de un determinado país, le resta eficiencia a la cadena global al no poder extender dicho operador su calidad de operador confiable a los demás países participantes de la cadena. Surge entonces la necesidad de que dicho reconocimiento sea supranacional y se extienda más allá de las fronteras de un país, y aquí se genera un problema: el reconocimiento individual que podría gestionar un OEA certificado en un determinado país, para ser certificado como tal en otro país, resultaría sumamente costoso e ineficiente. Se requiere entonces de un mecanismo global que permita reconocer la certificación OEA otorgada en un país diferente, en tanto sus respectivos programas OEA sean compatibles entre sí; esta figura es reconocida en el Marco de Normas SAFE y se denomina Acuerdo de Reconocimiento Mutuo.

En ese sentido, el Marco SAFE invita a las administraciones aduaneras a establecer mecanismos para el reconocimiento mutuo de la autorización de los operadores económicos autorizados, los controles aduaneros que se realicen y los beneficios que puedan otorgarse a los operadores de ambos programas. Cabe indicar que el estándar único establecido por el Marco SAFE para la certificación de un operador económico 
autorizado, facilita el desarrollo de los sistemas internacionales de reconocimiento mutuo de los programas OEA en los ámbitos bilateral, subregional y mundial.

Se requieren algunas condiciones para que un acuerdo de reconocimiento mutuo funcione, en particular que:

- Los programas OEA sean compatibles y cumplan con los estándares del Marco SAFE;

- $\quad$ Se apruebe un conjunto de normas comunes, aplicables tanto para las Aduanas como para los OEA

- Dichas normas deben aplicarse de manera uniforme

- $\quad$ Exista una delegación legal expresa, en el caso la facultad de certificación sea delegada a una autoridad designada por una Administración Aduanera

- La legislación de cada país debe permitir la celebración de un acuerdo de reconocimiento mutuo.

En adición a lo antes señalado, se tiene que el documento de la OMA denominado Directrices para el Desarrollo de un Acuerdo de Reconocimiento Mutuo ("Guidelines for Developing a Mutual Recognition Arrangement/Agreement") recomienda que, antes de iniciar un proceso de negociación, se debe contar con un Programa OEA implementado y maduro, entre otros.

Como resultado de este desarrollo y los beneficios percibidos por la suscripción de los acuerdos de reconocimiento mutuo, se ha incrementado en los últimos años el número de ARM suscritos en el mundo, los cuales ascienden a 57, más otros 35 en proceso de negociación.

En el caso del Perú, se han firmado recientemente los siguientes acuerdos de reconocimiento mutuo:

- Perú - Corea del Sur

- Perú - Uruguay

- Alianza del Pacífico (Perú, México, Colombia, Chile)

- Perú - EE. UU. 
Se encuentra en proceso de negociación el acuerdo de reconocimiento mutuo con la Comunidad Andina de Naciones (Perú, Colombia, Ecuador y Bolivia)

A manera de información, se adjunta una tabla con los acuerdos de reconocimiento suscritos a nivel mundial, con el detalle de los firmantes y el año de suscripción, observándose el crecimiento de los ARM suscritos en los últimos años, con el récord de doce acuerdos firmados el año 2017, no contándose aun con la información al 2018:

Tabla: Acuerdos de reconocimiento mutuo a nivel mundial 


\begin{tabular}{|c|c|c|c|}
\hline Date & Country & Date & Country \\
\hline June 2007 & New Zealand - USA & October 2014 & USA - Mexico \\
\hline May 2008 & Japan - New Zealand & December 2014 & USA - Singapore \\
\hline June 2008 & Canada - USA & March 2015 & Israel - Korea \\
\hline June 2008 & Jordan - USA & April 2015 & Korea - Dominican Republic \\
\hline June 2009 & Japan - USA & June 2015 & Hong Kong. China - Thailand \\
\hline July 2009 & EU - Norway"z & October 2015 & India-South Korea \\
\hline July 2009 & EU - Switzerland $d^{\sharp *}$ & November 2015 & Switzerland- Norway \\
\hline June 2010 & Canada - Japan & December 2015 & USA - Dominican Republic \\
\hline June 2010 & Canada - Korea & April 2016 & $\begin{array}{l}\text { Agadir Agreement Member } \\
\text { States (Tunisia, Egypt, } \\
\text { Morocco, Jordan) }\end{array}$ \\
\hline June 2010 & Canada - Singapore & March 2016 & Hong Kong. China - Malaysia \\
\hline June 2010 & EU - Japan & May 2016 & Mexico - Canada \\
\hline June 2010 & Korea - Singapore & July 2018 & Australia- New Zealand \\
\hline June 2010 & Korea - USA & August 2018 & Hong Kong. China - Japan \\
\hline January 2011 & Andorra - EU*t & December 2016 & Brazil - Uruguay \\
\hline May 2011 & Japan - Korea & December 2016 & Thailand - Korea \\
\hline June 2011 & Korea - New Zealand & January 2017 & China- Switzerland \\
\hline June 2011 & Japan - Singapore & July 2017 & Canada-Australia \\
\hline Мay 2012 & EU-USA & July 2017 & Korea - Australia \\
\hline June 2012 & China - Singapore & July 2017 & Korea - UAE \\
\hline July 2013 & Korea - China & July 2017 & Canada-Israel \\
\hline October 2013 & China - Hong Kong & July 2017 & Hong Kong. China - Australia \\
\hline November 2013 & $\begin{array}{l}\text { India- Hong Kong. } \\
\text { China }\end{array}$ & October 2017 & Korea - Malaysia \\
\hline February 2014 & $\begin{array}{l}\text { Hong Kong. China - } \\
\text { Korea }\end{array}$ & November 2017 & Israel - China \\
\hline March 2014 & Korea - Mexico & November 2017 & Australia - China \\
\hline May 2014 & EU - China & November 2017 & New-Zealand - China \\
\hline June 2014 & Korea - Turkey & December 2017 & Uruguay - Korea \\
\hline June 2014 & $\begin{array}{l}\text { Hong Kong. China - } \\
\text { Singapore }\end{array}$ & December 2017 & Peru - Korea \\
\hline
\end{tabular}

\begin{tabular}{|l|l|l|l|l|}
\hline June 2014 & Malaysia - Japan & March 2018 & Uruguay - Peru \\
\hline June 2014 & USA - Israel & & \\
\hline
\end{tabular}

Fuente: Compendium of AEO Programmes, OMA, junio 2018 


\subsection{Panorama general de los programas de operador económico autorizado en los países de la región}

A manera de conclusión preliminar del presente capítulo, se muestran algunas cifras sobre el crecimiento de los programas del operador económico autorizado en el continente americano.

De acuerdo con el Compendio de los Programas de Operadores Económicos Autorizados, elaborado por la OMA, existen actualmente 77 programas OEA operativos en todo el mundo. De este total, dieciocho países pertenecen a la región América (Argentina, Bolivia, Brasil, Canadá, Colombia, Costa Rica, Ecuador, Guatemala, Jamaica, México, Panamá, Paraguay, Perú, República Dominicana, Uruguay y Estados Unidos, Chile y El Salvador).

La denominación OEA es utilizada por la mayoría de los programas nacionales en América, con excepción de Canadá (PIP), Costa Rica (PROFAC), Estados Unidos (CTPAT), México (NEEC) y Uruguay (OEC).

Respecto al tipo de operador que puede ser certificado como OEA, los programas nacionales presentan distintos alcances, por ejemplo, en el caso de Brasil, Costa Rica, Guatemala, República Dominicana y Uruguay, se incluyen a todas las partes que intervienen en la cadena logística, condición más cercana a la definición de OEA del Marco de Normas SAFE. En el caso de Argentina, Chile, Ecuador, El Salvador y Paraguay en cambio, se limita la participación a los exportadores e importadores o a los agentes de aduana. Una fórmula intermedia es el caso del Perú, que incorpora además de los importadores, exportadores y agentes de aduana, a los almacenes aduaneros y a las empresas de envíos de entrega rápida.

De acuerdo con el Estudio sobre los Programas del Operador Económico Autorizado en los Países miembros de la ALADI del año $2019^{8}$, los operadores económicos autorizados en el mundo ascienden en total a más de 32.000 actores, de las cuales 14.885 se encuentran en la región América. Dentro de ellos, son Brasil, Canadá, Jamaica, México, República Dominicana y Estados Unidos los países con mayor número de acreditaciones.

\footnotetext{
${ }^{8} \mathrm{http} / / /$ www.aladi.org/biblioteca/Publicaciones/ALADI/Secretaria_General/SEC_Estudios/229rev1.pdf
} 
A continuación, se presenta un cuadro con el estado de los programas OEA operativos en la región América, incluyendo la denominación del programa, el año de inicio, el tipo de operador certificado y el número de empresas autorizadas:

Tabla 1 - Estado de los programas OEA en la región de América

\begin{tabular}{|c|c|c|c|c|}
\hline País & Nombre & Inicio & Tipo de operador & Numero \\
\hline Argentina & $\begin{array}{c}\text { Sistema Aduanero de Operadores } \\
\text { Confiables SAOC }\end{array}$ & 2006 & $\begin{array}{l}\text { Exportadores } \\
\text { Importadores }\end{array}$ & 4 \\
\hline Bolivia & OEA & 2015 & $\begin{array}{c}\text { Exportadores, importadores, Transportistas, } \\
\text { Agentes de aduana, Consolidadores y } \\
\text { Desconsolidadores de carga }\end{array}$ & 31 \\
\hline Brasil & OEA & 2017 & Todos & 84 \\
\hline Chile & OEA & 2017 & Exportadores, Agentes de aduana & 0 \\
\hline Canadá & Partners in Protection PIP & 1995 & $\begin{array}{l}\text { Exportadores, importadores, Transportistas, } \\
\text { Agentes de aduana, Mensajería, Almacenes }\end{array}$ & 1838 \\
\hline Colombia & OEA & 2011 & $\begin{array}{c}\text { Exportadores, } \\
\text { Importadores, Agentes de aduana }\end{array}$ & 47 \\
\hline Costa Rica & PROFAC & 2011 & Todos & 24 \\
\hline Ecuador & OEA & 2015 & Exportadores, Agentes de aduana & 5 \\
\hline El Salvador & OEA de El Salvador & 2015 & $\begin{array}{l}\text { Exportadores, } \\
\text { Importadores }\end{array}$ & 5 \\
\hline Guatemala & OEA de Guatemala & 2011 & Todos & 6 \\
\hline Jamaica & OEA & 2014 & Todos & 133 \\
\hline México & NEEC & 2012 & $\begin{array}{c}\text { Exportadores, importadores, Transportistas, } \\
\text { Agentes de aduana, Mensajería, Almacenes, } \\
\text { Parque Industrial }\end{array}$ & 857 \\
\hline Panamá & OEA & 2016 & Exportadores & 3 \\
\hline Paraguay & OEA & 2018 & Exportadores, Importadores & 1 \\
\hline Perú & OEA & 2012 & $\begin{array}{c}\text { Exportadores, Importadores, Agencias de } \\
\text { aduana, Almacenes, Empresas de Envíos de } \\
\text { Entrega Rápida }\end{array}$ & 110 \\
\hline $\begin{array}{l}\text { República } \\
\text { Dominicana }\end{array}$ & OEA & 2012 & Todos & 111 \\
\hline Uruguay & $\begin{array}{c}\text { Operador económico calificado } \\
\text { OEC }\end{array}$ & 2014 & Todos & 56 \\
\hline $\begin{array}{l}\text { Estados } \\
\text { Unidos }\end{array}$ & C-TPAT & 2001 & $\begin{array}{l}\text { Exportadores, importadores, Transportistas, } \\
\text { Agentes de aduana, Puertos, Consolidadores } \\
\text { de carga, Intermediarios y Fabricantes }\end{array}$ & 11,605 \\
\hline
\end{tabular}

Fuente: Estudio sobre los Programas del Operador Económico Autorizado en los Países miembros de la ALADI, 2019

Como puede apreciarse, el nivel de avance de los programas OEA de los países de la región América es diverso. Por un lado, destaca el programa C-TPAT de Estados Unidos que, como se indicó anteriormente, dio inicio al estándar de seguridad basado en la asociación de la aduana con operadores confiables, y constituye el modelo mundial a seguir; Canadá, que es el programa de seguridad más antiguo de la región, y el segundo en número de operadores certificados; y México, que como veremos más adelante, a partir de su asociación con el Perú mediante la iniciativa OEA de la Alianza del Pacifico, 
constituye una oportunidad para nuestro país de adoptar mejores prácticas en materia de seguridad de la cadena logística. Por último, existen programas en desarrollo que no cuentan aun con operadores certificados o estos son aún pocos (caso de Chile o El Salvador), o que vienen ejecutando planes piloto para su implementación (caso de Argentina y Paraguay).

En conjunto, se observa que la mayoría de los países de la región se viene ajustando al esquema OEA establecido en el Marco Normativo SAFE; en el caso del Perú, el programa OEA muestra un repunte importante con 110 operadores certificados a la fecha, y 35 solicitudes en trámite, ubicándose en el quinto lugar de la región, por número de participantes. 


\section{CAPÍTULO III: EL OPERADOR ECONÓMICO AUTORIZADO EN EL PERÚ}

\subsection{Marco regulatorio general}

La Ley General de Aduanas, Decreto Legislativo Nro. 10539 ${ }^{9}$, incorporó por primera vez la figura del Usuario Aduanero Certificado, denominación que posteriormente fue modificada por Operador Económico Autorizado, definiéndolo como el "operador de comercio exterior certificado por la SUNAT al haber cumplido con los criterios y requisitos dispuestos en el presente Decreto Legislativo, su Reglamento y aquellos establecidos en las normas pertinentes."

Posteriormente, en el mes de abril de 2009, la SUNAT suscribe la carta de intención ante la Organización Mundial de Aduanas mediante la que se compromete a implementar el Marco SAFE, incluyendo el Pilar 2: asociación Aduana -Empresa.

Mediante el Decreto Supremo Nro. 186-2012-EF, se aprobó el Reglamento de Certificación del OEA, estableciendo en el mismo los requisitos y procedimientos para obtener la certificación. Del mismo modo, se aprobó el Procedimiento General de Certificación del OEA INPCFA-PG-13 (versión 1), regulando los aspectos procedimentales, las facilidades a otorgarse y los requisitos de seguridad, con lo cual se dio inicio formalmente al programa OEA en el Perú.

Bajo este contexto, el fortalecimiento del Programa OEA se convirtió en un objetivo importante de la SUNAT y del país, debido a su importancia para la seguridad de la cadena logística y la facilitación aduanera, lo cual fue recogido en diversos instrumentos tales como:

- La Agenda de Competitividad 2014-2018 del Consejo Nacional de Competitividad, que prevé en su línea de "Internacionalización", Objetivo Nro. 03, Subcomponente: Uso de herramientas de facilitación, la actividad 2: "Reformar en el OEA: número, categoría y beneficios".

\footnotetext{
${ }^{9}$ Publicado el 27.6.2008.
} 
- El Plan Estratégico Nacional Exportador al 2025 que considera dentro de su Pilar 3 referido a la facilitación del comercio exterior y eficiencia de la cadena logística internacional, la línea de acción 3.2.3 dirigida a la promoción de la seguridad de la gestión aduanera y fronteriza que incluye entre sus programas la ampliación del número de operadores de comercio que califiquen como operadores económicos autorizados y el impulso a la suscripción de reconocimientos mutuos con aduanas de otros países.

- El Plan Estratégico 2015-2018 de la SUNAT que contempla como Objetivo Estratégico 3: Garantizar la seguridad de la cadena logística.

En ese orden de ideas, mediante el Decreto Legislativo Nro. 1235 se modificaron diversas disposiciones de la Ley General de Aduanas, estableciendo las condiciones para la certificación OEA, tales como:

a) Trayectoria satisfactoria de cumplimiento de la normativa vigente.

b) Sistema adecuado de registros contables y logísticos que permita la trazabilidad de las operaciones.

c) Solvencia financiera debidamente comprobada.

d) Nivel de seguridad adecuado.

Asimismo, se dispuso el otorgamiento de facilidades exclusivas para el operador económico autorizado en materia de simplificación y control aduaneros.

Finalmente, mediante Decreto Supremo Nro. 184-2016-EF se aprobó un nuevo Reglamento de Certificación del OEA que contiene los lineamientos para la forma y modalidad de aplicación de las condiciones, las causales de suspensión o cancelación de la mencionada certificación, y con Resolución de Intendencia Nacional Nro. 00352016/SUNAT/5F0000 se aprobó el procedimiento general "Certificación del Operador Económico Autorizado", DESPA-PG.29 con el nuevo esquema de requisitos y facilidades para el OEA; instrumentos legales que constituyen el marco normativo vigente del programa OEA en el Perú, cuyo detalle se explica a continuación. 


\subsection{Condiciones y requisitos para la certificación OEA}

Como se ha explicado en el acápite anterior, las condiciones que deben ser cumplidas por los operadores para acceder a la certificación OEA se encuentran establecidas en el Artículo $44^{\circ}$ de la Ley General de Aduanas; a su vez, los lineamientos para la acreditación de dichas condiciones, el procedimiento de certificación y las causales de suspensión o cancelación de la misma, se contemplan en el Reglamento de Certificación del Operador Económico Autorizado; finalmente, los requisitos para el cumplimiento y mantenimiento de cada una de estas condiciones, así como los beneficios otorgados y otras disposiciones complementarias, se aprobaron con el Procedimiento de Certificación del Operador Económico Autorizado. En tal sentido y teniendo como sustento el marco normativo antes mencionado, se detallan a continuación las principales disposiciones que regulan los requisitos para obtener la certificación OEA en el Perú:

\section{Disposiciones generales}

En este rubro la principal disposición es la que establece el alcance del programa OEA a los importadores, exportadores, almacenes aduaneros, agentes de aduana y empresas de envíos de entrega rápida, estando la Administración Aduanera facultada para incorporar a cualquier otro actor que intervenga en la cadena global de suministro

\section{Requisitos de Trayectoria satisfactoria de cumplimiento de la normativa vigente}

1. Requisitos generales

- Presentar, de encontrarse obligado, la declaración anual del impuesto a la renta de tercera categoría, así como la información de los estados financieros y balance de comprobación.

- Presentar sus declaraciones de obligaciones tributarias de los doce últimos meses. Este requisito se considera cumplido si el operador se encuentra comprendido en la relación de buenos contribuyentes.

- Haber regularizado, sus declaraciones aduaneras de los regímenes señalados en el procedimiento durante los doce últimos meses.

- No haber generado deudas por obligaciones tributarias y aduaneras que hayan originado medidas cautelares previas al procedimiento de cobranza coactiva, en los últimos cuatro años anteriores 
- No haber sido sancionado con resolución firme y consentida en los últimos cuatro años calendario concluidos, por las infracciones aduaneras señaladas en el procedimiento.

- Los representantes legales acreditados ante la SUNAT no deben registrar investigaciones o procesos judiciales en trámite, o tener condenas por delitos tributarios, aduaneros u otros delitos señalados en el procedimiento, o haber sido sancionados por infracciones administrativas vinculadas a delitos aduaneros en los últimos cuatro años.

2. Requisitos adicionales del exportador

- No registrar en los últimos doce meses ajustes de valor que represente un monto acumulado superior al 2\% del valor FOB declarado anual de sus importaciones.

- No registrar en los últimos doce meses liquidaciones de cobranza por indebida reposición de mercancías en franquicia arancelaria o restitución indebida de derechos arancelarios que represente un monto total superior al 2\% del valor FOB declarado anual del total de sus exportaciones.

3. Requisitos adicionales del importador

- No registrar en los últimos doce meses ajustes de valor que representen un monto acumulado superior al $2 \%$ del valor FOB declarado anual de sus importaciones.

- No registrar en los últimos doce meses liquidaciones de cobranza por tributos dejados de pagar, diferentes al ajuste de valor, como resultado de acciones de control posterior que represente un monto superior al $2 \%$ del valor FOB declarado del total de sus importaciones.

Requisitos de Sistema adecuado de registros contables y logísticos que permita la trazabilidad de las operaciones

- Contar con un sistema de control interno que permita identificar, analizar y adoptar medidas correctivas y de seguimiento sobre las operaciones aduaneras y comerciales.

- Contar con un sistema informático para el registro, control y actualización de sus operaciones logísticas y contables, que permita su trazabilidad.

- Llevar sus libros y registros contables de conformidad a lo dispuesto por las normas que se apliquen a la actividad del operador.

\section{Requisitos de Solvencia Financiera debidamente comprobada}


1. Requisitos generales

- Contar con estados financieros elaborados que reflejen solvencia financiera con capacidad de cumplir sus obligaciones.

- No reflejar pérdidas durante tres años consecutivos en los últimos cuatro años calendario concluidos.

- No estar comprendido en un procedimiento concursal de reestructuración patrimonial, quiebra o liquidación.

- No contar con más de 3 resoluciones de pérdida de aplazamiento o fraccionamiento notificadas, en los últimos cuatro años.

- No tener deuda tributaria o aduanera en una cobranza coactiva en trámite.

- Acreditar un patrimonio neto declarado ante la SUNAT en la Declaración Jurada Anual del Impuesto a la Renta de Tercera Categoría.

2.Requisitos adicionales del exportador

- Haber realizado exportaciones en los últimos dos años calendario concluidos.

3.Requisitos adicionales del importador

- Haber numerado declaraciones aduaneras de importación en los últimos dos años calendario concluidos.

4.Requisito adicional del agente de aduana

- Haber numerado declaraciones de importación y exportación definitiva, por un valor FOB superior a los trescientos millones y 00/100 dólares de los Estados Unidos de América (US\$ 300000 000,00) en los últimos cuatro años calendario concluidos.

5.Requisito adicional de las Empresas de Servicio de Entrega Rápida

- Haber numerado declaraciones de envíos de entrega rápida de importación y exportación, por un valor FOB superior a los cinco millones y 00/100 dólares de los Estados Unidos de América (US\$ 5000 000,00) en los últimos cuatro años calendario concluidos

\section{Requisitos de Nivel de Seguridad Adecuado}

En relación con los requisitos de seguridad, se ha señalado anteriormente que los diversos riesgos que existen en el comercio internacional (narcotráfico, contrabando, tráfico de 
armas, terrorismo, etc.) han motivado que las administraciones aduaneras promuevan el desarrollo e implementación de programas de seguridad como el OEA, a fin de contribuir al fortalecimiento de la seguridad de la cadena logística internacional.

Bajo este contexto, los requisitos de seguridad del programa OEA en el Perú abordan de manera integral los principales aspectos de seguridad de la cadena logística, los cuales toman como referencia los estándares internacionales del Marco SAFE, así como de los programas OEA más consolidados a nivel global.

Por su extensión, los requisitos de seguridad del programa OEA en el Perú se detallarán y comentarán cuando se efectué el análisis comparativo de los marcos regulatorios de los programas OEA de los países de la Alianza del Pacífico, de acuerdo con los cuadros elaborados para dicho fin.

\subsection{Procedimiento de certificación como operador económico autorizado}

El procedimiento de certificación, incluido el plazo para la evaluación de las solicitudes, las causales de suspensión y cancelación y los efectos de esta, entre otras disposiciones, se encuentra regulado en el Reglamento de Certificación OEA, siendo sus principales disposiciones las siguientes:

1. Presentación de la Solicitud de certificación como OEA

La solicitud de certificación como OEA puede efectuarse por más de un tipo de operador, presentando para tal efecto la documentación en forma conjunta, a efectos de una evaluación integral.

2. Verificación y evaluación del cumplimiento

El procedimiento establece el periodo de evaluación respecto del cumplimiento de los requisitos de la certificación como OEA. Además, para la verificación y evaluación del cumplimiento de estos requisitos, se efectuarán visitas de validación, las cuales deben ser previamente coordinadas con los operadores. Estas evaluaciones serán integrales en el caso de que existan requisitos comunes, cuando se hayan presentado para más de un tipo de operador.

3. Procedimiento de Evaluación Periódica de la Certificación como OEA 
Comprende una autoevaluación periódica, conforme a un formato simplificado con el objeto de que el OEA pueda revisar constantemente que mantiene los requisitos, además de comunicar a la aduana los posibles cambios que pudieran existir o mejoras que hayan implementado, siendo además un instrumento que les permite gestionar el riesgo para determinar el alcance de las evaluaciones periódicas, las cuales pueden ser parciales.

4. Procedimiento de Suspensión y Cancelación de la Certificación como OEA

El Reglamento de Certificación OEA establece como causales de suspensión de la certificación:

- No otorgar las facilidades a la Administración Aduanera para que verifique el cumplimiento de las condiciones y requisitos como OEA.

- Incumplir las condiciones y requisitos para mantener la certificación como OEA.

- Usar indebidamente la certificación o las facilidades obtenidas como OEA.

- La fusión con otros operadores no certificados como OEA.

- Haber presentado una solicitud de suspensión de la certificación como OEA.

Del mismo modo, se establecen como causales de cancelación:

- No subsanar o justificar las observaciones efectuadas a satisfacción de la Administración Aduanera, dentro del plazo otorgado en la resolución de suspensión como OEA.

- Haber sido suspendido de la certificación como OEA más de dos veces en los últimos tres años, con las excepciones legales establecidas legalmente.

- Haber presentado una solicitud para la cancelación de la certificación como OEA.

\subsection{Beneficios otorgados al operador económico autorizado}

Uno de los elementos fundamentales del Marco SAFE es el otorgamiento de beneficios por parte de la aduana a los operadores que cumplan los estándares de seguridad de la cadena logística; de tal forma que un programa OEA solo podrá funcionar de manera efectiva si se logra un equilibrio entre la seguridad y la facilitación del comercio, lo cual se obtendrá a través de los beneficios que se otorguen a los OEA, como la simplificación 
de los controles y trámites, en proporción a su participación en el aseguramiento de la cadena global de suministro.

Bajo este contexto, se entiende que el OEA se caracteriza por ser un operador confiable y seguro para las operaciones aduaneras, el cual es certificado por la propia Administración Aduanera al cumplir con una serie de requisitos que involucran cumplimiento de la normatividad, solvencia financiera, gestión comercial y normas de seguridad de la cadena logística. Dicho rol de las empresas es motivado por el otorgamiento a su favor de facilidades tangibles y medibles, que constituyan una mejora efectiva respecto a los procedimientos a los que se someten los operadores económicos no certificados.

En el caso del Perú, el marco regulatorio vigente faculta a la Administración Aduanera a dictar facilidades para los OEA en materia de control y simplificación administrativa, las cuales fueron aprobadas en el Anexo 1 del Procedimiento de Certificación OEA comentado, y se agrupan en los siguientes rubros:

- Consultas, orientación y capacitación

- Disminución del nivel de control aduanero

- Atención preferente en trámites aduaneros

- Reducción de plazos en los trámites aduaneros

- Exención de garantías

- Reconocimiento mutuo

En el anexo 3 del presente trabajo, se detallan las facilidades otorgados por el programa OEA del Perú, así como el tipo de operador beneficiado. 


\section{CAPÍTULO IV: EL PROGRAMA DE OPERADOR ECONÓMICO AUTORIZADO EN EL MARCO DE LA ALIANZA DEL PACÍFICO}

\subsection{Visión General}

La Alianza del Pacifico nació como una iniciativa del Perú en el año 2010 para conformar un área de integración y libre circulación de bienes, servicios, capitales y personas, que constituya una plataforma económica común con proyección al mundo. El Acuerdo fue suscrito el año $2012^{10}$ por Colombia, Chile, México y Perú como estados miembros, y por Panamá y Costa Rica en calidad de estados observadores, entrando en vigor en el mes de julio de 2015 .

A la fecha, la Alianza del Pacífico es el mecanismo de integración comercial más importante en América Latina, siendo que las exportaciones totales de sus países miembros sumaron 560,4 millones de dólares en 2017, mientras que las importaciones alcanzaron la cifra de 571,2 millones de dólares, concentrando en volumen total de comercio, más del $50 \%$ del comercio de América Latina y el Caribe ${ }^{11}$.

Por otro lado, y tomando en cuenta los PBI de cada uno de sus miembros, la Alianza del Pacifico representa el 37\% de la economía de América Latina, constituyendo la octava economía del mundo y la cuarta economía que más contribuirá al crecimiento mundial en los próximos años, siendo además depositaria del 45\% de toda la inversión extranjera recibida en América Latina ${ }^{12}$.

En consecuencia, resulta evidente que las aduanas juegan un papel preponderante en el desarrollo de los objetivos de la Alianza del Pacífico, ya que al promoverse la facilitación del comercio deben impulsarse medidas tales como, la agilización del despacho aduanero que permita que las mercancías sean despachadas en el punto de llegada sin ser trasladadas temporalmente a un depósito u otro recinto, el empleo de

\footnotetext{
${ }^{10}$ En el marco de la IV Cumbre Presidencial realizada el 6 de junio de 2012 en Paranal - Chile

${ }^{11}$ La Alianza del Pacifico. situación perspectivas y propuestas para su consolidación-Fabian Novak 2018

${ }^{12}$ Fabian Novak, ob. cit.
} 
sistemas electrónicos o automatizados que permitan una eficaz y oportuna gestión de riesgo, la interoperabilidad de los sistemas electrónicos entre las aduanas de los cuatro países que facilite el intercambio de información, el desarrollo de un conjunto de elementos y procesos de datos comunes conforme al Modelo de Datos de la OMA, entre otras disposiciones.

Es en ese escenario donde cobra mayor relevancia la figura del operador económico autorizado, como estándar mundial de seguridad para la cadena internacional de suministro y herramienta que combina la facilitación y el control aduanero.

Para dicho fin, en el Protocolo Adicional al Acuerdo Marco de la Alianza Pacífico, firmado en el año 2014 en Cartagena de Indias, Colombia, se establecieron disposiciones sobre facilitación del comercio y cooperación aduanera, regulándose expresamente en el artículo 5.8 sobre la figura del operador económico autorizado.

Dicho artículo estableció que las administraciones aduaneras fomentarán la implementación y fortalecimiento de los programas OEA de conformidad con el Marco Normativo SAFE. Asimismo, dispuso que las aduanas incentivarán y trabajarán en la suscripción de acuerdos de reconocimiento mutuo de sus Programas OEA.

En atención a esta recomendación, y luego de la constitución de un grupo de trabajo especial a cargo del estudio y comparación del marco regulatorio de los respectivos programas de operador económico autorizado, así como de la armonización de dichas disposiciones, las administraciones aduaneras de Perú, Chile, Colombia y México suscribieron el Acuerdo de Reconocimiento Mutuo de sus programas de Operador Económico Autorizado. En el marco de la XIII Cumbre de la Alianza del Pacífico realizada en Puerto Vallarta, México, el 21 de julio de 2018, se constituyó el primer Acuerdo de Reconocimiento Mutuo multilateral en el mundo, siendo reconocido como un modelo de buenas prácticas por parte de la Organización Mundial de Aduanas.

El citado Acuerdo reconoce la compatibilidad de los programas OEA de los países miembros, así como la validez de las certificaciones OEA emitidas por cada uno de ellos, incluidos los beneficios otorgados en materia de reducción de inspección y prioridad en el despacho aduanero, entre otros, reconocidos por cada uno de los programas OEA.

Sobre este punto, es importante señalar que a partir de la información correspondiente al marco regulatorio vigente de los programas OEA de los países de la 
Alianza del Pacifico, se realiza el presente análisis comparativo, esto sin perjuicio de la compatibilidad de los programas formalmente declarada en el texto del citado Acuerdo.

Para un mejor entendimiento del análisis a efectuarse, a continuación, se desarrollan los aspectos más relevantes del marco regulatorio de los programas de operador económico autorizado de México, Colombia y Chile.

\subsection{El Programa del operador económico autorizado en México}

El programa de operador económico autorizado en México se inició el año 2012 con la denominación "Nuevo Esquema de Empresas Certificadas" (NEEC), la cual fue posteriormente cambiada a Operador Económico Autorizado, a fin de adecuarla al estándar de la mayoría de los programas nacionales, quedando su autorización a cargo del Servicio de Administración Tributaria de México (SAT).

El programa OEA de México incorpora a distintos rubros de operadores de comercio exterior, agrupados en dos modalidades: operador económico autorizado y socio comercial. La modalidad del operador económico autorizado puede ser solicitada por los importadores, exportadores, empresas del rubro aeronáutico, textil, controladores, recintos fiscalizados estratégicos, entre otras. A su vez, la modalidad del socio comercial certificado agrupa a los transportistas terrestres, agentes aduanales, transportistas ferroviarios, parques industriales, recintos fiscalizados y empresas de mensajería y paquetería.

El éxito del programa OEA en México se evidencia con el alto número de operadores de comercio exterior que cuentan con la certificación OEA, los cuales para el año 2018 sumaban 786 operadores, cuyas actividades representan el 55\% del comercio exterior de México, siendo su composición la siguiente:

- 558 exportadores e importadores.

- 122 agentes de aduana.

- 100 transportistas terrestres.

- 3 recintos fiscalizados.

- 2 recintos fiscalizados estratégicos.

- 1 empresa de mensajería. 
Respecto al proceso de certificación OEA en México consta de las siguientes etapas:

- Análisis del estado fiscal y aduanero del solicitante.

- Análisis del perfil de seguridad de la empresa y visita de validación.

- Emisión de la certificación OEA cuya validez es de 2 años renovables automáticamente.

Con relación a los requisitos exigidos para obtener la certificación OEA, estos son de naturaleza fiscal, aduanera o de seguridad, siendo los principales los siguientes:

- Contar con una opinión positiva respecto al cumplimiento de sus obligaciones fiscales y aduaneras.

- No encontrarse en el listado de empresas incumplidas.

- $\quad$ No encontrarse suspendido en el Padrón de Importadores.

- Informar de sus clientes y proveedores en el extranjero, así como de sus proveedores de insumos nacionales.

- No haberse interpuesto querella o denuncia penal en contra de sus socios o accionistas, representante legal o integrantes de la administración, en los últimos 3 años.

- Contar con un control de inventarios actualizado y automatizado.

- Cumplir con los requisitos de seguridad agrupados en los rubros de: planeación de la seguridad en la cadena de suministros, seguridad física, controles de acceso físico, socios comerciales, seguridad de procesos, gestión aduanera, seguridad de los vehículos de carga, contenedores, carros de tren, remolques o semirremolques, seguridad del personal, seguridad de la información y documentación, capacitación en seguridad y concientización y manejo e investigación de incidentes.

Por último, el programa OEA en México presenta un esquema de beneficios atractivo, amplio y diferenciado según los rubros y modalidades de la certificación otorgada, otorgando las siguientes facilidades:

- Simplificación de los trámites aduaneros. 
- Reducción porcentual de los reconocimientos físicos.

- Agilización del despacho de aduanas.

- Corrección de sus declaraciones aduaneras sin autorización previa.

- Pago consolidado y diferido de sus obligaciones tributario-aduaneras.

- Asignación de un especialista como ejecutivo de cuenta.

- Carriles exclusivos para importación y exportación.

- Mayores plazos para la importación temporal.

- Beneficios otorgados en el marco de los Arreglos de Reconocimiento Mutuo firmados con diversos países.

Cabe señalar que el programa OEA en México tiene como líneas de acción principales para el futuro, el incremento de los OEA certificados, el fortalecimiento de las alianzas internacionales a través de los acuerdos de reconocimiento mutuo, la integración con otras iniciativas de simplificación (ventanilla única) y el fomento de la cooperación con otras entidades gubernamentales (Policía, Aviación Civil, etc.).

\subsection{El Programa del operador económico autorizado en Colombia}

Los antecedentes del programa de operador económico autorizado en Colombia se remontan al año 2008, con la suscripción por parte de la Dirección de Impuestos y Aduanas Nacionales de Colombia, de la carta de adhesión al marco normativo de la Organización Mundial de Aduanas, iniciándose al año siguiente un plan piloto con empresas del sector privado, a fin de establecer el marco regulatorio del programa.

Como resultado de este proyecto, el Gobierno de Colombia efectuó el lanzamiento oficial del programa OEA en el año 2011 y su respectiva reglamentación, basada en los estándares internacionales establecidos en el Marco SAFE.

Inicialmente, la figura OEA fue prevista solo para los exportadores de determinados productos de exportación tradicional y no tradicional, extendiéndose posteriormente a los importadores, y en el año 2018, a los agentes de aduana. A la fecha, los operadores económicos autorizados en Colombia suman 78 empresas, donde la 
mayoría son solo empresas exportadoras (41) y el resto importadoras, o una combinación de ambas, y agentes de aduana.

Sin embargo, el aspecto más resaltante del programa de operador económico autorizado de Colombia es sin lugar a duda su enfoque interinstitucional, al contar con la participación de otras entidades de control como es el caso del Instituto Colombiano Agropecuario $^{13}$ y el Instituto Nacional de Vigilancia de Medicamentos y Alimentos ${ }^{14}$, estableciéndose para dicho fin dos categorías de operador económico autorizado: Seguridad y simplificación, y Seguridad sanitaria y simplificación, según la participación de alguna de estas entidades en el proceso de verificación y certificación.

La implementación de estas categorías permite a los solicitantes escoger la categoría que más se adapte a sus actividades, en función a los productos que exportan y los requisitos especiales que se requieren.

Otro aspecto para destacar es la integración en el programa de operador económico autorizado como estándar único, de otras iniciativas sobre cumplimiento y seguridad vigentes en Colombia, caso de los denominados "Usuario Aduanero Permanente" y "Usuario Altamente Exportador", los cuales gozaban de un esquema de beneficios en materia de simplificación aduanera.

Respecto al proceso de autorización, este comprende entre otras actividades:

- Verificación de la trayectoria de cumplimiento de la empresa, respecto a sus obligaciones ante la Aduana y las otras entidades de control.

- Verificación de la cadena de suministro de la empresa por parte de la Aduana y las otras entidades de control.

- Emisión de la autorización como operador económico autorizado, la cual tiene una vigencia indefinida, con revalidaciones dentro de los dos años siguientes a la expedición de la certificación.

\footnotetext{
${ }^{13}$ El Instituto Colombiano Agropecuario (ICA) está a cargo de la prevención, vigilancia y control de los riesgos sanitarios, biológicos y químicos para las especies animales y vegetales con el fin de proteger la salud de las personas, los animales y las plantas y asegurar las condiciones del comercio.

${ }^{14}$ El Instituto Nacional de Vigilancia de Medicamentos y Alimentos (INVIMA) tiene como función principal ejercer el control de calidad y seguridad de los medicamentos, productos biológicos, alimentos, bebidas, cosméticos entre otros productos.
} 
Con relación a los beneficios y teniendo en cuenta que las autoridades de control (Aduanas, Policía, entidades de control sanitario y fitosanitario) los reconocen como operadores confiables, participan igualmente del esquema de beneficios, siendo los más resaltantes:

- Asignación de un oficial de control por cada una de las autoridades de control.

- Reducción en el número de controles en los regímenes aduaneros de exportación, importación y tránsito aduanero, por parte de todas las autoridades que intervienen en el control de la mercancía (control aduanero, policial, sanitario o fitosanitario).

- Garantías globales reducidas.

- Inspección de las autoridades de control en el local del exportador.

- Pago consolidado de sus obligaciones tributario-aduaneras.

- Inspecciones no intrusivas de la Policía Nacional.

- Interacción con el VUCE Colombia.

- No presentar una declaración aduanera anticipada en los casos en que sea obligatoria.

- No es necesario garantizar el cumplimiento de las obligaciones aduaneras.

- Reducción de multas en un cincuenta por ciento (50\%).

- Autorización para realizar pagos diferidos de los derechos de importación.

Finalmente, resulta necesario señalar los beneficios otorgados en el marco de los Acuerdos de Reconocimiento Mutuo suscritos por Colombia con las autoridades aduaneras de otros países, por los cuales se reconoce su condición de OEA certificado en dichos países.

\subsection{El Programa del operador económico autorizado en Chile}

El programa del operador económico autorizado en Chile entró en vigor el año 2017 como parte de diversas medidas orientadas a modernizar la legislación aduanera en Chile y dotar de nuevas facultades a su Servicio Nacional de Aduanas.

De manera similar que la mayoría de los modelos OEA implementados en el mundo, el programa OEA en Chile tiene carácter voluntario y gratuito, otorgando la certificación únicamente a las compañías exportadoras y agentes de aduanas, pero con la proyección de extenderlo en fecha próxima a los importadores y empresas de 
mensajería. Teniendo en cuenta que se trata de un programa con un poco más de un año de existencia, solo cuenta con un total de nueve operadores certificados. Es importante resaltar la singularidad de la experiencia chilena respecto a la tardía implementación del programa OEA, respecto a sus pares en la región, por cuanto a pesar que Chile destaca como un país con las mejores prácticas en materia de comercio exterior, adoptando una decidida estrategia de apertura al mercado, se vio afectado por distintos factores que ralentizaron la continuidad del proyecto ${ }^{15}$, como fue el caso de la inestabilidad interna del Servicio Nacional de Aduanas, la oposición de la Asociación Nacional de Funcionarios de Aduanas de Chile y el gremio de los agentes aduaneros, así como el poco apoyo entregado por el Gobierno y la empresa privada ${ }^{16}$.

Sin embargo, esta situación se ha revertido a la fecha, principalmente desde la firma del Acuerdo de Reconocimiento Mutuo con los países de la Alianza del Pacífico, que permite el reconocimiento de la certificación OEA otorgada en Chile y la entrada directa dichos mercados.

Con relación al proceso de acreditación OEA en Chile, las solicitudes presentadas se someten a una evaluación de riesgos para determinar el cumplimiento de las normas aduaneras, financieras y fiscales, en base a la información proporcionada por el interesado, y a la realización de procedimientos de verificación "in situ" para determinar el cumplimiento de las normas de seguridad.

Concluido el proceso de evaluación, la certificación es otorgada con una vigencia de tres años, después del cual se debe solicitar su renovación, efectuándose su seguimiento y reevaluación permanentes a fin de verificar que el operador cumpla con las obligaciones y requisitos. De incumplirse esta obligación, la Aduana puede suspender o revocar la certificación, decisión que es impugnable por los interesados.

Con relación a los beneficios, estos se relacionan igualmente a la simplificación de trámites y reducción de controles, y la mejora de imagen de la empresa certificada como OEA y el posicionamiento de sus marcas, pues será reconocida local e internacionalmente como un proveedor seguro. Los principales beneficios otorgados por el programa OEA en Chile son:

\footnotetext{
${ }^{15}$ Inicialmente lanzado en el año 2009.

${ }^{16}$ Roberto Oviedo Umaña, “Análisis del programa operador económico autorizado”, Universidad de Chile, 2011
} 
- Tiempo de espera reducido y despacho acelerado de sus mercancías;

- Implementación de esquemas de seguridad para las empresas.

- Certificación como socio comercial confiable.

- Beneficios otorgados en el marco de los acuerdos de reconocimiento mutuo suscritos con otros países.

\subsection{Comparación de la regulación de los programas de operador económico autorizado del Perú, México, Colombia y Chile, respecto al alcance de la certificación y los beneficios otorgados}

\subsubsection{Justificación del alcance de la comparación}

En el presente trabajo se ha expuesto la manera en que las amenazas globales surgidas en los últimos años, vienen afectado la continuidad y tangibilidad de la cadena internacional de suministro, impactando en mayor o menor medida a determinados países, caso de los EE. UU; lo cual dio lugar a la aparición de múltiples iniciativas en materia de seguridad, la principal de ellas el programa C-TPAT, que a su vez sirvió de modelo al estándar global del operador económico autorizado, que como vimos anteriormente constituye el involucramiento de aquellos actores considerados seguros y confiables, en la seguridad de la cadena de suministro en la que intervienen.

Vimos también que por la naturaleza global de las operaciones de comercio exterior, la participación de estos operadores seguros no puede limitarse al país donde se les otorgó la certificación, sino que debe extenderse a aquellos otros países que cuenten con el mismo estándar OEA y en donde se demuestre la compatibilidad de sus respectivos programas, de tal manera que el reconocimiento de la condición de operador seguro se extienda a sus operaciones realizadas en el otro país; estamos aquí ante la figura de los acuerdos de reconocimiento mutuo.

La globalización del comercio ha dado lugar a un mayor impulso a la suscripción de estos acuerdos de reconocimiento mutuo, condición que no ha sido ajena al Perú al haberse suscrito hasta la fecha varios de estos acuerdos, siendo uno de los principales el suscrito con los países de la Alianza del Pacifico. 
No se puede dejar de mencionar tampoco que, conforme a lo señalado por la Organización Mundial de Aduanas, la negociación de un acuerdo de reconocimiento presenta múltiples desafíos, como, por ejemplo:

- El enfoque de los programas de OEA en cada país (alcance, tipo de operadores, requisitos, etc.) es a menudo diferente.

- Cada programa tiene su propia terminología.

- Los diferentes beneficios otorgados en cada país pueden hacer difícil establecer la reciprocidad.

- Los programas OEA de cada país se dirigen a diferentes eslabones de la cadena internacional.

- La ausencia de una técnica o mecanismo para hacer frente a la cadena de suministro en su conjunto.

En el caso del Acuerdo de Reconocimiento Mutuo suscrito con los países de la Alianza del Pacifico, el proceso de negociación involucró igualmente la evaluación de la fundamentación legal, la denominación del programa, los tipos de operadores certificados, las categorías de autorización, los requisitos para la obtención de la certificación, el procedimiento de certificación, la verificación de estándares de seguridad, las visitas de validación, renovación y revalidación de la certificación, las causales de suspensión y cancelación y los beneficios otorgados en cada uno de los países.

Como resultado de esta evaluación, se evidenciaron similitudes respecto a cada uno de los puntos señalados; no obstante, se advirtieron también diferencias respecto al alcance del programa, los beneficios otorgados y los actores que pueden ser certificados como OEA en cada uno de estos países, lo que si bien es cierto no conllevó a una disconformidad o el incumplimiento de los criterios generales establecidos para el estándar OEA internacional, sí resulta importante identificarlas, a fin de evaluar si se trata de mejores prácticas que eventualmente deben ser incorporadas e implementadas en el programa OEA del Perú.

En ese orden de ideas y considerando que el trabajo de armonización de los estándares aplicados en cada uno de los países de la Alianza del Pacífico realizado para los fines de la firma del Acuerdo, se orientó principalmente a verificar la compatibilidad de los requisitos específicos y de seguridad. El presente trabajo se limita a la evaluación comparativa del alcance y requisitos generales de los respectivos programas OEA, y 
principalmente a los beneficios que vienen otorgando los programas de México y Colombia $^{17}$, identificando en primer lugar la diferencia de los tratamientos regulatorios para estos rubros, para luego evaluar la pertinencia de su incorporación en el programa OEA del Perú. Sobre este punto se debe considerar que los esquemas de requisitos y beneficios constituyen variables fundamentales para determinar si un programa OEA es atractivo o no; por esa misma razón, las mejoras que se incorporen en los citados rubros serán fundamentales para lograr ese objetivo.

\subsubsection{Análisis comparativo del marco regulatorio OEA en Colombia y México}

Luego de establecido el alcance específico del presente análisis, a continuación, se procede a su desarrollo en base a los tres aspectos principales verificados en la comparación: el programa interinstitucional OEA de Colombia, la incorporación de múltiples actores en el programa OEA de México, y los beneficios en materia tributaria u otorgados por otras entidades de control, en ambos países.

\section{El programa interinstitucional OEA de Colombia}

El objetivo principal del programa OEA a nivel mundial, es la seguridad y facilitación del comercio; sin embargo, para cumplir con dicho objetivo no basta la interacción entre las aduanas, o la asociación entre las aduanas y la empresa privada, sino también se requiere de la participación de todas las agencias gubernamentales que intervienen en el control aduanero, por lo que resulta cada vez más importante la cooperación entre las Aduanas y las autoridades públicas nacionales e internacionales involucradas en la seguridad de la cadena logística.

En ese orden de ideas, los estándares internacionales de gestión coordinada de fronteras y ventanilla única permiten la interacción entre las Aduanas y los demás organismos de control, con el objetivo de que las autoridades públicas respondan ante los desafíos de seguridad de la cadena logística, evitando la duplicidad de requisitos y controles, simplificando procedimientos aduaneros y estableciendo estándares internacionales de control que aseguren el flujo de mercancías con el propósito de facilitar el comercio.

\footnotetext{
${ }^{17}$ No se ha considerado la información correspondiente al programa OEA de Chile, por cuanto dicho programa tiene solo un año de funcionamiento, además de que su alcance es aún reducido.
} 
La seguridad de la cadena logística involucra la participación de múltiples entidades de control, como, por ejemplo, la policía o las autoridades de transporte, o los servicios de control sanitario, fitosanitario o zoosanitario, o las autoridades certificadoras del ingreso o salida de determinadas mercancías, las cuales pueden acordar ejercer controles únicos o realizados en un único acto de verificación.

Esta cooperación para el caso del proceso de certificación OEA, puede incluir el intercambio de información, la evaluación conjunta de requisitos y riesgos, validaciones e inspecciones conjuntas, así como la verificación de los programas de seguridad y las medidas de control correspondientes a cada una de estas entidades gubernamentales.

Respecto a los países de la Alianza del Pacifico, es precisamente Colombia el país pionero en la implementación exitosa de la gestión coordinada en fronteras en materia del operador económico autorizado ${ }^{18}$, no existiendo una figura similar en los programas vigentes de México, Chile o Perú ${ }^{19}$.

Conforme se aprecia del anexo 1, la característica más resaltante del programa OEA en Colombia es la participación de otras autoridades de control, lo cual permite la realización de controles conjuntos, con la mejora en tiempos y costos que esto produce, constituyendo una facilitación efectiva del comercio al reducir el impacto de medidas no arancelarias, como es el caso de los controles previos o concurrentes a cargo de otras entidades (policía, autoridad sanitaria, etc.).

Se ha señalado anteriormente que este programa interinstitucional involucra a la fecha la participación de la Dirección de Impuestos y Aduanas Nacionales de Colombia (DIAN) y la Policía Nacional, así como del Instituto Colombiano Agropecuario y el Instituto Nacional de Vigilancia de Medicamentos y Alimentos, en los casos que corresponda; contemplando la próxima incorporación de otras entidades de control, como

\footnotetext{
${ }^{18}$ La implementación de requisitos y el otorgamiento de beneficios en materia tributaria y de competencia de otros organismos de control han permitido que el programa OEA de Colombia sea reconocido a nivel internacional como un ejemplo en el desarrollo del marco SAFE.

${ }^{19}$ En el caso del Perú, el artículo 4 del Decreto Legislativo Nro. 1433 incorpora la Décimo Cuarta Disposición Complementaria Final de la Ley General de Aduanas, la cual dispone que las entidades nacionales que intervienen en el control aduanero establezcan medidas de seguridad de la cadena de suministro y facilidades para los operadores económicos autorizados; sin embargo, no se establece de que medidas o facilidades se trata, por lo que esta disposición termina siendo declarativa, y no dispositiva o mandatorio; además del hecho de que no se encuentra aún vigente.
} 
es el caso de la Superintendencia de Puertos y Transporte y la Dirección General Marítima de Colombia.

De acuerdo con lo señalado, el programa OEA de Colombia se estructura en dos categorías, en función a la participación de estas entidades de control:

- Categoría OEA Seguridad y Facilitación.

Es la autorización que se otorga con la verificación del cumplimiento de las condiciones y requisitos que garanticen la seguridad en la cadena de suministro internacional y que permite la obtención de beneficios en materia de facilitación de las operaciones de comercio exterior.

La autorización, implementación y desarrollo de esta categoría corresponde a la DIAN y la Policía Nacional de Colombia

- Categoría OEA Seguridad y Facilitación Sanitaria.

Es la autorización que se otorga con la verificación del cumplimiento de las condiciones y requisitos establecidos en la normativa OEA y adicionalmente de aquellas condiciones y requisitos en materia de protección sanitaria, zoosanitaria y fitosanitaria, que permite la obtención de beneficios en materia de facilitación aduanera, otorgados por la Aduana y las entidades de control vinculadas.

La autorización, implementación y desarrollo de esta categoría corresponde a la DIAN, la Policía Nacional de Colombia, el INVIMA y el ICA.

En consecuencia, las empresas podrán optar por la categoría que corresponda a las actividades que realicen, cumpliendo para esto con los requisitos, condiciones y obligaciones establecidas para cada categoría, recibiendo a cambio beneficios exclusivos. Cabe señalar que la Categoría OEA Seguridad y Facilitación Sanitaria solo aplicará a las empresas que, por sus actividades, están sujetas al control sanitario y fitosanitario de ICA e INVIMA.

En suma, ambas categorías tienen un componente obligatorio de seguridad y facilitación, pero solo la Categoría OEA Seguridad y Facilitación Sanitaria, incorpora un componente especial de carácter sanitario o fitosanitario.

Además de los requisitos y condiciones comunes, las empresas que soliciten la certificación OEA en la Categoría Seguridad y Facilitación Sanitaria deben cumplir con lo siguiente: 
- No haber sido objeto de sanciones impuestas por el ICA, relacionadas con el incumplimiento de las condiciones zoosanitarias y fitosanitarias durante los dos años anteriores a la presentación de la solicitud.

- No tener deudas por servicios u obligaciones legalmente exigibles a favor del ICA.

- No haber sido objeto de sanciones sanitarias impuestas por el INVIMA, por el incumplimiento de buenas prácticas, respecto al manejo de productos de competencia de la Entidad durante los dos años anteriores a la presentación de la solicitud.

Sobre este punto, es importante comentar la reciente modificación de la Ley General de Aduanas en nuestro país, que dispuso que las entidades nacionales que intervienen en el control aduanero establezcan medidas de seguridad de la cadena de suministro y facilidades para los operadores económicos autorizados en el Perú; sin embargo, y a la luz de la experiencia interinstitucional del programa OEA colombiano, no resultaría suficiente la dación de esta única disposición, la cual termina siendo declarativa en tanto no se implemente efectivamente la participación de estas entidades de control en el programa OEA del Perú.

Se observa también de la experiencia colombiana que si bien es cierto que la aduana debe constituirse como única autoridad de control en el proceso de certificación de un OEA, caso de la SUNAT en el Perú y la DIAN en Colombia, un programa interinstitucional que involucre la participación de entidades con facultades o autonomías distintas, debería contar con un marco normativo común y con la jerarquía legal suficiente que permita establecer requisitos, procesos de certificación y beneficios, a cargo de entidades distintas a la Aduana.

En el caso de Colombia esta situación se resolvió con la expedición de un Decreto Presidencial firmado por los titulares ministeriales de las entidades participantes en el Programa, el cual no solo estableció las bases normativas respecto a su alcance, condiciones, requisitos, obligaciones, procedimiento de autorización, revalidación, suspensión y cancelación de la autorización, sino también los beneficios para cada una de las categorías OEA y el establecimiento de los órganos de coordinación en materia del OEA, caso del Grupo Consultivo, el Comité Técnico OEA y principalmente el Comité 
Interinstitucional del OEA, a cargo de la gestión coordinada de las entidades participantes.

En el Perú, en cambio, el marco normativo de la Ley General de Aduanas es general, estableciendo las condiciones de certificación y algunas facilidades en materia de simplificación y control aduaneros, delegando la regulación de los aspectos principales del programa, así como el otorgamiento de otras facilidades al Reglamento de Operador Económico Autorizado y al Procedimiento de Certificación OEA que emita la SUNAT. Este esquema normativo, si bien es cierto que resulta sumamente ágil y flexible para los fines del programa OEA en el Perú, al otorgar a la Administración Aduanera las facultades para regular su alcance, los requisitos y procedimientos de certificación y el otorgamiento de facilidades, solo alcanza al ámbito de su competencia, esto es, los temas estrictamente aduaneros, no pudiendo extenderse a los aspectos que son competencia de otras entidades que intervienen en el control aduanero, como serían las autoridades policiales o sanitarias, que cuentan con su propia normativa especial, en cuyo caso se requeriría para nuestro país de una norma con rango de ley general.

Por otro lado, se ha comentado que las disposiciones referidas a la participación de otras entidades de control en el programa OEA del Perú, incorporadas en nuestra legislación (último párrafo del artículo $45^{20}$ y Décimo Cuarta Disposición Complementaria Final de la Ley General de Aduanas) si bien es cierto tienen rango de ley, terminan resultando declarativas, pues solo indican que para su participación en el programa, estas entidades establezcan medidas de seguridad y facilidades, careciendo de efecto mandatorio respecto a la implementación efectiva de estas medidas. Adicionalmente, se debe indicar sobre este punto que, a diferencia del programa OEA de Colombia, no existe en el Perú un órgano coordinador interinstitucional en materia del OEA con las facultades suficientes para impulsar la integración efectiva de estas entidades, que aproveche el desarrollo normativo existente.

A manera de resumen parcial, se concluye del análisis de la mejor practica del programa interinstitucional OEA de Colombia, en la necesidad de que el programa OEA en el Perú incorpore igualmente la participación de otras entidades gubernamentales de control, caso de las autoridades sanitarias y fitosanitarias, incorporándose en el programa

\footnotetext{
${ }^{20}$ Según la modificación del artículo 45 de la Ley General de Aduanas dispuesta por el Decreto Legislativo Nro. 1235 del 26.9.2015.
} 
OEA un esquema de requisitos adecuado a sus requerimientos específicos de seguridad, así como los beneficios que estas entidades otorguen a las empresas que participen en el programa. Teniendo en cuenta el carácter singular de las actividades de comercio exterior vinculadas al control sanitario o fitosanitario, se debe crear un nivel o categoría dentro del programa OEA del Perú que distinga a estos operadores de los demás, a fin de no imponer a todos los OEA certificados, requisitos u obligaciones que no corresponden a las actividades que realizan. Estos cambios, por involucrar competencias de distintas entidades, deberán estar contenidos en una norma con el rango legal suficiente, por lo que en el acápite destinado a las propuestas de mejora del programa OEA, se adjunta el proyecto de ley correspondiente.

\section{La integración de múltiples actores en el programa OEA de México}

Como se explicó anteriormente, la cadena logística internacional en la actualidad es cada vez más compleja, en donde las fronteras nacionales han sido sustituidas por un solo circuito global, el cual integra unidades de producción o servicio, medidas de seguridad, controles aduaneros, etc.; esta economía de escala ha permitido simplificar procesos, reducir costos y asegurar el suministro de cualquier bien en prácticamente cualquier lugar del planeta. Hemos visto también que la extensión de esta cadena y las potenciales vulnerabilidades en cada uno de los elementos que la componen, han hecho necesaria la creación de estándares de seguridad; sobre este punto resulta ilustrativa la figura que presentamos a continuación, que muestra el múltiple origen de las piezas de un avión Boeing $787^{21}$, lo cual evidencia la existencia de una compleja red de cadenas logísticas internacionales para la producción de cualquier artículo de consumo, y por ende, la necesidad de que dichas redes se integren en un sistema efectivo de seguridad y control.

\footnotetext{
${ }^{21}$ https://www.uschamber.com/series/above-the-fold/global-supply-chains-explained-one-graphic
} 
Figura: Las cadenas logísticas internacionales en un avión Boeing 787

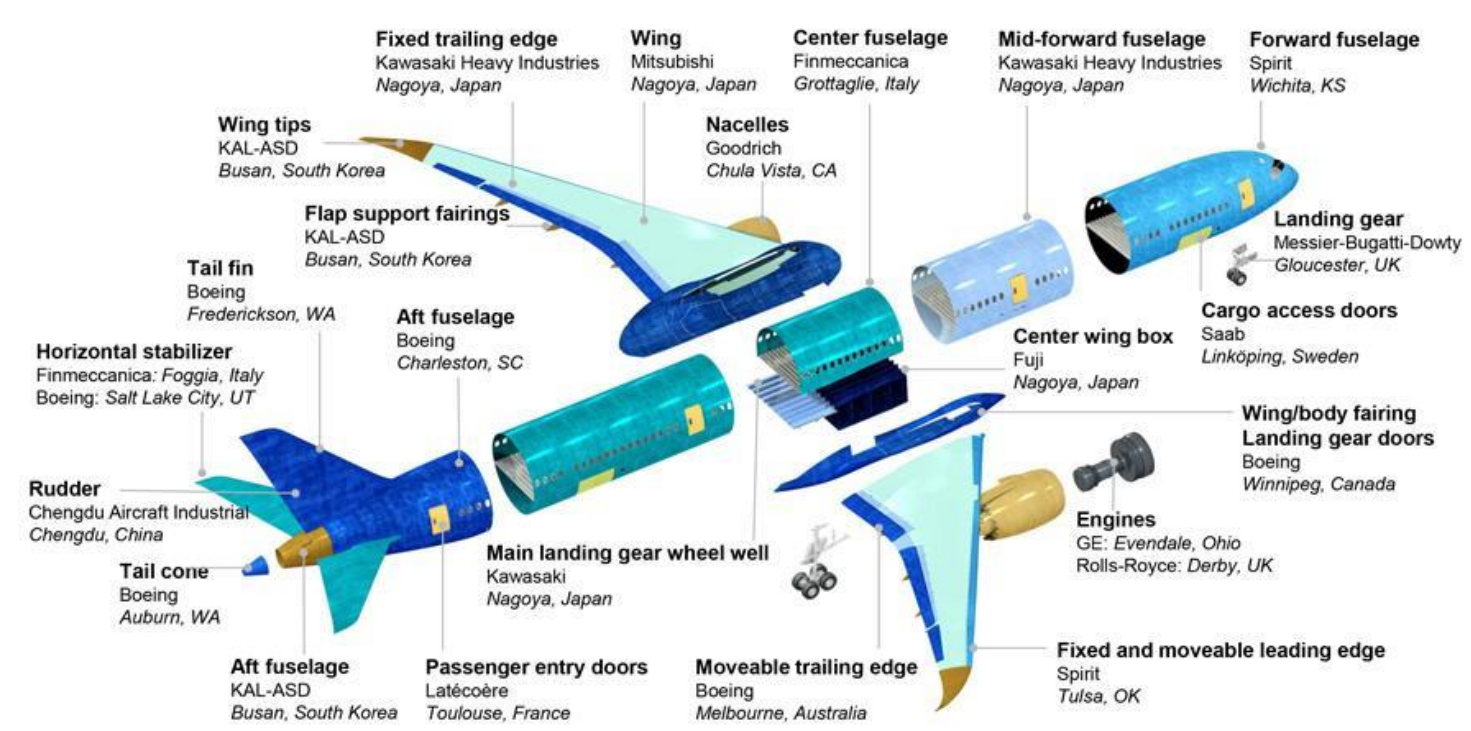

Copyright 02015 Boeing. All rights reserved.

Sobre el particular, la definición de operador económico autorizado de la OMA establece que un OEA es cualquier parte interviniente en el traslado internacional de mercancías, que cumple con las normas de la OMA o las normas de seguridad equivalentes de la cadena logística. En tal sentido, un fabricante, importador, exportador, agente de aduana, transportista, agentes de carga, operador de puertos, aeropuertos o terminales, operador de transporte multimodal, operador de almacenes, distribuidor o transitario, u otro actor interviniente, puede ser un OEA.

En consecuencia, todos los actores que intervienen en una cadena internacional de suministro constituyen potenciales empresas OEA; lo cual guarda relación con el ideal comentado de contar con una cadena íntegramente autorizada, en donde todos los participantes en una operación de comercio internacional son certificados por la Aduana al cumplir con los estándares de seguridad de la carga y suministro de información.

Sin embargo, será la normatividad de cada país la que finalmente determine la incorporación gradual de los distintos tipos de operadores de comercio exterior, según el eslabón de la cadena logística que se quiera priorizar, en donde casi siempre el exportador o el importador, o ambos, han sido los participantes iniciales en la mayoría de los programas OEA del mundo. 
Los factores a considerar para la decisión de incorporar a un determinado tipo de operador al programa OEA son variados, como por ejemplo el nivel de desarrollo de los estándares de seguridad con que ya cuenten las potenciales empresas participantes; un nivel de desarrollo por debajo del estándar internacional OEA, requerirá de la implementación previa de planes piloto que permitan a las empresas adecuarse progresivamente a la exigencia de dicho estándar; de otro modo, se corre el riesgo de no tener postulantes, o de tenerlos, que estos no cumplan con los requisitos establecidos; debemos indicar que no cabe la flexibilización de los estándares de seguridad, a diferencia de los esquemas de beneficios para los OEA, más aún si dicho estándar es objeto de validación en la negociación de los acuerdos de reconocimiento mutuo que suscriba cada país. Del mismo modo, existen factores de carácter económico, como es el hecho incentivar la participación de determinados sectores que se quieran desarrollar (empresas del rubro industrial, extractivo, manufacturero, pequeñas y medianas empresas, etc. que realicen operaciones de comercio exterior).

$\mathrm{Al}$ respecto, el programa OEA de México destaca por incorporar en su esquema de certificación de empresas seguras a múltiples actores de la cadena logística internacional, bajo las modalidades de operador económico autorizado y socios comerciales certificados. Cabe indicar que esta distinción es solo enunciativa, por cuanto las empresas certificadas bajo cualquiera de estas modalidades están sujetas al cumplimiento de requisitos generales y específicos, así como a un procedimiento de validación y certificación. A su vez cada una de estas modalidades se divide en varios rubros, correspondientes a distintos tipos de operadores o actores de la cadena internacional de suministro.

En ese sentido, la modalidad "Operador Económico Autorizado" (OEA) en México cuenta con los siguientes rubros:

- OEA rubro Importadora/Exportadora: empresas que realizan importación o exportación de mercancías.

- OEA rubro Controladora: empresas certificadas que integren las operaciones de manufactura de una o más sociedades controladas.

- OEA rubro Aeronaves: empresa manufacturera del rubro aeronaves.

- OEA rubro SECIIT: empresas beneficiarias del régimen de importación temporal que cuentan con un sistema electrónico para el control de inventarios de sus importaciones. 
- OEA rubro Textil: empresa manufacturera del rubro textil.

- OEA rubro Recinto Fiscalizado Estratégico: empresa beneficiaria del régimen de elaboración, transformación o reparación en recinto fiscalizado, el cual consiste en la introducción de mercancías extranjeras o nacionales, a dichos recintos para su elaboración, transformación o reparación, para ser retornadas al extranjero o para ser exportadas, respectivamente

- OEA rubro Tercerización Logística: empresa que presta servicios logísticos respecto al manejo de mercancías y gestión de la carga.

A su vez, la modalidad "Socio Comercial Certificado" (SCC) cuenta con 6 rubros:

- SCC rubro Auto Transportistas Terrestres: empresas que prestan el servicio de transporte internacional de carga por carretera.

- SCC rubro Agentes Aduanales: empresas autorizadas por la Aduana para gestionar el despacho aduanero.

- SCC rubro Transportista Ferroviario: empresas que prestan el servicio de transporte internacional de carga por ferrocarril.

- SCC rubro Parques Industriales: empresa que opera recintos autorizados para la operación de plantas de manufactura o centros de distribución de mercancías extranjeras o nacionales.

- SCC rubro Recintos Fiscalizados: empresas que prestan el servicio de almacenaje de mercancías.

- SCC rubro Empresas de Mensajería y Paquetería: empresas que realizan envíos de entrega rápida.

Como se puede apreciar, el programa OEA de México tiene un fuerte componente de política económica, como es el caso de la incorporación de distintos rubros manufactureros, sociedades controladoras, recintos fiscalizados estratégicos y parques industriales, en donde el objetivo no es solo el aseguramiento de las cadenas logísticas de suministro donde intervienen estos actores, sino también incentivar su desarrollo y fortalecimiento a nivel nacional e internacional, a fin de posicionar a México como un clúster o hub regional, e incluso mundial, si tomamos en cuenta su cercanía con Estados Unidos de América, que concentra la cuarta parte del PBI mundial y es el mayor productor industrial del mundo. Esta motivación económica no quita en lo absoluto que el estándar OEA en México sea un referente de éxito en materia de seguridad y facilitación del comercio internacional. 
Por lo expresado, es importante evaluar previamente las razones que sustentan la necesidad de incorporar a un nuevo actor al programa OEA de un país; la existencia de mejores prácticas como las comentadas en México respecto a los operadores que participan en el programa, no significa que el modelo deba copiarse y menos aún que el éxito esté asegurado.

Para la evaluación de este punto respecto al programa OEA del Perú, se debe tomar en cuenta en primer lugar que varios de estos actores ya participan en forma directa o indirecta en nuestro programa ${ }^{22}$; de la modalidad OEA o SCC comentadas, los importadores/exportadores, los agentes de aduana, los recintos fiscalizados ${ }^{23}$ y las empresas de mensajería y paquetería ${ }^{24}$, ya se encuentran incorporadas en el programa. Por otro lado, las empresas manufactureras de los rubros textil y aeronaves o los beneficiarios de importación temporal certificados como OEA en México, si bien no tienen una categoría especial en el programa OEA del Perú, no cuentan con un esquema especial de requisitos o beneficios, si participan del mismo en su condición de importadores o exportadores. Respecto a las empresas de tercerización logística o socios comerciales certificados tales como los transportistas (en sus distintas modalidades) o los parques industriales, a diferencia de México, no se tiene a la fecha en el Perú un desarrollo suficiente y uniforme que permita su incorporación efectiva al programa OEA.

En cambio, sí resulta importante evaluar la participación de las sociedades controladoras y los recintos fiscalizados estratégicos en el programa OEA de México, por tratarse en el primer caso de una figura de actualidad que no tiene mayor regulación en nuestro país, a pesar de su presencia cada vez mayor en todas las actividades económicas; y en el segundo caso, por ofrecer a través de esta plataforma estratégica, la posibilidad de que las pequeñas y medianas empresas se integren en una economía de escala que las haga más competitivas a nivel nacional e internacional.

En el caso de las sociedades controladoras, entendidas como una modalidad de "Holding” o grupo económico, su participación y reconocimiento formal en el programa OEA de México implica otorgar mayor transparencia a las actividades económicas que realizan, por cuanto las vinculaciones de las empresas subsidiarias o unidades de negocio

\footnotetext{
${ }^{22}$ En el caso del Perú, el programa OEA se inició el 2013 incluyendo a los exportadores, los almacenes aduaneros y los agentes de aduana, posteriormente se incorpora a los importadores y finalmente a las empresas de envíos de entrega rápida.

${ }^{23}$ Almacenes aduaneros en la legislación nacional.

${ }^{24}$ Empresas de envíos de entrega rápida en la legislación nacional.
} 
se hacen visibles (además de la consolidación fiscal). En el Perú, en cambio, la falta de un desarrollo normativo suficiente en las leyes societarias y normas complementarias dificulta la determinación de sus responsabilidades y obligaciones como un ente consolidado, lo cual a su vez complica el establecimiento de un esquema de requisitos y beneficios especiales en nuestro programa OEA. En suma, si bien es cierto que la actividad de los grupos económicos en el Perú es relevante, en particular en las operaciones de comercio exterior, no existe a la fecha un nivel de desarrollo suficiente que recomiende la incorporación de estos actores, tal como existe en México, por lo menos en el corto plazo.

Respecto a los recintos fiscalizados estratégicos incorporados en el programa OEA de México, se mencionó que se trata de un régimen reconocido internacionalmente por el cual se introducen en un área delimitada, mercancías o nacionales para almacenarlas, exhibirlas, venderlas, distribuirlas, transformarlas, repararlas o elaborar productos. De este modo, se logra reducir tiempos y costos logísticos, disminuir los gastos por tributos de importación, gestionar las importaciones y exportaciones en el menor plazo, eliminar procesos innecesarios e incrementar la seguridad de la mercancía. En estricto, se trata de un inmueble ubicado dentro de la circunscripción de cualquier aduana, el cual se habilita para la introducción de mercancías bajo el citado régimen aduanero, por parte de un tercero u operador autorizado por la Aduana para efectuar dicha destinación.

Por otro lado, el documento de la OMA denominado "El Operador Económico Autorizado y las pequeñas y medianas empresas ${ }^{25}$ " señala que, para el objetivo de conseguir cadenas logísticas totalmente seguras, las pequeñas y medianas empresas son una parte fundamental de estas cadenas, las cuales en algunos casos pueden estar compuestas en su mayor parte o íntegramente por pequeñas y medianas empresas certificadas como operadores económicos autorizados, por lo que se debe promover el Marco SAFE entre las pequeñas y medianas empresas. Esto sin dejar de reconocer que el impacto proporcional del coste de las medidas de seguridad en las pequeñas y medianas empresas es mayor que en las empresas más grandes. Del mismo modo, el Acuerdo de Facilitación del Comercio de la Organización Mundial de Comercio $^{26}$ (OMC) señala

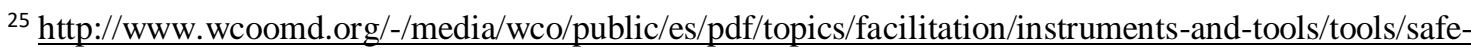
package/safe package $\mathrm{x}$ es.pdf?la=en

${ }^{26}$ https://www.wto.org/spanish/tratop_s/tradfa_s/tradfa_s.htm
} 
respecto a los criterios para seleccionar a un operador económico autorizado que no deben restringir en la medida de lo posible la participación de las pequeñas y medianas empresas.

En ese orden de ideas y siguiendo el modelo del programa OEA en México, para mejorar la competitividad de las medianas y pequeñas empresas en el Perú e impulsar su internacionalización a nivel global, es necesario incentivar su participación en el programa OEA. Para dicho fin, el denominado en México "recinto fiscalizado estratégico", que en nuestra legislación aduanera vigente corresponde a una modalidad de zona franca comercial e industrial permitiría a las pequeñas y medianas empresas, no solo introducir mercancías y realizar actividades de transformación y consolidación en dichos recintos como parte del régimen aduanero especial que corresponda, disminuyendo los costos logísticos individuales e incrementando la seguridad de la carga, sino también que le permitiría reducir los costos de implementación de los requisitos de seguridad para obtener la certificación OEA en el Perú; todas vez que estos se orientarán al recinto fiscalizado en conjunto, el cual deberá cumplir con los estándares de seguridad, control y demás requisitos que permitan su certificación como OEA, a fin de gozar de los beneficios que se le otorguen, a los cuales accederán en forma indirecta las pequeñas y medianas empresas ${ }^{27}$. No puede dejarse de mencionar, sin embargo, que el éxito de la incorporación de estos actores al programa OEA en el Perú, no podrá lograrse en tanto el Estado no impulse el desarrollo económico de estos recintos o zonas de exclusión comercial o industrial. Debe recordarse que el modelo de zonas francas existe en el país desde hace varios años (zonas especiales de desarrollo) sin que haya obtenido el éxito esperado $^{28}$, a pesar de los múltiples beneficios otorgados ${ }^{29}$, por lo que urge replantearlo para el cumplimiento de los objetivos comentados.

\footnotetext{
${ }^{27}$ Se debe indicar que el análisis de la conveniencia de incorporar a un recinto fiscalizado estratégico o zona franca al programa OEA, no excluye el hecho de que existan otros actores, que si bien es cierto no forman parte de los programas OEA de México, Colombia y Chile, también debería evaluarse su eventual incorporación, como es el caso de los operadores portuarios o aeroportuarios, los cuales además de contar con la infraestructura suficiente, tienen implementados estándares de seguridad compatibles con los modelos internacionales.

${ }^{28}$ A la fecha solo operan las ZED de Tacna, Ilo, Matarani y Paita. La ZED Loreto requiere de adecuación normativa y las ZED de Tumbes y Puno carecen de recursos para su implementación.

${ }^{29}$ Exoneración del impuesto a la renta; suspensión de impuestos de importación; permanencia ilimitada de bienes; exportaciones con $0 \%$ de IGV y recuperación de impuesto a las exportaciones, entre otros beneficios.
} 


\section{Beneficios tributarios y facilidades otorgados por otras entidades de control en los programas OEA de México y Colombia}

Conforme se aprecia del cuadro comparativo de los beneficios otorgados en los programas de operador económico autorizado de los países de la Alianza del Pacifico que obra en el anexo 2 del presente trabajo, en el marco de la negociación del acuerdo de reconocimiento mutuo entre estos países, se obtuvo la información detallada de los beneficios otorgados en los programas OEA de los países de la Alianza del Pacífico, en particular México y Colombia, procediéndose a su análisis comparativo.

Como se ha comentado anteriormente, de la citada evaluación se advirtieron algunas diferencias; no obstante, ninguna de estas diferencias advertidas conllevó a una disconformidad de todo el esquema de beneficios, por lo que se concluyó que los programas OEA de los países integrantes de la Alianza del Pacífico eran compatibles entre sí respecto de todos los aspectos evaluados (que incluyo además los requisitos generales, los procedimientos de certificación y validación, los estándares de seguridad, entre otros).

Sin embargo y tal como se ha indicado en repetidas oportunidades, resulta importante la evaluación de estas singularidades a fin de identificar aquellas que constituyan realmente una mejor práctica para el desarrollo y fortalecimiento del programa OEA del Perú, y en qué medida son susceptibles de incorporarse en el mismo.

Para un mejor entendimiento, se han agrupado estas mejores prácticas en materia de beneficios para los OEA en México y Colombia, en seis rubros: simplificación, atención preferente y plazos especiales en trámites aduaneros, discrecionalidad en materia de responsabilidad aduanera, beneficios tributarios y otros otorgados por entidades distintas a la Aduana que intervienen en el control; las que se detallan a continuación:

\section{a) Simplificación de trámites aduaneros}

- Rectificar partidas arancelarias, régimen aduanero, país de origen de la mercancía, datos contenidos en declaraciones que amparen vehículos o que a consecuencia de dicha rectificación se genere un saldo a favor del interesado, sin que sea necesaria la autorización por parte de la autoridad (todos los tipos).

- En el caso de mercancías susceptibles de ser identificadas individualmente, podrán importarlas sin anotar los números de serie en la declaración de aduanas, debiendo llevar solo un registro actualizado de dicha información (todos los tipos). 
- Descargo de mercancía importadas temporalmente en el control de inventarios (cuenta corriente) por partida arancelaria con base al consumo real, sin que sea necesario identificarlas por número de serie, marca o modelo (aeronaves).

- Cambio de régimen de temporal a definitivo de varias operaciones en una sola declaración (todos los tipos).

- Consolidación de mercancías correspondientes a distintos regímenes especiales, en un proceso de despacho conjunto para la importación, introducción a depósito fiscal o a Recinto Fiscalizado Estratégico en operaciones de tráfico aéreo (empresas manufactureras).

- Presentación de declaraciones electrónicas simplificadas, incluyendo consolidadas (importador manufacturero).

- Presentación para operaciones con declaraciones consolidadas del "aviso electrónico de importación y de exportación”, sin tener que presentar la factura (empresas manufactureras).

\section{b) Atención preferente en trámites aduaneros}

- Prioridad en la evaluación de las solicitudes para la ventanilla única de comercio exterior (VUCE).

- Importación de mercancías utilizando carriles exclusivos. (importador)

\section{c) Plazos especiales en trámites aduaneros}

- Extensión del plazo de importaciones temporales (empresas manufactureras, aeronaves)

\section{d) Discrecionalidad en materia de responsabilidad aduanera}

- Tramitar declaración de importación y exportación definitiva de mercancías excedentes o no declaradas, detectadas en el reconocimiento de la autoridad, siempre que su valor no exceda de 15,000 USD o el $20 \%$ del valor total de la operación (todos los tipos de OEA).

- Tramitar declaración de importación temporal o retorno de las mercancías excedentes o no declaradas que sean detectadas durante el reconocimiento o ejercicio de facultades de comprobación de la autoridad (todos los tipos).

- Tramitar declaración de importación definitiva de mercancías excedentes o no declaradas detectadas por la autoridad, siempre que su valor no exceda del $40 \%$ del valor total de la operación (aeronaves).

- No se suspende o cancela la autorización del agente de aduana: 
- Siempre que no excedan de cinco errores cometidos durante cada año calendario.

- Cuando la irregularidad detectada haya sido subsanada por el importador.

- No se cancela la autorización del agente de aduana, cuando:

- El valor de la operación no exceda de 3,000 dólares.

- En importación definitiva, cuando el valor de las mercancías declarado no exceda de 5,000 dólares.

- Cuando la autoridad aduanera detecte irregularidades en datos relativos al proveedor en el extranjero, domicilio fiscal del importador, transmisión electrónica, o en el aviso consolidado, o el valor declarado sea menor en un 50\% o más al valor de transacción de mercancías idénticas y similares, la empresa OEA podrá sujetarse al procedimiento de determinación de tributos y sanciones, sin que proceda el embargo de las mercancías y de los medios de transporte (todos los tipos).

- Cuando la empresa OEA no acredite el cumplimiento de regulaciones y restricciones no arancelarias y otras normas oficiales u omita el pago de cuotas compensatorias, podrá atenerse al procedimiento de determinación correspondiente, sin que se proceda el embargo de las mercancías y de los medios de transporte (todos los tipos).

\section{e) Beneficios tributarios}

- Aplicación de la tasa prevista en PROSEC (Programa de Promoción Sectorial) ${ }^{30}$ en el cambio de un régimen de importación temporal a definitivo (todos los tipos).

- Aplicación de la tasa prevista en PROSEC cuando se transfieran mercancías (todos los tipos).

- Las declaraciones que amparen la importación temporal, la introducción a un depósito fiscal o a un recinto fiscalizado estratégico, se pueden pagar cada semana o dentro de los primeros 20 días de cada mes, según la opción ejercida (todos los tipos).

\footnotetext{
${ }^{30}$ Los Programas de Promoción Sectorial (PROSEC) en México son un instrumento dirigido a personas jurídicas productoras de determinadas mercancías, mediante los cuales se les permite importar con arancel ad-Valorem preferenciales, diversos bienes para ser utilizados en la elaboración de productos específicos, independientemente de que las mercancías a producir sean destinadas a la exportación o al mercado nacional.

http://www.siicex.gob.mx/portalSiicex/Transparencia/prosec/prosec-infgeneral.htm
} 
- Aplicación de una tasa 0\% de IVA por la prestación del servicio de elaboración, transformación o reparación a las mercancías importadas temporalmente por la empresa OEA (empresas controladoras).

- En el caso del robo de los remolques, semirremolques o portacontenedores importados temporalmente que pudieran sufrir las empresas, al aplicar el procedimiento establecido para su importación definitiva, podrán determinar la tasa del Impuesto General de Importación considerando la cantidad equivalente en moneda nacional al $50 \%$ del valor contenido en la columna denominada "Loan" (valor promedio para crédito), sin aplicar deducción alguna. (Transportistas terrestres)

- Importación para el consumo de maquinaria industrial que no se produzca en el país, destinada a la transformación de materias primas, por parte de los usuarios altamente exportadores, sustituida ahora por la denominación OEA, si adquieren tal calidad, no está sujeta al pago del IVA (exportadores).

- Los responsables del impuesto sobre las ventas con derecho a devolución, que ostenten la calidad de OEA, puedan solicitar la devolución de saldos a favor en forma bimestral, sin que tengan que esperar a la presentación de la declaración de renta.

- Para los responsables del impuesto sobre las ventas con derecho a devolución, que ostenten la calidad de OEA, el término para que la Administración realice la devolución es de 30 días y no en el plazo ordinario de 50 días.

Cabe señalar que los cinco primeros beneficios son otorgados por el programa OEA de México y los tres últimos por el programa OEA de Colombia. Al igual que en el Perú, las funciones tributarias y aduaneras en México y Colombia se encuentran administradas por una sola institución.

\section{f) Beneficios otorgados por otras entidades que intervienen en el control (programa OEA de Colombia)}

- Inspección no intrusiva para las operaciones de exportación (todos los tipos).

- Para la categoría OEA seguridad y facilitación sanitaria además se tendrán los siguientes beneficios: 
- Autorización para llevar a cabo la inspección de mercancías objeto de exportación ordenada por el ICA o el INVIMA, en las instalaciones del exportador y depósito habilitado, cuando a ello hubiere lugar.

- Disminución del número de inspecciones físicas para las operaciones de exportación por parte del ICA o del INVIMA.

Habiéndose expuesto las innovaciones en materia de beneficios otorgados por los programas OEA de México y Colombia, respecto a los beneficios que son otorgados por el programa OEA en el Perú, se procede a continuación a su análisis comparativo y a la evaluación de su conveniencia de incorporarse en el esquema de beneficios del programa OEA en nuestro país.

Con relación a los beneficios relacionados a la simplificación de trámites aduaneros para los OEA en México y Colombia, la rectificación de datos de la declaración aduanera sin que se requiera de la aceptación de la autoridad aduanera ya existe en el Perú para los despachos anticipados, en donde la rectificación electrónica es automática en ciertos casos. Sí resulta innovador en cambio, la facilidad otorgada por México para presentar una declaración aduanera sin que sea necesario consignar los datos de identificación de las mercancías (número de serie, marca o modelo) los cuales se consignaran en los registros de inventario del importador para efecto de su control posterior. Del mismo modo, la presentación de declaraciones consolidadas para destinar mercancías a distintos regímenes aduaneros, o la regularización conjunta de varias declaraciones previas, constituyen medidas de simplificación tangibles y efectivas incorporadas en dicho programa, las cuales inciden en la reducción de tiempos y costos de las operaciones de comercio exterior.

Con relación a los beneficios relacionados a la atención preferente de los OEA, la utilización de carriles exclusivos denominados "FAST" en el programa OEA de México, es una de las facilidades más importantes, por cuanto la agilización de la circulación y el despacho de mercancías dará lugar a que el tiempo de espera sea menor y se reduzcan los costos operativos de las empresas. Si bien es cierto que esta modalidad se aplica principalmente en fronteras terrestres, donde se favorece la circulación de los transportistas terrestres internacionales certificados como OEA o que transporten carga de un OEA, no es excluyente que pueda aplicarse en otras vías de transporte, o que tome la forma de un canal preferencial para la atención integral del despacho y movilización 
de carga de exportación, por lo que es una figura que puede ser tomada en cuenta en el programa OEA del Perú.

En lo referido al otorgamiento de plazos especiales en los regímenes aduaneros en los programas OEA de México y Colombia, nuestra legislación aduanera especial ya contempla plazos de permanencia mayores para ciertas mercancías importadas temporalmente, sin que sea necesario contar con la certificación especial OEA. Este es el caso, por ejemplo, de la importación de aeronaves efectuada al amparo de la Ley Nro. 29624 que permite la suspensión de tributos hasta por cinco años, sin que sea necesario presentar garantía, como en el régimen aduanero común. En este caso, prevalece la política estatal de favorecer a determinados sectores económicos, independientemente de que cumplan o no con un estándar de seguridad de la carga.

Respecto a los beneficios otorgados por México y Colombia relacionados a la discrecionalidad para la determinación de la responsabilidad en materia de infracciones u otras inconformidades atribuibles al OEA, ya se contempla en nuestra Ley General de Aduanas la aplicación gradual de sanciones, en la forma y condiciones que establezca la Administración aduanera ${ }^{31}$, por la cual se puede reducir el monto de las sanciones según criterios de frecuencia o valor. De la misma manera, el régimen de incentivos en materia de sanciones ${ }^{32}$ reduce significativamente la cuantía de estas, según el momento en que se produzca la subsanación voluntaria y el pago de la sanción. Finalmente, el artículo 190 de la Ley General de Aduanas dispone que en materia de sanciones se tomarán en cuenta los hechos y circunstancias presentados respecto a la comisión de la infracción ${ }^{33}$, los cuales incluso podrán eximir de responsabilidad al infractor, disposición que guarda

\footnotetext{
31 Artículo 204'.- Gradualidad

Las sanciones establecidas en la presente Ley podrán ser aplicadas gradualmente, en la forma y condiciones que establezca la Administración Aduanera.
}

\section{Artículo $200^{\circ}$.- Régimen de Incentivos}

La sanción de multa aplicable por las infracciones administrativas y/o tributarias aduaneras, cometidas por los Operadores de Comercio Exterior, se sujeta al siguiente Régimen de Incentivos, siempre que el infractor cumpla con cancelar la multa y los intereses moratorios de corresponder, con la rebaja correspondiente.

(...).

33 Artículo 190.- Aplicación de las sanciones

(...)

Al aplicar las sanciones de suspensión, cancelación o inhabilitación se deben tener en cuenta los hechos y las circunstancias que se hubiesen presentado respecto a la comisión de la infracción, de tal manera que la sanción a imponerse sea proporcional al grado y a la gravedad de la infracción cometida.

(...). 
relación con el principio de razonabilidad en materia de infracciones administrativas, contemplado en el numeral 3 del artículo 248 de la Ley Nro. 27444, Ley del Procedimiento Administrativo General, y las condiciones eximentes o atenuantes de responsabilidad por infracciones previstas en el artículo 257 del citado cuerpo de leyes. En suma y respecto a este rubro, nuestra legislación aduanera común contempla facilidades incluso mayores que las otorgadas a las empresas OEA en los programas de México y Colombia, por lo que no resulta necesaria su incorporación.

Pero, sin lugar a dudas, las principales innovaciones verificadas en los programas OEA de México y Colombia se presentan en los rubros correspondientes a los beneficios tributarios y los beneficios otorgados por otras entidades gubernamentales que participan en el control aduanero y en el programa OEA.

En el caso de los beneficios tributarios otorgados por los programas OEA de México y Colombia, se contempla para determinadas operaciones realizadas por los OEA, la reducción de las tasas del impuesto al valor agregado, así como el incremento de los porcentajes de crédito fiscal admitidos para estos casos, la devolución anticipada del IVA en menores plazos y la posibilidad de efectuar el pago de estos tributos con plazos extendidos. Respecto a los impuestos aduaneros, se contemplan tasas preferenciales para los impuestos a la importación.

Sobre el particular y respecto a la posibilidad de otorgar beneficios de naturaleza tributaria en nuestro programa OEA se debe tener en cuenta que de acuerdo con la Norma IV del Código Tributario, solo por Ley o por Decreto Legislativo se pueden crear, modificar o suprimir tributos, señalar el hecho generador de la obligación, la base imponible y la alícuota, así como conceder exoneraciones o beneficios tributarios, o establecer privilegios, preferencias y garantías para la deuda tributaria, entre otras disposiciones. Por otro lado, es importante señalar que los beneficios exclusivos otorgados a los OEA en la mayoría de países, se refieren principalmente a facilidades en materia de simplificación y control aduanero, mas no a beneficios de naturaleza estrictamente tributaria relacionados con la reducción de la alícuota, el crédito fiscal o la devolución anticipada de impuestos, esto en razón a que los beneficios tributarios se orientan en mayor medida a incentivar de forma directa a determinados sectores, actividades económicas o áreas geográficas, y no a la implementación de un estándar de seguridad por parte de los operadores de comercio exterior. En ese orden de ideas y a 
diferencia de México y Colombia, las normas aduaneras que regulan el programa OEA en el Perú no podrían establecer beneficios de esta naturaleza, incluso cuando tengan el rango de ley, como el caso de la Ley General de Aduanas, por cuanto no se trata de normas especiales que regulan los elementos esenciales de los citados tributos.

A modo de ejemplo, se debe tomar en cuenta el caso del programa de cumplimiento tributario de la SUNAT denominado "Régimen del Buen Contribuyente" 34 , que si bien es cierto no se trata de un programa de seguridad, contiene elementos comunes con el programa OEA. Dicho régimen contempla beneficios referidos a plazos especiales para la declaración y pago de tributos, la atención preferente en la tramitación de las solicitudes de devolución o reintegro de tributos, o los servicios atendidos en los Centros de Atención al Contribuyente; esto es, facilidades relacionadas exclusivamente a medidas de simplificación administrativa.

En consecuencia y sobre la base del análisis comparativo efectuado respecto a las experiencias de México y Colombia, una propuesta inicial en materia de beneficios sobre servicios tributarios para el programa OEA en el Perú sería que se incorpore en una primera fase beneficios similares a los que se vienen otorgando a la fecha en el régimen del Buen Contribuyente, por cuanto el perfil de cumplimiento satisfactorio de sus obligaciones tributarias también forma parte de los requisitos exigibles para la certificación OEA.

Respecto a las facilidades otorgadas por otras entidades que intervienen en el control aduanero, que es el caso exclusivo de INVIMA y el ICA en el programa OEA de Colombia, referidas a la reducción del número de inspecciones físicas y su realización en el local del exportador o almacén aduanero, se trata de una condición necesaria para la incorporación de estas entidades gubernamentales en el programa OEA, al igual que la inclusión de sus propios requisitos de certificación y medidas de seguridad especiales.

En el Perú, las funciones de control sanitario de diversas mercancías de importación y exportación son ejercidas por el Servicio Nacional de Sanidad Agraria (SENASA), la Dirección General de Medicamentos, Insumos y Drogas (DIGEMID) y el Organismo Nacional de Sanidad Pesquera (SANIPES), por lo que su incorporación en el Programa OEA requerirá al igual que en Colombia, además de la aprobación de requisitos de certificación y seguridad relacionados con las actividades bajo su control, el

\footnotetext{
${ }^{34}$ Creado por el Decreto Legislativo Nro. 912, sus modificatorias y normas reglamentarias.
} 
establecimiento de beneficios en materia de simplificación y control respecto a esas mismas actividades de su competencia, como por ejemplo aquellas referidas a un menor número y un lugar más conveniente al exportador para la realización de inspecciones físicas.

Sin embargo y tal como se comentó, es imprescindible la creación en el Perú de un órgano de enlace y coordinación que articule el esfuerzo conjunto de estas entidades y su orientación al impulso y fortalecimiento de un verdadero programa OEA interinstitucional, de manera similar a la fórmula utilizada en la legislación colombiana. Se comentó también que nuestra legislación ya contiene disposiciones que otorgan a la Aduana un rol promotor y coordinador para la participación de estas entidades, además de señalar que estas entidades establezcan medidas de seguridad y facilidades que permitan implementar efectivamente dicha incorporación. En la práctica, estas disposiciones no han surtido efecto, recurriéndose en la práctica solo a la firma de convenios de integración, intercambio de información u otros acuerdos que carecen de efecto mandatorio; por esta razón, uno de los ejes principales de la propuesta de mejora normativa contenida en este trabajo, es la necesidad de crear un comité de coordinación interinstitucional del operador económico autorizado, integrado por los Ministerios de los que dependen las entidades gubernamentales que realizan el control del ingreso y salida de mercancías (el Ministerio de Agricultura y Riesgo en el caso de SENASA; el Ministerio de Salud en el caso de DIGEMID y el Ministerio de la Producción en el caso de SANIPES), dicha norma de creación deberá tener el rango de ley, toda vez que no solo contendrá la creación de este órgano, sino también establecerá los lineamientos para el otorgamiento de las facilidades por parte de estas entidades gubernamentales, además de disponer expresamente la facultad de la SUNAT para establecer medidas que establezcan un tratamiento preferencial en materia de servicios tributarios para los OEA. 


\section{CAPÍTULO V: PROPUESTAS DE MEJORA DEL MARCO REGULATORIO EN EL PERÚ RESPECTO AL ALCANCE DE LA CERTIFICACIÓN Y BENEFICIOS DEL PROGRAMA DE OPERADOR ECONÓMICO AUTORIZADO}

Se ha analizado en detalle la importancia de la figura del operador económico autorizado, no solo para la seguridad de la cadena logística internacional, sino también por el beneficio económico que reporta a las empresas certificadas la reducción de tiempos, costos y demás medidas de facilitación de los tramites, no solo aduaneros, sino también los correspondientes a otras entidades que intervienen en el control del ingreso y salida de mercancías.

Sin embargo, este beneficio debe extenderse a todo el comercio exterior del país que cuente con dicho programa, de tal forma que las cadenas logísticas seguras, sea de exportación o importación, representen un porcentaje cada vez mayor del total de operaciones de comercio realizadas hacia o desde el país. Se comentó a manera de ejemplo que el porcentaje de participación de los OEA en el comercio exterior de México asciende a casi el 55\% del total de operaciones, lo cual constituye una mejora importante como país y un incentivo para el fortalecimiento del programa OEA, no solo a nivel local sino también para los países vinculados con México, a través de los acuerdos o tratados internacionales, y específicamente a través de los acuerdos de reconocimiento mutuo.

Surge entonces la necesidad de establecer dentro del marco regulatorio y operativo del programa del operador económico autorizado, las mejoras que incidan en su fortalecimiento y en los objetivos comentados en el párrafo anterior, siendo el objetivo de este trabajo, presentar algunas propuestas de mejora en lo referido al marco regulatorio del alcance de la certificación y los beneficios a otorgarse.

Aun cuando no es materia del presente trabajo, no se puede dejar de mencionar que la mejora del marco regulatorio por sí sola no logrará el objetivo esperado; se requiere por ejemplo del impulso de la negociación de nuevos acuerdos de reconocimiento mutuo con los programas OEA de otros países, que constituyan socios comerciales o estratégicos, en función al objetivo país comentado y los objetivos del propio programa en el Perú. 


\subsection{Necesidad de mejorar el marco regulatorio ante las nuevas amenazas}

El marco regulatorio del operador económico autorizado debe ser dinámico a fin de incorporar el tratamiento legal de aquellos aspectos impuestos por la realidad actual del comercio exterior. Se comentó anteriormente, que las amenazas a la cadena global de suministro han evolucionado en la misma medida en que dicha cadena se ha virtualizado e incluido herramientas informáticas para su control; del mismo modo, la innovación tecnológica en todos los campos y la incorporación de aspectos vinculados a la sanidad animal y vegetal, requieren una revisión del ámbito de aplicación de la normatividad OEA.

\subsubsection{Los delitos informáticos en las cadenas de suministro}

Así, los ataques cibernéticos y demás amenazas a la seguridad de la información requieren que los estándares de seguridad del programa OEA incorporen disposiciones específicas que prevengan dichos males. Considerando que estas amenazas afectan principalmente a los países con mayor desarrollo tecnológico y que cuentan con un mayor número de redes y cadenas de suministro, son precisamente estos países los que lideran la incorporación de nuevos estándares de seguridad en el programa $\mathrm{OEA}^{35}$. En ese sentido, el programa OEA del Perú requerirá igualmente de la incorporación de dichos estándares, a fin de hacerlo compatible con los modelos internacionales comentados; de otro modo se dificultará su integración en las cadenas internacionales seguras a través de la suscripción de nuevos acuerdos de reconocimiento mutuo con los países con mayor desarrollo.

\subsubsection{La renovación tecnológica permanente en materia aduanera}

Del mismo modo, se requiere una modernización constante de la infraestructura aduanera, a fin de dotarla de plataformas informáticas suficientes y compatibles con las existentes en los países con los cuales se haya suscrito acuerdos de reconocimiento mutuo, de otra forma no se logrará la implementación efectiva de las facilidades otorgadas en estos

\footnotetext{
${ }^{35}$ El programa C-TPAT ha modificado recientemente sus estándares de seguridad incorporando aspectos relacionados con la ciberseguridad, la protección de la cadena de suministro de contaminantes y plagas agrícolas, la prevención del lavado de dinero y el financiamiento del terrorismo, y el uso y la gestión adecuados de la tecnología de seguridad, entre otros puntos. https://www.cbp.gov/newsroom/national-media-release/cbp-s-customs-trade-partnership-againstterrorism-finalized-update
} 
acuerdos. Por ejemplo, el principal beneficio obtenido por las empresas OEA con estos acuerdos, es el reconocimiento de su condición de operador seguro en los países firmantes del acuerdo, para esto, su registro o código de identificación ante sus respectivas administraciones aduaneras o tributarias ${ }^{36}$, debe ser reconocido por los sistemas informáticos aduaneros de los otros países, a fin de otorgarle las facilidades o beneficios que les correspondan. De no existir esta correspondencia informática, sea por el uso de plataformas obsoletas o por una capacidad de almacenaje insuficiente, no podrían implementarse en forma efectiva los beneficios del acuerdo, con lo que terminaría resultando inaplicable. Otro ejemplo de esta necesidad es la ejecución por parte de las aduanas de una adecuada gestión de riesgo de las empresas OEA y sus operaciones, dichos modelos deberán también incorporar en sus bases de datos a las empresas OEA certificadas en los demás países firmantes del acuerdo, por lo que se requerirá de la infraestructura informática necesaria, así como las bases de datos compatibles que permitan el uso e intercambio de dicha información.

\subsubsection{La prevención de las amenazas sanitarias y agrícolas}

Por último, se indicó también que un aspecto que ha cobrado relevancia en el marco regulatorio de los programas OEA, es la incorporación de estándares de seguridad en materia de prevención de la contaminación sanitaria o agrícola, lo cual a su vez refuerza la necesidad de incorporar en el programa OEA a las entidades gubernamentales a cargo de la prevención de estas amenazas; un ejemplo de estas amenazas es el denominado agro-terrorismo o terrorismo agrícola, el cual apunta a la contaminación de cualquier componente agrícola o suministro de alimentos, incluyendo la introducción intencional de plagas o enfermedades vegetales y animales, entre otros ejemplos.

En suma, todas estas iniciativas buscan contar con un programa OEA atractivo, tanto por sus beneficios como por su seguridad efectiva, lo cual se logrará con el impulso de medidas como las comentadas y las mejoras que se implementen en su marco regulatorio.

En tal sentido y como resultado de la evaluación efectuada en el presente trabajo, se proponen a continuación algunas mejoras del marco regulatorio del programa de operador económico autorizado que consideramos importantes para su fortalecimiento:

\footnotetext{
${ }^{36}$ Registro Único del Contribuyente (RUC) en el caso del Perú.
} 


\subsection{Mejoras propuestas del marco regulatorio}

\subsubsection{Participación de las entidades gubernamentales que intervienen en el control de mercancías que ingresan o salen del territorio nacional}

Sobre este punto, se comentó que las disposiciones contenidas en la Ley General de Aduanas no han sido efectivas para la implementación efectiva de la participación en el programa OEA de otras entidades gubernamentales que intervienen en el control aduanero, a través del establecimiento de medidas de seguridad o beneficios en materia de simplificación de los controles o tramites a su cargo, por lo que se proponen las siguientes medidas:

- Creación de categorías OEA

Como resultado de la incorporación de otras entidades gubernamentales que intervienen en el control aduanero de mercancías, se dijo que deben incorporarse requisitos relacionados con las actividades bajo su control; sin embargo, no todas las empresas OEA realizan actividades o destinan mercancías sujetas al control de estas entidades, por lo que resultaría absurdo exigirles a todas las empresas los mismos requisitos especiales.

En consecuencia, se propone en primer lugar, identificar las distintas necesidades de control y los beneficios que pueden ser otorgados a los OEA por parte de las entidades de control, y a continuación establecer categorías que distingan el esquema de requisitos y beneficios que se exigirá, según la actividad que realicen, de tal forma que a todas las empresas certificadas como OEA se les exija los requisitos de cumplimiento y seguridad comunes o generales, y solo a las empresas certificadas bajo alguna de las categorías, los requisitos especiales que se establezcan.

En el presente caso, se proponen dos categorías:

1. Categoría Seguridad Aduanera.

Se trata del esquema común de requisitos de cumplimiento y seguridad, el cual está vigente en el programa OEA del Perú a la fecha.

2. Categoría Seguridad Aduanera y Sanitaria.

Se trata de un esquema especial, en donde además del cumplimiento de los requisitos referidos en el punto anterior, se incorporan los requisitos propuestos por las entidades de control y los beneficios especiales a otorgarse 
a las empresas OEA, relacionados con las actividades bajo control de otras entidades gubernamentales.

En suma, se busca lograr un sistema integrado de requisitos y facilidades según la categoría que solicite y obtenga la empresa OEA certificada.

Cabe señalar que el artículo 3 del Reglamento de Certificación del Operador Económico Autorizado, dispone que la Administración Aduanera establecerá la forma, requisitos y plazos para la incorporación gradual de los operadores de comercio exterior que pueden solicitar la certificación como OEA, por lo que consideramos que la creación de estas categorías, previa incorporación de las demás entidades de control y sus respectivos esquemas de requisitos de certificación y facilidades, no requiere de alguna norma habilitante.

\section{- Creación de un Comité Multisectorial OEA}

Teniendo en cuenta que un programa OEA interinstitucional requiere de la participación de distintas entidades de control, las cuales cuentan con sus propios marcos regulatorios, ámbitos de competencia y niveles de dirección, resulta complicado lograr dicha integración y más aún implementar un esquema de requisitos y beneficios especial para las empresas OEA que realicen actividades bajo su control.

Por tal motivo, se propone la aprobación de una norma con rango de Ley que establezca un comité multisectorial que no solo coordine la implementación de esta participación, sino también proponga modelos de requisitos de certificación, beneficios exclusivos otorgados por cada entidad, entre otras facultades que se establezcan en su norma de creación.

Inicialmente este comité estará integrado por los siguientes sectores cuyos organismos ejecutores participan en actividades de control aduanero:

- Ministerio de Agricultura y Riesgo.

Forma parte de este sector el Servicio Nacional de Seguridad Agraria (SENASA) a cargo de la seguridad y sanidad agrícola.

- Ministerio de Salud.

Forma parte de este sector la Dirección General de Medicamentos, Insumos y Drogas (DIGEMID) a cargo de lograr que la población tenga acceso a medicamentos seguros, eficaces y de calidad y que estos sean usados racionalmente. 
- Ministerio de la Producción.

Forma parte de este sector el Organismo Nacional de Sanidad Pesquera (SANIPES) a cargo de normar, supervisar y fiscalizar la sanidad e inocuidad en toda la cadena productiva de los recursos y productos pesqueros y acuícolas

Cabe señalar que esta relación no es restrictiva, por lo que podrán incorporarse otras entidades, previa evaluación y aprobación del Comité; es el caso de la Autoridad Nacional Portuaria, en el caso de que se incorporen en el programa OEA los puertos marítimos; así como la Policía Nacional del Perú, a cargo del control antidrogas de las mercancías que ingresan o salen del país, entre otras entidades que podrían participar en un futuro en el programa OEA.

\subsubsection{Nuevos actores en el programa del operador económico autorizado}

Como se ha explicado, cuanto más eslabones de la cadena logística internacional se incorporen al programa OEA, más segura será esta cadena; sin embargo, el desarrollo de los operadores de comercio exterior que intervienen en dicho flujo, no es el mismo en cada país, se requerirá entonces de un periodo de desarrollo y adecuación, a través de planes piloto u otros programas temporales, de tal forma que se asegure la incorporación efectiva de los operadores, cuya participación se considere necesaria en el programa.

De la evaluación realizada, consideramos que se debe evaluar la conveniencia de incorporar en el programa OEA del Perú a los siguientes operadores:

- Las zonas especiales de desarrollo (ZED).

Se ha tomado la denominación correspondiente a nuestra legislación nacional, que en estricto se refiere a las zonas industriales o de transformación y maquila, sin perjuicio de que se incorporen otras zonas de exclusión con distinta denominación que cumplen con la misma finalidad, las cuales permitirían a través de una economía de escala, incorporar a las pequeñas y medianas empresas usuarias de la ZED que cumplan con el estándar de seguridad OEA de manera global ${ }^{37}$, que de manera individual no podrían cumplir o les resultaría demasiado oneroso, incentivando de este modo una actividad económica fundamental para el país,

\footnotetext{
${ }^{37}$ De las condiciones y requisitos establecidos para obtener la certificación OEA, indudablemente resulta lo más costoso la implementación de las medidas de seguridad para la carga e instalaciones, que en el presente caso serian acreditados por la ZED en conjunto, quedando los demás requisitos sujetos al cumplimiento individual de los usuarios de la ZED acreditados indirectamente como OEA.
} 
generadora de inversión y empleo directo, cuya participación en el programa OEA es incluso recomendada por la Organización Mundial de Aduanas.

Sin embargo, se debe tomar en cuenta que el estímulo de otorgar una certificación de operador seguro a estas zonas especiales no garantiza su éxito económico; ya comentamos que el modelo de zonas francas en el Perú tiene muchos años, a pesar de lo cual su desarrollo ha sido muy limitado o se ha desnaturalizado ${ }^{38}$; se requerirá entonces que el Estado Peruano establezca medidas económicas o de otra índole destinadas a impulsar su crecimiento, que tendrían ahora como incentivo adicional, la posibilidad de certificar como operadores seguros.

Por tal motivo y tratándose además de operadores nunca antes certificados, es recomendable que previamente se implementen programas piloto o planes de acción lo suficientemente largos como para permitir su incorporación progresiva, efectuando los ajustes normativos que correspondan, de ser el caso.

- Los puertos y aeropuertos.

En el presente caso se trata de los administradores de instalaciones portuarias o aeroportuarias, las cuales constituyen los puntos de ingreso y salida del país, además de tratarse de áreas con mayor riesgo de contaminación de la carga; por lo que es importante su incorporación al programa OEA. Cabe señalar que nuestra Ley General de Aduanas ya contempla a la fecha la exigencia de requisitos de infraestructura y seguridad para a estos operadores ${ }^{39}$, además de la existencia de

38 Las zonas francas industriales o de transformación han devenido en la practica en zonas de comercialización o distribución logística, caso de la Zona Franca de Tacna

39 De acuerdo con el artículo 38 del Reglamento de la Ley General de Aduanas, los puertos, aeropuertos deben cumplir con requisitos de infraestructura y seguridad tales como:

- Balanzas que cuenten con certificados de calibración vigente con valor oficial, emitidos por el INACAL o por entidades prestadoras de servicios de calibración acreditadas por esta entidad pública, las cuales deberán ser adecuadas a su operatividad;

- Maquinarias, equipos y herramientas necesarios para el manipuleo de contenedores o similares, o de la carga;

- Equipo de iluminación fija y móvil, que permita efectuar eficazmente el control aduanero, incluso en horario nocturno; así como contar con luces de emergencia;

- Sistema de monitoreo por cámaras de televisión, que permitan a la administración aduanera visualizar en línea las operaciones que se realicen;

- Sistema de información para el reconocimiento de los datos de identificación de los contenedores, y de la placa única nacional de rodaje o de elementos de información similares de los vehículos que ingresan o salen de sus recintos;

- Sistema de comunicación de datos y equipos de cómputo que permitan su interconexión con la SUNAT, para el desarrollo de su actividad;

- Sistema informático que permita la trazabilidad completa de la carga y de los contenedores o similares, al cual la Administración Aduanera tendrá acceso permanente en línea; y,

- Sistema de identificación para el registro de las personas que acceden a las zonas operativas, al cual la Administración Aduanera podrá acceder en línea. 
estándares de seguridad operativa obligatorios para este tipo de instalaciones ${ }^{40}$, por lo que consideramos que su incorporación resultaría menos complicada.

Del mismo modo, la existencia de contratos ley que regulan el otorgamiento de concesiones a los puertos o aeropuertos, no entra en conflicto con las normas que establezcan su incorporación en el programa OEA, por cuanto debemos recordar que se trata de un programa voluntario; resta en consecuencia crear el marco legal y las condiciones y beneficios que hagan atractivo el programa a estos nuevos operadores.

Finalmente, y de acuerdo con el artículo 3 del Reglamento de Certificación del Operador Económico Autorizado antes mencionado, la Administración Aduanera tiene la facultad para establecer la incorporación gradual de nuevos operadores, por lo que para este punto no se requiere de alguna norma habilitante.

\subsubsection{Nuevos beneficios en materia de simplificación y atención preferente}

El inciso d) del artículo 45 de la Ley General de Aduanas señala que la Administración Aduanera dispondrá las facilidades en materia de control y simplificación aduanera que pueden obtener los operadores económicos autorizados.

En tal sentido, es un objetivo permanente de la Aduana establecer mayores y mejores facilidades en materia de simplificación de trámites y controles, que se reflejen en un beneficio económico real para las empresas OEA y un mayor atractivo del programa.

En consecuencia y de la evaluación de las mejores prácticas de los programas OEA de los países de la Alianza del Pacifico, se proponen las siguientes facilidades:

- Establecer beneficios diferenciados para cada tipo de operador certificado como OEA. En el caso de las zonas especiales de desarrollo y los puertos, cuya incorporación se recomienda, se propone otorgarles las siguientes facilidades:

- Realización de inspecciones integradas en el interior de las zonas especiales de desarrollo.

\footnotetext{
${ }^{40}$ En el caso de las instalaciones portuarias, el Código internacional para la protección de los buques y de las instalaciones portuarias (Código ISPS) es un estándar internacional adoptado por la Organización Marítima Internacional (OMI) para detectar y prevenir amenazas. En el caso de los aeropuertos, el Anexo 17 Seguridad de la Aviación (AVSEC, Aviation Security) de la Organización para la Aviación Civil Internacional (OACI) incorpora las normas de seguridad aplicables para estas instalaciones y la carga aérea.
} 
Teniendo en cuenta que las ZED operan como plataformas logísticas, incorporan en su interior todos los servicios logísticos y aduaneros para la realización de las operaciones de comercio exterior; en consecuencia, las inspecciones que realicen la aduana y todas las entidades gubernamentales intervinientes en el control de las mercancías que ingresan o salen de estas ZED, deberán efectuarse en forma conjunta en las áreas de reconocimiento e inspección que se habiliten en las ZED, reduciendo de este modo los tiempos y costos de movilización de la carga para los usuarios de la ZED que cuenten con la certificación OEA.

- Presentación de declaraciones simplificadas consolidadas para el despacho de mercancías de ingreso o salida en las zonas especiales de desarrollo.

Siendo que el inciso a) del artículo 45 de la Ley General de Aduanas, permite a los OEA presentar una sola declaración de mercancías que ampare los despachos realizados en un plazo determinado, se considera que esta facilidad no solo alcanza a las declaraciones aduaneras de mercancías, sino también a las declaraciones simplificadas consolidadas cuyos despachos puedan ser gestionados directamente por los OEA ${ }^{41}$.

- Realización de la carga o descarga en el puerto o aeropuerto sin intervención de la autoridad aduanera.

Si bien es cierto que una adecuada gestión de riesgo en base a la información anticipada transmitida por los operadores de comercio exterior, reduce el control de la carga y descarga de las mercancías correspondientes a un operador seguro como el OEA, es posible reducir o eliminar este control físico, en tanto las instalaciones portuarias cuenten con los sistemas automáticos de identificación, registro y seguimiento de la carga, personas y medios de transporte, que permitan a la aduana acceder en forma permanente y en tiempo real a dicha información, a fin de efectuar dicho control en forma virtual. Para dicho fin, el puerto deberá cumplir con los estándares de seguridad exigibles por el programa OEA, los cuales deberán incorporar como requisitos adicionales para este tipo de operador, contar con los sistemas de control mencionados, sujetos a la verificación de la aduana.

\footnotetext{
${ }^{41} \mathrm{La}$ facilidad para que los OEA puedan efectuar directamente sus despachos aduaneros sin necesidad de contar con el servicio de un despachador de aduana, se incorporó con el inciso d) del artículo 27 de la Ley General de Aduanas, modificada por el Decreto Legislativo 1433.
} 
Esta facilidad, además de mejorar la competitividad de los operadores portuarios certificados como OEA, permitirá implementar en forma efectiva los carriles exclusivos "Fast" para la atención de los tramites y operaciones aduaneras realizados por las empresas OEA.

- Declaración con datos generales y registro de inventarios. Se propone esta facilidad consistente en presentar declaraciones con datos generales, cuya regularización se efectuará en los registros de inventario de cada empresa, los cuales estarán a disposición de la autoridad aduanera para efecto de cualquier acción de control.

Sobre el particular, los numerales 7.2.1, 7.3.2 y 7.3.3 del Capítulo 3 "Formalidades de desaduanamiento y otras formalidades" de las Directivas del Anexo General del Convenio de Kyoto Revisado ${ }^{42}$, elaborado por la Organización Mundial de Aduanas, establece como procedimientos especiales para las "personas autorizadas" que cumplan con una trayectoria de cumplimiento y utilicen un sistema eficaz de registros comerciales, la realización de sus despachos sobre la base de un mínimo de información, la auto-liquidación de derechos e impuestos por medio del empleo de registros comerciales, y la presentación de la declaración de mercancías por medio de una simple inscripción en los registros comerciales de la persona autorizada. Del mismo modo, estos procedimientos especiales podrán combinarse ya que se ha determinado que la persona autorizada mantendrá altos niveles de cumplimiento de los requisitos aduaneros.

En tal sentido, se propone que los OEA exportadores e importadores puedan presentar sus declaraciones con datos generales o mínimos que permitan identificar la mercancía, efectuando la regularización únicamente en sus registros comerciales, tanto de los datos complementarios como de los tributos, en los casos que corresponda. Cabe señalar que la idoneidad y fiabilidad de estos requisitos habrá sido previamente verificada por la Administración Aduanera, por lo que al constatarse que los registros comerciales de la persona autorizada funcionan correctamente, las declaraciones presentadas deberán ser consideradas como correctas.

42 http://www.wcoomd.org/-/media/wco/public/es/pdf/topics/facilitation/instruments-andtools/tools/conventions/kyoto-convention/cap3.pdf?la=en 
- Declaraciones aduaneras consolidadas para destinar mercancías a distintos regímenes.

Se propone establecer una declaración única que permita a las empresas OEA la regularización de distintos regímenes temporales solicitados con anterioridad.

Como complemento de la facilidad anterior, referida a la presentación de declaraciones globales que amparen despachos realizados en un plazo determinado, pero referidos a un solo régimen aduanero (es decir, se admiten varias declaraciones, pero solo del régimen de importación, o de exportación, etc.) resulta importante incluir la facilidad de que estas declaraciones múltiples incluyan mercancías destinadas previamente a distintos regímenes temporales, esto resulta importante en el caso de regímenes de transformación, donde un producto compensador ${ }^{43}$ puede incorporar componentes o insumos ingresados al amparo de distintos regímenes, los cuales podrán ser regularizados con una sola declaración global.

- Canales de atención preferente. Se propone, con esta medida, el establecimiento de un canal de control exclusivo para el OEA, tanto para el trámite de sus destinaciones aduaneros, la carga o descarga de mercancías y en general cualquier canal de atención físico o virtual que requiera de la intervención o control de la autoridad aduanera, sea sobre las personas, medios de transporte o mercancías, de tal forma que se produzca una reducción de tiempos (y costos) real y efectiva para el OEA.

Por ejemplo, un canal de atención exclusivo en los controles fronterizos permitirá que las empresas importadoras y exportadoras OEA realicen un tránsito rápido y con menos inspecciones, esto en razón a ser considerados embarques de bajo riesgo.

Cabe señalar que esta propuesta de beneficios no sustituye el esquema vigente en el programa OEA, sino más bien se trata de beneficios adicionales, con las particularidades referidas al tipo de operador beneficiado.

Del mismo modo y conforme a la facultad otorgada a la Administración aduanera por el artículo 45 de la Ley General de Aduanas para disponer facilidades exclusivas para el

\footnotetext{
${ }^{43}$ Productos finales elaborados en el territorio nacional con materias primas o mercancías importadas del extranjero
} 
OEA, solo se requerirá de la emisión de la Resolución de Superintendencia que los incorpore al anexo del citado procedimiento.

\subsubsection{Beneficios en materia de servicios tributarios}

Respecto a los beneficios en materia de servicios tributarios, se propone la incorporación de facilidades en materia de simplificación y control relacionadas a tributos internos o servicios vinculados, de manera similar al régimen del buen contribuyente.

Sobre el particular, los requisitos para otorgar la certificación OEA contemplan contar con una trayectoria de cumplimiento de sus obligaciones tributarias, además de no tener indicios, estar comprendidos o tener sentencias condenatorias relacionadas a delitos tributarios, aduaneros, lavado de activos, entre otros, así mismo, demostrar solvencia financiera y patrimonial, y adicionalmente aspectos vinculados a sistemas contables y logísticos que permitan la trazabilidad de sus operaciones, y niveles de seguridad conforme a estándares internacionales.

Sin embargo, y a pesar de la existencia de esta vinculación con el cumplimiento de obligaciones tributarias, y de que las funciones tributarias y aduaneras del Estado se encuentran a cargo de una sola entidad (SUNAT), las facilidades otorgadas en el procedimiento solo contemplan facilidades en materia aduanera.

Por otro lado, y si bien es cierto que la SUNAT se encuentra facultada para dictar normas en materia tributaria y aduanera en el ámbito de su competencia, conforme a lo dispuesto en el artículo $5^{\circ}$ de la Ley $N^{\circ} 29816$ - Ley de Fortalecimiento de la SUNAT, es también cierto que los procedimientos de naturaleza tributaria y sus formalidades se encuentran reguladas expresamente en el Código Tributario, por lo que se requeriría de una norma de la misma jerarquía que permita otorgar facilidades en materia de simplificación y control tributarios. Del mismo modo, el derecho a la precedencia en la atención de un servicio público, guardando riguroso orden de ingreso, se encuentra contemplada en una norma con rango de $\mathrm{ley}^{44}$, por lo que es necesaria una norma de similar jerarquía que establezca expresamente las facilidades vinculadas al servicio tributario, o en todo caso otorgue a la Administración Tributaria la facultad para

44 Numeral 1 del artículo 66 del Texto Único Ordenado de la Ley 27444, Ley del Procedimiento Administrativo General, aprobado mediante Decreto Supremo 004-2019-JUS 
otorgarlas, de manera similar a la formula dispuesta en el inciso d) del artículo 45 de la Ley General de Aduanas, en materia aduanera.

En nuestra opinión, esta última alternativa es la mas idónea, tanto por el hecho de ser una delegación normativa válida, como por permitir mayor flexibilidad en el tratamiento de las facilidades que se otorguen, además de guardar uniformidad con el marco regulatorio establecido en materia aduanera.

En consecuencia, el proyecto de norma legal propone dotar a la Administración Aduanera, de la facultad legal suficiente para establecer un trato preferencial para los OEA en los procedimientos y servicios tributarios a cargo de la SUNAT, inclusive aquellos procedimientos regulados en el Código Tributario y la Ley del Procedimiento Administrativo.

Sin perjuicio de lo señalado en el párrafo anterior, las facilidades que implican temas de tributos internos y cuya aprobación debería efectuarse luego de otorgada la facultad a la SUNAT conforme a lo señalado en el párrafo anterior, son las siguientes:

- Atención preferente en la atención de recursos de reclamación para el importador y el exportador

- Atención preferente en trámites de devolución

- Atención preferente en solicitudes de devolución del Saldo a Favor Materia del Beneficio del Exportador.

- Atención prioritaria en ventanillas de SUNAT.

- Asignación de sectoristas para la orientación en materia tributaria

Cabe señalar que este modelo de beneficios en materia tributaria es similar al contemplado en el régimen del buen contribuyente, con excepción del otorgamiento de plazos especiales para la declaración y pago de tributos.

\subsubsection{Beneficios otorgados por otras entidades gubernamentales de control}

Se explicó anteriormente que el comité multisectorial se encargará de elaborar la propuesta de requisitos y beneficios a cargo de otras entidades, en base a la evaluación de los procedimientos, tramites y demás formalidades exigidas por estas, para el control de ingreso y salida de mercancías.

Sin embargo, y a fin de superar cualquier conflicto de competencia o falta de interés para aprobar medidas de facilitación efectivas y realmente beneficiosas para las empresas OEA certificadas en la categoría de Seguridad Aduanera y Sanitaria, se propone 
incorporar en el proyecto de norma de creación del comité multisectorial, la aprobación de lineamientos para la aprobación de estas facilidades, a fin de crear un marco normativo vinculante para las entidades gubernamentales de control, en el ámbito de sus respectivas competencias de tal forma que los beneficios que establezcan, cumplan con los objetivos mencionados.

En tal sentido, los beneficios otorgados por estas entidades deberán alinearse necesariamente con algunos de los siguientes objetivos:

- La simplificación de los trámites a su cargo. -

Para cumplir con este lineamiento, el beneficio propuesto deberá orientarse a la reducción de requisitos y formalidades exigibles por la entidad, la aceptación de información simple o basada en una presunción de veracidad, entre otros.

- La atención preferente en los trámites a su cargo. -

Adicionalmente a la simplificación de los tramites y demás actuaciones a cargo de la Administración, la precedencia en la atención debe ser otorgada preferentemente a las empresas OEA.

- La reducción de plazos para la atención de tramites o la realización de inspecciones a su cargo. -

Conforme a lo indicado anteriormente, además de la simplificación y la atención preferencial, los plazos establecidos legalmente para la ejecución o la resolución de los tramites e inspecciones, deberán reducirse para el caso de los OEA

- La disminución de las inspecciones a su cargo como resultado de la gestión de riesgo.

Mejor aún que la disminución de los trámites, tiempos de atención y plazos legales, resulta la reducción de las intervenciones de la Administración, para lo cual las entidades gubernamentales de control deberán implementar en forma efectiva un sistema de gestión de riesgo de las operaciones bajo su control, a fin de reducir los controles físicos.

- La inspección no intrusiva o realizada en el local del exportador. -

La utilización de medios de inspección no intrusiva (escáneres fijos o móviles) se practica generalmente en las instalaciones portuarias o aeroportuarias y demás recintos fiscalizados, pero no en el local del exportador, por lo que se propone como lineamiento la utilización en las inspecciones de mecanismos móviles de 
control no intrusivo, así como la realización de estas inspecciones en el local del exportador.

Para los fines comentados, proponemos el siguiente proyecto de norma legal, que incorpora varias de las mejoras comentadas, iniciativa que debe complementarse con las demás medidas cuya aprobación corresponde a la Administración Aduanera (categorías, nuevos OEA y beneficios aduaneros y tributarios). 


\begin{abstract}
PROYECTO DE LEY QUE CREA EL COMITÉ DE COORDINACIÓN MULTISECTORIAL DEL OPERADOR ECONÓMICO AUTORIZADO, APRUEBA LINEAMIENTOS PARA EL OTORGAMIENTO DE FACILIDADES Y ESTABLECE EL TRATAMIENTO PREFERENCIAL AL OPERADOR ECONÓMICO AUTORIZADO EN LOS PROCEDIMIENTOS Y SERVICIOS TRIBUTARIOS BRINDADOS POR SUNAT
\end{abstract}

\author{
LEY \\ Artículo Primero. - Comité de Coordinación Multisectorial del Operador \\ Económico Autorizado \\ Crease el Comité de Coordinación Multisectorial del Operador Económico \\ Autorizado como órgano de coordinación y enlace para la implementación efectiva de la \\ participación de las entidades nacionales que intervienen en el control de las mercancías \\ que ingresan o salen del territorio aduanero, en el programa del Operador Económico \\ Autorizado. \\ Artículo Segundo. - Conformación del Comité \\ El Comité de Coordinación Multisectorial del Operador Económico Autorizado \\ está conformado por: \\ a) El Superintendente Nacional de Aduanas y de Administración Tributaria (SUNAT) o \\ quien haga sus veces. \\ b) El Ministro de Economía y Finanzas o quien haga sus veces. \\ c) El Ministro de Agricultura y Riego o quien haga sus veces. \\ d) El Ministro de Salud o quien haga sus veces. \\ e) El Ministro de la Producción o quien haga sus veces.
}

En el caso de efectuarse la delegación de la representación, esta deberá recaer en los organismos públicos adscritos a cada Ministerio que ejerzan las funciones de control. En el caso de la SUNAT dicha representación podrá ser ejercida por el Superintendente 
Nacional Adjunto de Aduanas o el órgano de la SUNAT que tenga a su cargo el programa del Operador Económico Autorizado.

La incorporación de otras entidades que intervengan en el control de mercancías que ingresan o salen del país, será aprobada mediante Decreto Supremo a propuesta del Comité.

\section{Artículo Tercero. - Funciones del Comité}

Son funciones del Comité de Coordinación Multisectorial del operador económico autorizado, las siguientes:

a) Servir como instancia de coordinación y enlace de las entidades nacionales que intervienen en el control de las mercancías que ingresan o salen del territorio aduanero.

b) Evaluar, aprobar y proponer a la SUNAT la incorporación de requisitos para la certificación del operador económico autorizado, que correspondan a estándares de cumplimiento o seguridad a cargo de las entidades nacionales que intervienen en el control de las mercancías que ingresan o salen del territorio aduanero.

c) Evaluar, aprobar y proponer a las entidades nacionales que intervienen en el control de las mercancías que ingresan o salen del territorio aduanero, el establecimiento de facilidades exclusivas para los operadores económicos autorizados, en materia de simplificación y control.

d) Gestionar ante la SUNAT y las entidades nacionales que intervienen en el control de las mercancías que ingresan o salen del territorio aduanero, la implementación efectiva de los requisitos de certificación, medidas de seguridad y facilidades propuestas por el Comité para los operadores económicos autorizados, para lo cual podrá establecer cronogramas de ejecución, cursar requerimientos, proponer proyectos de normas legales o cualquier otra acción que sea necesaria para el cumplimiento de disco fin.

e) Proponer la incorporación al Comité de otras entidades que intervienen en el control de mercancías que ingresan o salen del país.

\section{Artículo Cuarto. - Validez de los acuerdos del Comité Técnico}


Los acuerdos del Comité Técnico sobre el operador económico autorizado deben ser cumplidos por las entidades representadas en el mismo, dentro del ámbito de sus respectivas competencias.

\section{Artículo Quinto. - Secretaria Técnica}

La Secretaría Técnica del Comité es ejercida por la SUNAT a través del Superintendente Nacional Adjunto de Aduanas o el órgano de la SUNAT que tenga a su cargo el programa del Operador Económico Autorizado.

\section{Artículo Sexto. - Funciones de la Secretaria Técnica}

Son funciones de la Secretaria Técnica del Comité las siguientes:

a) Convocar a reunión a los integrantes del Comité

b) Elaborar los acuerdos, actas y documentos de gestión del Comité.

c) Solicitar a los integrantes cualquier información o documentación que guarde relación con los temas a cargo del Comité.

\section{DISPOSICIONES COMPLEMENTARIAS FINALES}

Disposición Complementaria Primera. - Lineamientos para el establecimiento de facilidades a los operadores económicos autorizados, por parte de las entidades nacionales que intervienen en el control de las mercancías que ingresan o salen del territorio aduanero.

Las entidades nacionales que intervienen en el control de las mercancías que ingresan o salen del país, establecen facilidades exclusivas en materia de simplificación y control para los operadores económicos autorizados, tomando en cuenta los siguientes lineamientos:

a) La simplificación de los trámites a su cargo.

b) La atención preferente en los trámites a su cargo.

c) La reducción de plazos para la atención de tramites o la realización de inspecciones a su cargo.

d) La disminución de las inspecciones a su cargo como resultado de la gestión de riesgo.

e) La inspección no intrusiva o realizada en el local del exportador. 
Disposición Complementaria Segunda. - Tratamiento preferencial al operador económico autorizado en los procedimientos y servicios tributarios brindados por SUNAT

La SUNAT establecerá medidas dirigidas a otorgar un tratamiento preferencial a los exportadores e importadores certificados como operadores económicos autorizados en la atención de los procedimientos y servicios tributarios a cargo de la SUNAT, inclusive aquellos procedimientos regulados en el Código Tributario y la Ley del Procedimiento Administrativo General - Ley Nro. 27444.

\section{Disposición Complementaria Tercera. - Vigencia}

La disposición anterior entra en vigor a partir de la vigencia de los procedimientos que emita la SUNAT que den cumplimiento a las disposiciones contenidas en este dispositivo legal. 


\section{CONCLUSIONES}

La figura del operador económico autorizado constituye en la actualidad el mecanismo más eficiente de protección y prevención de la cadena internacional de suministro.

La importancia del operador económico autorizado hace necesario el crecimiento y fortalecimiento permanente de los programas de operador económico autorizado a nivel mundial, a fin de crear cadenas globales seguras.

En el caso del Perú, el desarrollo del programa de operador económico autorizado ha cobrado mayor impulso con la suscripción de acuerdos de reconocimiento mutuo de los programas OEA, siendo uno de los más relevantes el suscrito con los países de la Alianza del Pacífico (México, Colombia y Chile).

Sin embargo, el fortalecimiento del programa de operador económico autorizado en el Perú requiere de la mejora constante de su marco regulatorio y de la implementación de medidas destinadas a incrementar la adhesión al programa.

Para dicho fin resulta importante el estudio de las mejores prácticas internacionales en materia del programa OEA, como es el caso de las experiencias exitosas de los países de la Alianza del Pacifico.

En consecuencia y como resultado de la evaluación efectuada de las mejores prácticas comentadas, se considera necesaria la implementación de las siguientes propuestas orientadas al fortalecimiento del programa OEA en el Perú.

- Impulso de la suscripción de nuevos acuerdos de reconocimiento mutuo, en base a criterios de desarrollo del programa y objetivos estratégicos del país.

- Innovación normativa y tecnológica, respecto al reto de las nuevas amenazas a la cadena logística y la interoperabilidad con los programas OEA de otros países.

- Participación en el programa OEA de otras entidades gubernamentales que intervienen en el control aduanero, para lo cual se propone la creación de un comité multisectorial que articule dicha participación. 
- Nuevas categorías vinculadas a la participación de otras entidades de control y nuevos operadores incorporados en el programa OEA, conforme a las mejores prácticas revisadas.

- Nuevos beneficios, en materia aduanera vinculados a la simplificación de trámites, en materia tributaria vinculados al trato preferente en los servicios tributarios, y otros vinculados a las actividades que son competencia de las entidades gubernamentales de control.

Se propone un proyecto de ley que contiene el marco regulatorio de la participación de otras entidades gubernamentales de control, los lineamientos para las facilidades que estas entidades otorguen, y la facultad otorgada a la SUNAT para establecer beneficios en materia de los servicios tributarios.

En suma, se busca con esto que exista una certificación OEA de todos los tipos de operadores de comercio exterior, según el nivel de seguridad y cumplimiento acreditados, que participe de una mayor cuota del comercio exterior del país, con reconocimiento internacional en base a beneficios efectivos en materia tributaria y aduanera, y que integre a todas las entidades de control en un esquema de certificación único. 


\section{REFERENCIAS}

- Estudio sobre los programas del operador económico autorizado en los países miembros de la ALADI con especial énfasis en los requisitos de certificación. Asociación Latinoamericana de Integración, ALADI, marzo 2019. http://www.aladi.org/biblioteca/Publicaciones/ALADI/Secretaria General/SEC Estudios/229rev1.pdf

- Marco Normativo SAFE para asegurar y facilitar el comercio mundial. Organización Mundial de Aduanas, junio 2018. http://www.wcoomd.org//media/wco/public/es/pdf/topics/facilitation/instruments-and-tools/tools/safepackage/safe-framework.pdf?la=en

- Compendium of Authorized Economic Operator Programmes, World Customs Organization, 2018. http://www.wcoomd.org//media/wco/public/global/pdf/topics/facilitation/instruments-andtools/tools/safe-package/aeo-compendium.pdf?db=web.

- Directrices de la Aduana sobre la Gestión integrada de la cadena logística, Organización Mundial de Aduanas, junio de 2004 http://www.wcoomd.org//media/wco/public/es/pdf/topics/facilitation/instruments-and-tools/tools/safepackage/safe_package_ii_es.pdf?la=en

- Directrices sobre la puesta en aplicación de los programas de OEA, Organización Mundial de Aduanas, junio de 2009

http://www.wcoomd.org//media/wco/public/es/pdf/topics/facilitation/instruments-and-tools/tools/safepackage/safe package iii es.pdf?la=en

- Strategy Guide for AEO Mutual Recognition, World Customs Organization, 2018 http://www.wcoomd.org//media/wco/public/global/pdf/topics/facilitation/instruments-andtools/tools/safe-package/strategy-guide-for-aeo-mutual-recognition.pdf?la=en

- El Operador Económico Autorizado y las Pequeñas y Medianas Empresas, Organización Mundial de Aduanas, http://www.wcoomd.org/- 
/media/wco/public/es/pdf/topics/facilitation/instruments-andtools/tools/safe-package/safe package $x$ es.pdf?la=en

- El transporte mundial de la carga aérea. Cadena de suministro segura para la carga aérea y el correo y directrices en materia de facilitación, Organización Mundial de Aduanas, 2013.

http://www.wcoomd.org//media/wco/public/es/pdf/topics/facilitation/instruments-and-tools/tools/jointwco-icao-brochure/icaowcomovingaircargo2013sp.pdf?la=en

- Coordinated Border Management Compendium, World Customs Organization, 2015

http://www.wcoomd.org/Imedia/wco/public/global/pdf/topics/facilitation/instruments-andtools/tools/safe-package/cbm-en_lr.pdf?la=en

- Members who have expressed their intention to implement the WCO Framework of Standards to Secure and Facilitate Global Trade, World Customs Organization, 2015

http://www.wcoomd.org//media/wco/public/global/pdf/topics/facilitation/instruments-andtools/tools/safe-package/wco-table-intention-to-implement-the-fos-en-fr-oct2015-final.pdf?la=en

- Erika Anzola Burgos, "El operador económico autorizado en Colombia” Editorial Legis, 2016.

- Roberto Oviedo Umaña, “Análisis del programa operador económico autorizado", Universidad de Chile, 2011.

- Ana Ramos Tuson, "La certificación de operador económico autorizado. Periodo 2018-2013" Universidad Politécnica de Valencia, 2014.

- Enrico Raffaeli, "The contribution of the Authorised Economic Operator towards Global Supply Chain Safety and Security”. Erasmus University, 2017.

- Aleksandar Erceg, "Influence of Authorized Economic Operator on Supply Chain Security”, Business Logistics in Modern Management 2014, 14th International Scientific Conference - Osijek, Croatia.

- David Blanchard (2010), Supply Chain Management Best Practices, 2nd. Edition, John Wiley \& Sons, ISBN 9780470531884 
- Young, Richard R., Esqueda, Paul, Vulnerabilidades de la cadena de suministros: consideraciones para el caso de América Latina. Academia. Revista Latinoamericana de Administración [en línea] 2005, (primer semestre). 
ANEXOS 
Anexo 1: Cuadro comparativo de los requisitos generales OEA de los países miembros de la Alianza del Pacifico

\begin{tabular}{|c|c|c|c|c|}
\hline & PERÚ & MEXICO & COLOMBIA & CHILE \\
\hline BASE LEGAL & $\begin{array}{l}\text { Ley General de Aduanas Art. 2, } 44 \text { y } 45 . \\
\text { Reglamento OEA (D.S. } N^{\circ} \text { 184-2016- } \\
\text { EF) } \\
\text { Procedimiento de Certificación OEA. }\end{array}$ & $\begin{array}{l}\text { Ley Aduanera. Art. 100-A. } \\
\text { Reglas Generales de Comercio Exterior. } \\
\text { Título } 7\end{array}$ & $\begin{array}{l}\text { Decreto } 3568 \text { del } 26 \text { de septiembre de } 2011 . \\
\text { Decreto } 1894 \text { de } 2015 \text { (Modifica } \\
\text { parcialmente Decreto } 3568 \text { de } 2011 \text { ). } \\
\text { Resolución } 15 \text { de febrero } 17 \text { de } 2016 \text {. }\end{array}$ & $\begin{array}{l}\text { Ley } \mathrm{N}^{\circ} \text { 20.997, Moderniza la } \\
\text { Legislación Aduanera, Art. } 1 . \\
\text { Reglamento OEA Decreto } \mathrm{N}^{\circ} 1140 \text {, } \\
\text { del Ministerio de Hacienda. } \\
\text { Resolución } \mathrm{N}^{\circ} 246 \text {, de la Dirección } \\
\text { Nacional de Aduanas. }\end{array}$ \\
\hline NOMBRE & Operador Económico Autorizado (OEA) & Operador Económico Autorizado (OEA) & Operador Económico Autorizado (OEA) & $\begin{array}{l}\text { Operador Económico Autorizado } \\
\text { (OEA) }\end{array}$ \\
\hline VIGENCIA & $\begin{array}{l}\text { Indefinida, sujeto a evaluaciones } \\
\text { periódicas o validaciones anuales. }\end{array}$ & $\begin{array}{l}\text { Vigencia de } 2 \text { años, a excepción de lo } \\
\text { siguiente: } \\
\text { Las empresas que cuenten } \\
\text { simultáneamente con la certificación } \\
\text { OEA y el Registro en el Esquema de } \\
\text { Certificación de Empresas en la } \\
\text { modalidad de IVA e IEPS, rubro AAA, } \\
\text { la vigencia será de } 3 \text { años. }\end{array}$ & $\begin{array}{l}\text { Indefinida, con revalidaciones dentro de los } \\
2 \text { años siguientes a la expedición de la } \\
\text { Autorización. }\end{array}$ & 3 años sujeto a revisiones. \\
\hline TIPOS & $\begin{array}{ll}\text { - } & \text { Exportadores } \\
\text { - } & \text { Importadores } \\
\text { - } & \text { Agentes de Aduana } \\
\text { - } & \text { Almacenes } \\
\text { - } & \text { Empresas de servicio de entrega } \\
& \text { rápida }\end{array}$ & $\begin{array}{l}\text { Modalidad Operador Económico } \\
\text { Autorizado (OEA) } \\
\text { - } \quad \text { Exportadores / Importadores } \\
\text { - } \quad \text { Recintos Fiscalizados Estratégicos } \\
\text { - } \quad \text { Tercerización Logística } \\
\text { Modalidad Socio Comercial Certificado } \\
\text { (SCC) } \\
\text { - } \quad \text { Auto Transportistas Terrestres } \\
\text { - } \quad \text { Agentes Aduanales } \\
\text { - } \quad \text { Transportista Ferroviario } \\
\text { - } \quad \text { Parques Industriales } \\
\text { - } \quad \text { Recintos Fiscalizados } \\
\text { - } \quad \text { Empresas de Mensajería y } \\
\quad \text { Paquetería }\end{array}$ & $\begin{array}{ll}\text { - } & \text { Exportadores } \\
\text { - } & \text { Importadores } \\
\text { - } & \text { Agentes de Aduana }\end{array}$ & $\begin{array}{ll}\text { - } & \text { Exportadores } \\
\text { - } & \text { Agentes de Aduana }\end{array}$ \\
\hline CATEGORIAS & No aplica & $\begin{array}{l}\text { La modalidad OEA cuenta con } 6 \text { rubros, } \\
\text { que se enlistan a continuación: } \\
\text { - } \quad \text { OEA rubro } \\
\text { Importadora/Exportadora } \\
\text { - } \quad \text { OEA rubro Controladora }\end{array}$ & $\begin{array}{ll}\text { 1. } & \text { Seguridad y Facilitación } \\
\text { 2. } & \text { Seguridad y Facilitación Sanitaria }\end{array}$ & No aplica \\
\hline
\end{tabular}




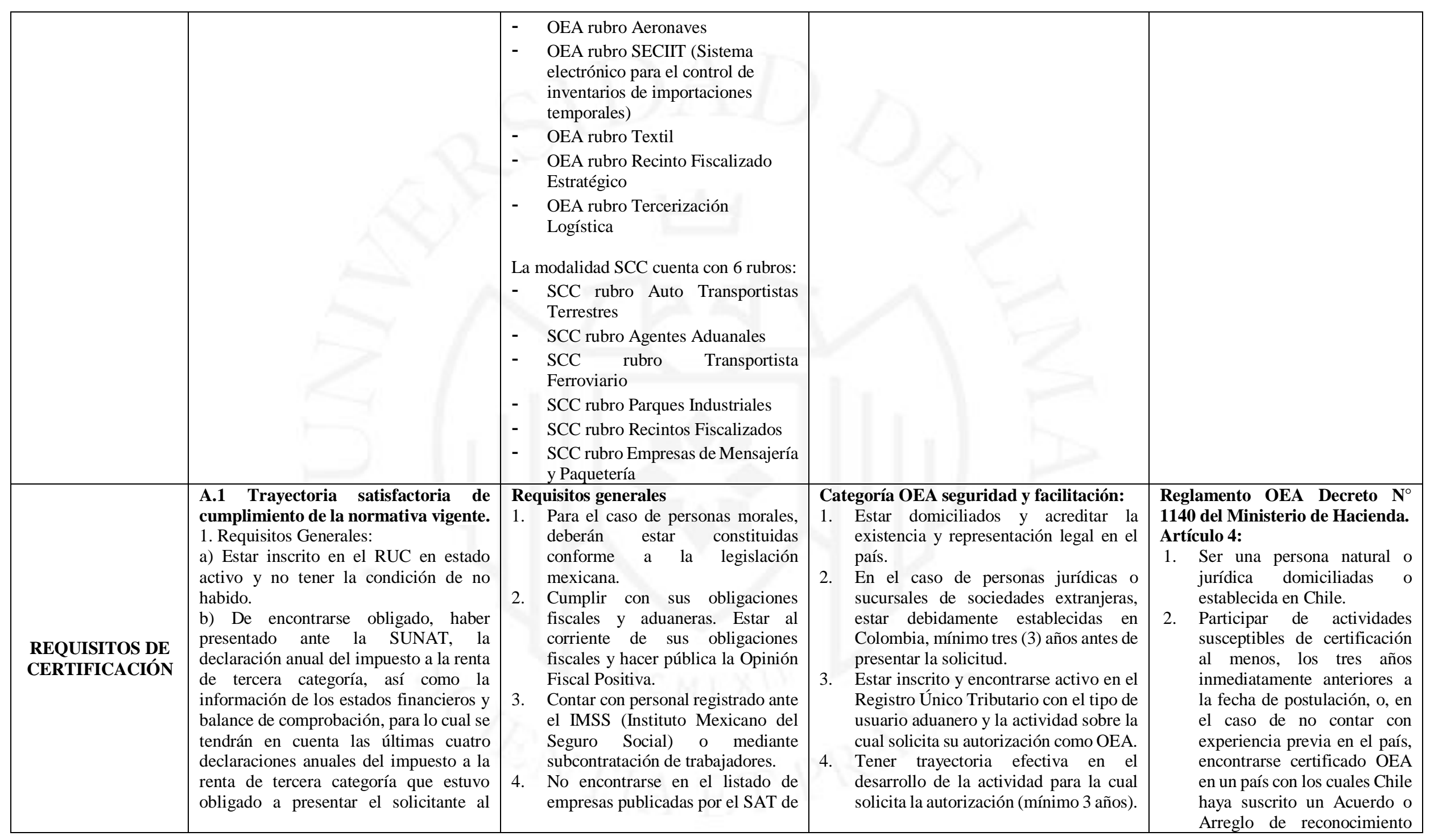




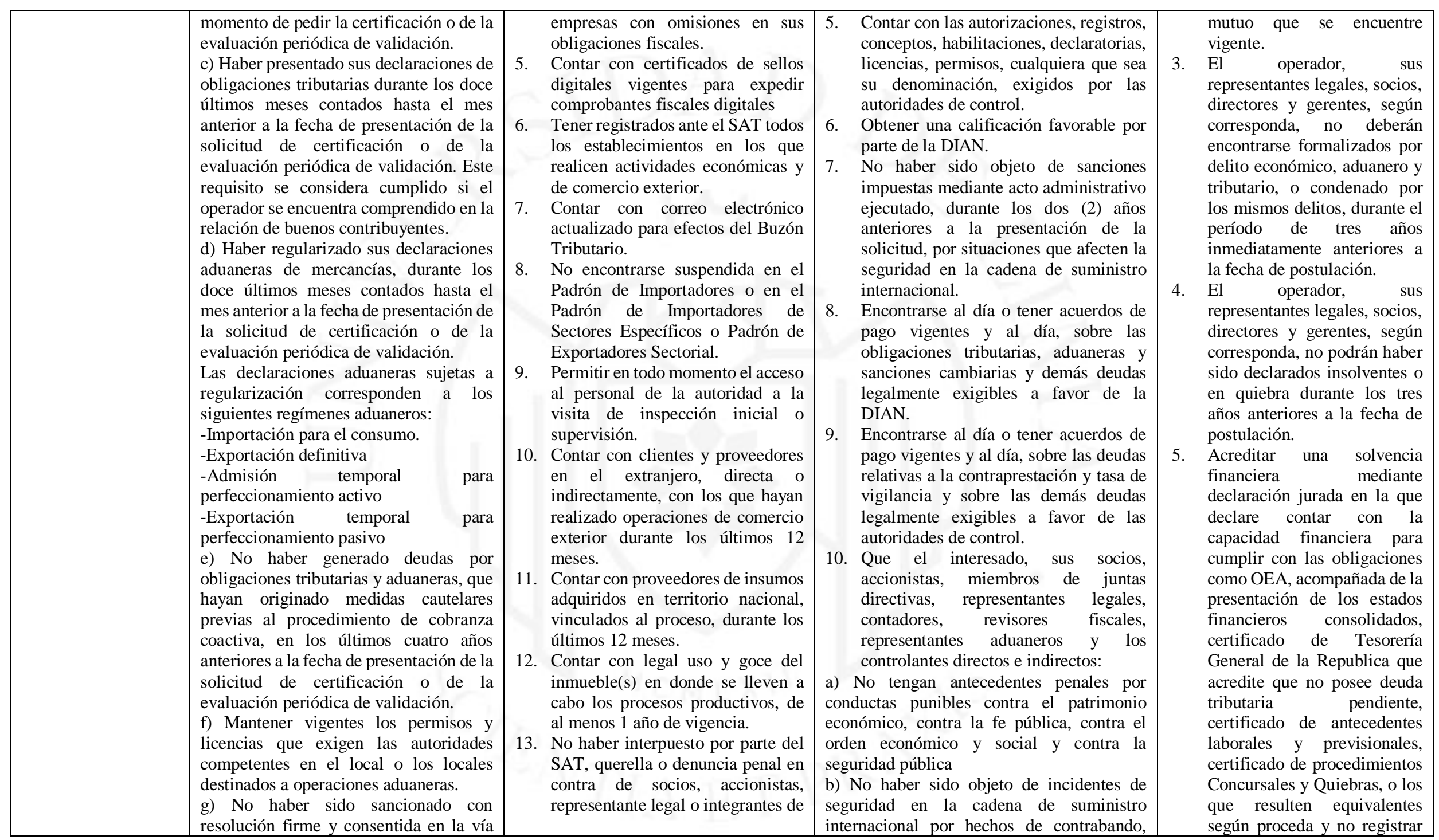




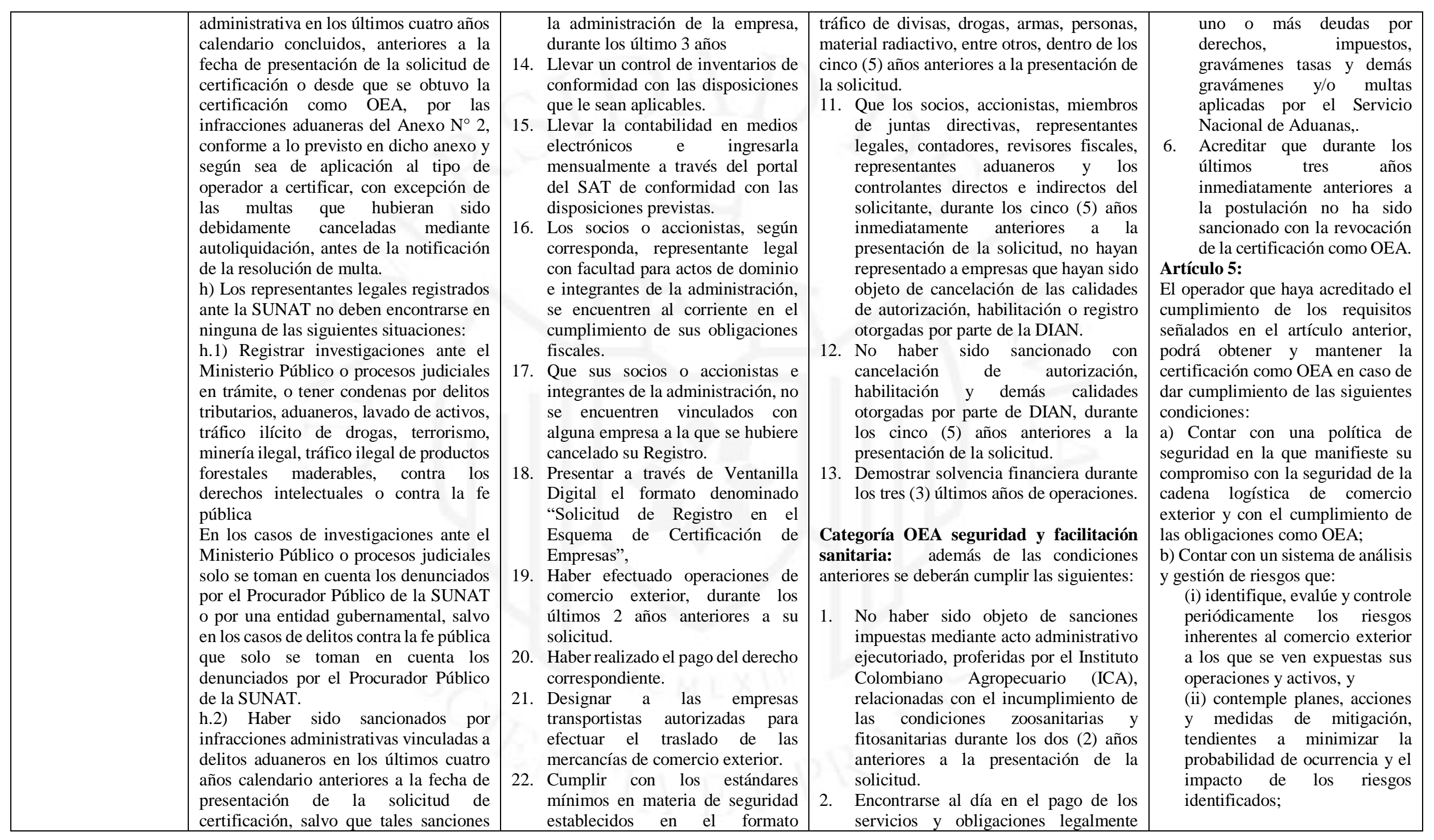




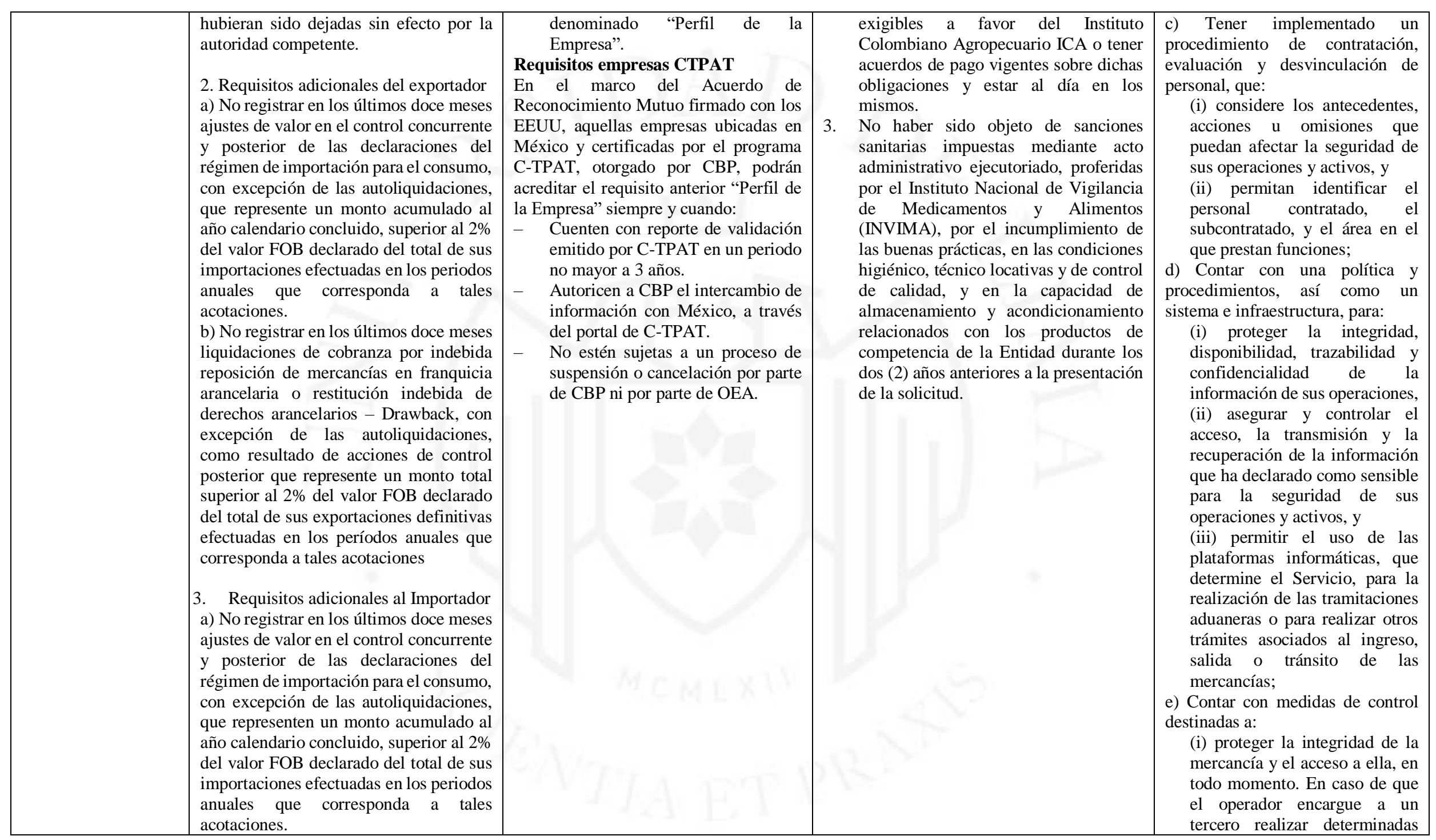




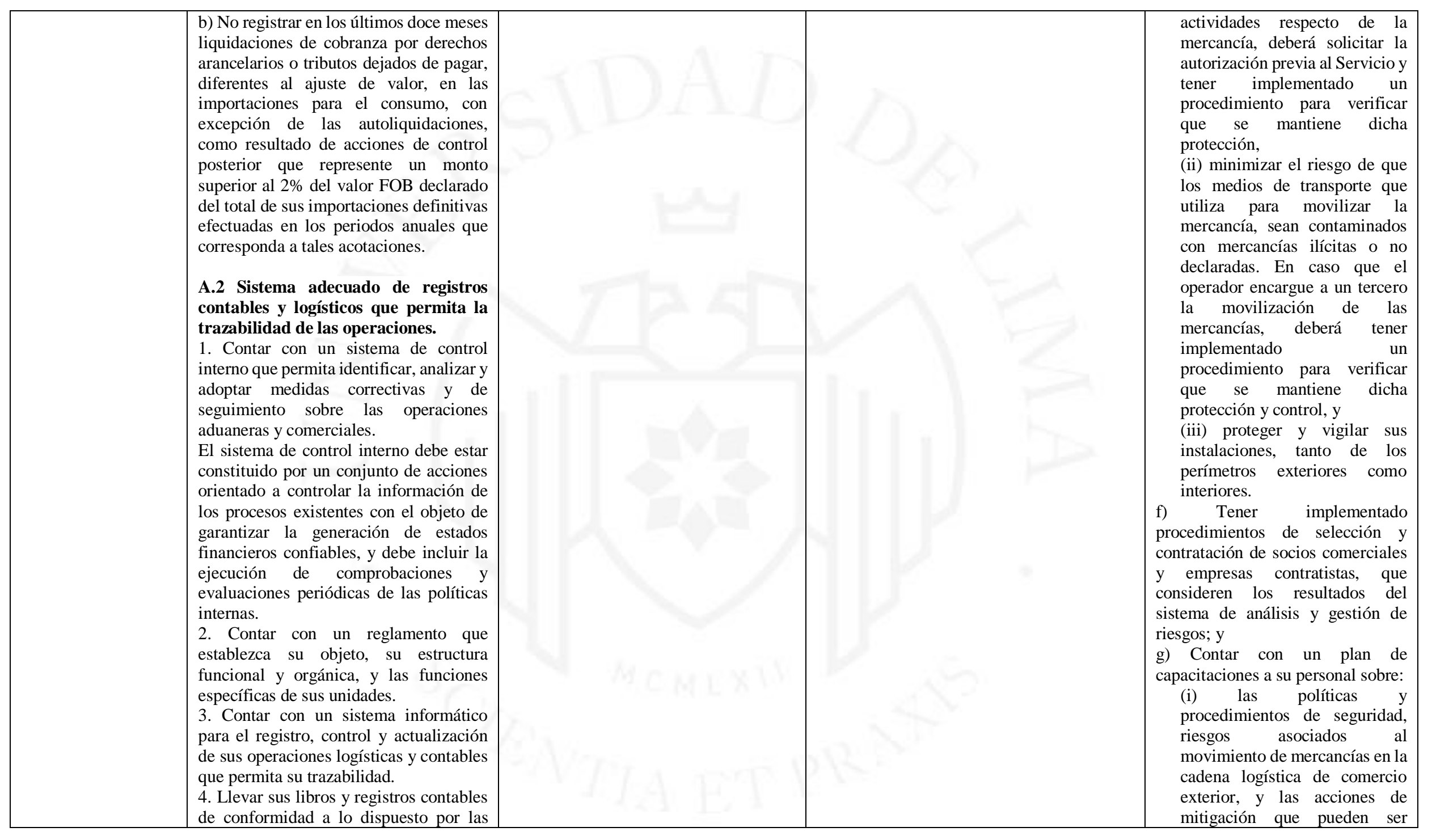




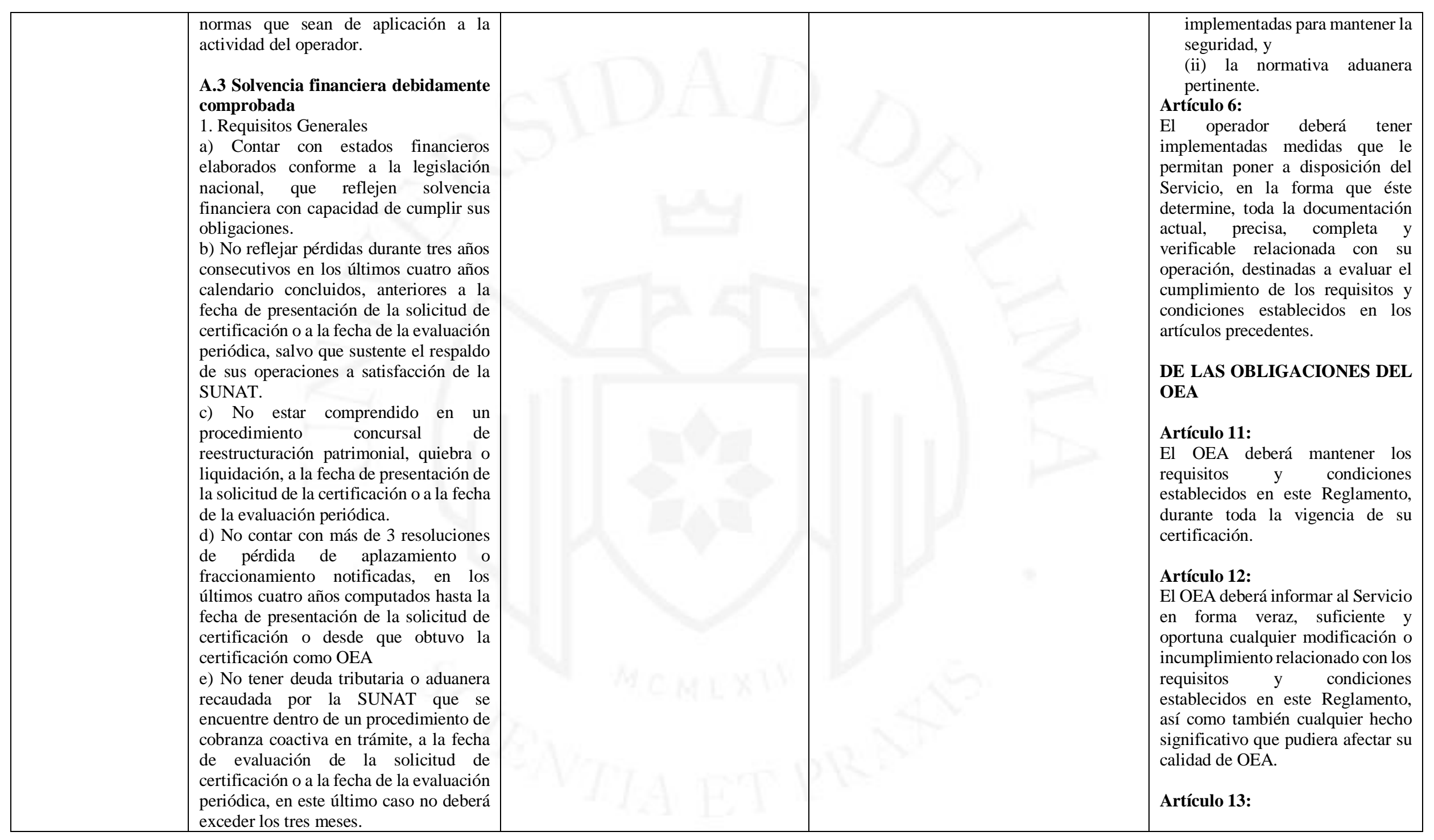




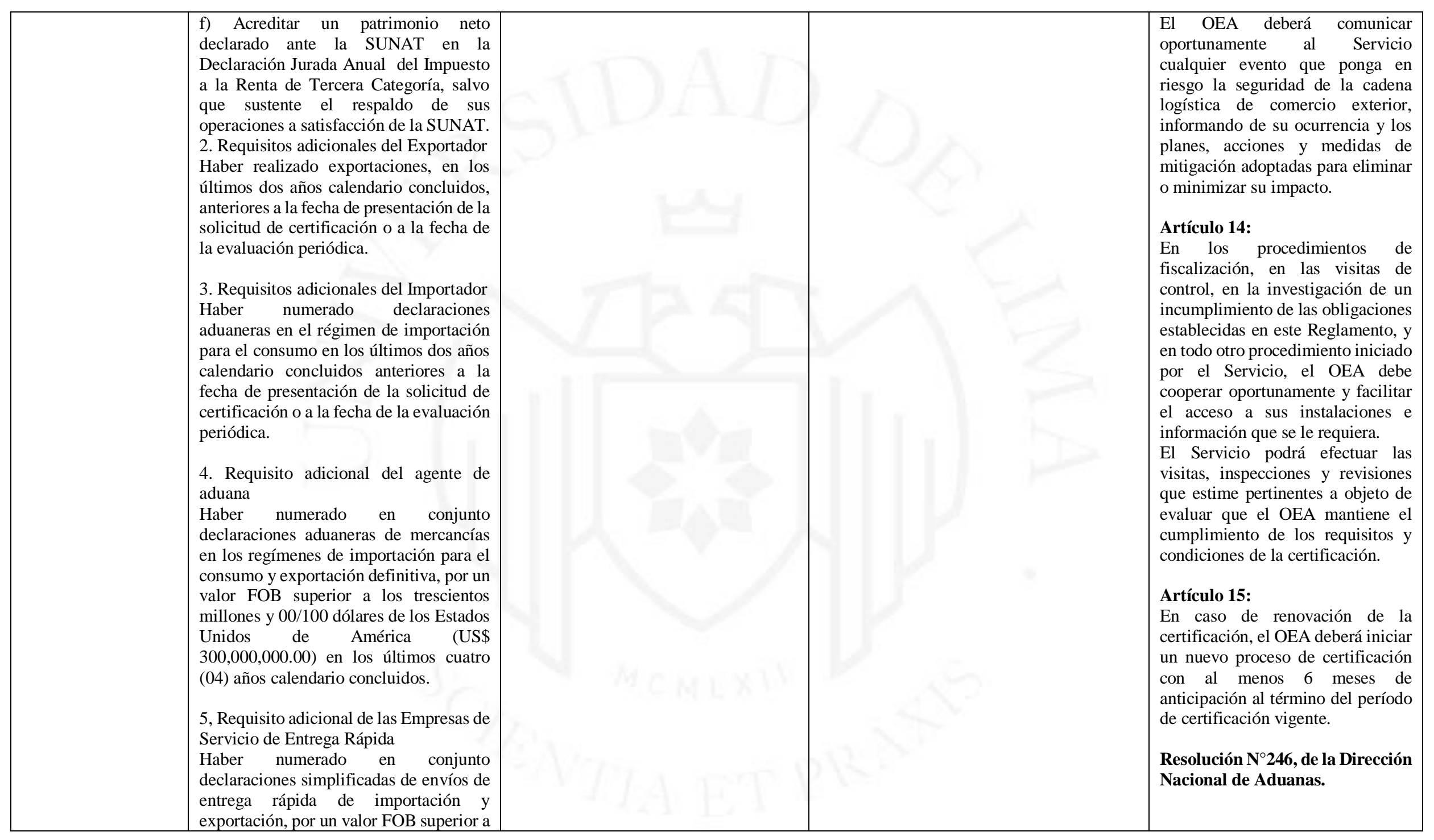




\begin{tabular}{|c|c|c|c|c|}
\hline & $\begin{array}{l}\text { los cinco millones y } 00 / 100 \text { dólares de } \\
\text { los Estados Unidos de América (US } \$ 5 \\
000000,00 \text { ) en los últimos cuatro años } \\
\text { calendario concluidos. } \\
\text { A.4 Nivel de seguridad adecuado. } \\
\text { Se cumple mediante los requisitos } \\
\text { previstos en el Anexo } \mathrm{N}^{\circ} 6 \text { del presente } \\
\text { procedimiento. } \\
\text { Presentar formato virtual de Solicitud de } \\
\text { Certificación. }\end{array}$ & & & $\begin{array}{l}\text { Numeral } 4 \text { del título II.1: Etapa } \\
\text { de Evaluación Documental y } \\
\text { Verificación del Nivel de } \\
\text { Cumplimiento Aduanero: } \\
\text { "La Subdirección de Fiscalización } \\
\text { remitirá, en copia, el Formulario de } \\
\text { Antecedentes para la Certificación } \\
\text { como OEA, a la Unidad de Análisis } \\
\text { e Inteligencia y Gestión de Datos, } \\
\text { con los antecedentes adjuntos, con } \\
\text { la finalidad de que se pronuncie, } \\
\text { dentro del plazo de } 15 \text { días sobre el } \\
\text { perfil de riesgo aduanero del } \\
\text { operador" }\end{array}$ \\
\hline PROCEDIMIENTO & 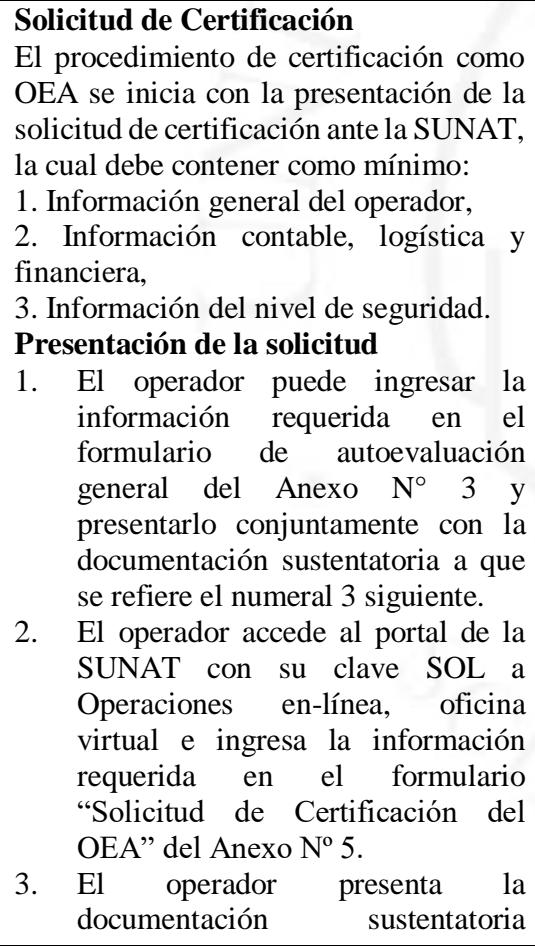 & $\begin{array}{l}\text { El proceso de Operador Económico } \\
\text { Autorizado consta de } 5 \text { etapas: } \\
\text { a) Análisis Fiscal y Aduanero } \\
\text { - Presentar a través de Ventanilla } \\
\text { Digital el formato denominado } \\
\text { "Solicitud de Registro en el } \\
\text { Esquema de Certificación de } \\
\text { Empresas", cumpliendo con lo } \\
\text { establecido en el instructivo del } \\
\text { trámite. } \\
\text { Al momento de la solicitud, debe de } \\
\text { haber realizado el pago del } \\
\text { derecho (aplica para la modalidad } \\
\text { OEA). } \\
\text { Anexar el perfil de seguridad, el } \\
\text { cual deberá estar debidamente } \\
\text { requisitado para cada una de las } \\
\text { instalaciones en las que se realizan } \\
\text { operaciones de comercio exterior. } \\
\text { Se lleva a cabo un análisis de su } \\
\text { estado actual fiscal y aduanal en las } \\
\text { bases de datos institucionales } \\
\text { (situación de sus domicilios, } \\
\text { aduanas por las que realiza } \\
\text { operaciones, agentes aduanales con } \\
\text { los que opera, clientes y }\end{array}$ & $\begin{array}{l}\text { Las etapas para el trámite de la solicitud de } \\
\text { autorización como Operador Económico } \\
\text { Autorizado en Colombia son } 7 \text { y se } \\
\text { encuentran previstas en el artículo } 9 \text { del } \\
\text { Decreto } 3568 \text { de } 2011 \text {, modificado por el } \\
\text { artículo } 8 \text { del Decreto } 1894 \text { del } 2015 \text {. } \\
\text { 1. Diligenciamiento y presentación de la } \\
\text { solicitud. } \\
\text { La empresa diligencia la solicitud a través de } \\
\text { los servicios informáticos electrónicos y } \\
\text { entrega físicamente los documentos soporte. } \\
\text { En caso de no entregarse la totalidad de los } \\
\text { documentos soporte señalados en el artículo } \\
\text { anterior, se requerirá al solicitante por una } \\
\text { sola vez para que dentro de los diez (10) días } \\
\text { siguientes al recibo de la comunicación, los } \\
\text { allegue. } \\
\text { Se entenderá presentada la solicitud cuando } \\
\text { la misma haya sido recibida y se le haya } \\
\text { asignado un número de solicitud, y los } \\
\text { documentos soporte hayan sido radicados en }\end{array}$ & $\begin{array}{l}\text { Proceso de Certificación como } \\
\text { OEA } \\
\text { El proceso de certificación como } \\
\text { OEA está conformado por dos } \\
\text { etapas consecutivas: } \\
\text { a) Evaluación Documental y } \\
\text { Verificación del Nivel de } \\
\text { Cumplimiento Aduanero } \\
\text { b) Visitas de Verificación, } \\
\text { debiendo el operador aprobar cada } \\
\text { una de ellas para ser certificado } \\
\text { como OEA, según el tipo de } \\
\text { operador que corresponda. } \\
\text { El proceso total de certificación } \\
\text { como OEA no podrá exceder del } \\
\text { plazo de } 120 \text { días contados a partir } \\
\text { del día siguiente de la fecha de } \\
\text { completados todos los antecedentes } \\
\text { requeridos, el cual podrá ser } \\
\text { prorrogado por un plazo adicional } \\
\text { de hasta } 60 \text { días. Vencido este } \\
\text { plazo, sin que exista } \\
\text { pronunciamiento por parte del }\end{array}$ \\
\hline
\end{tabular}




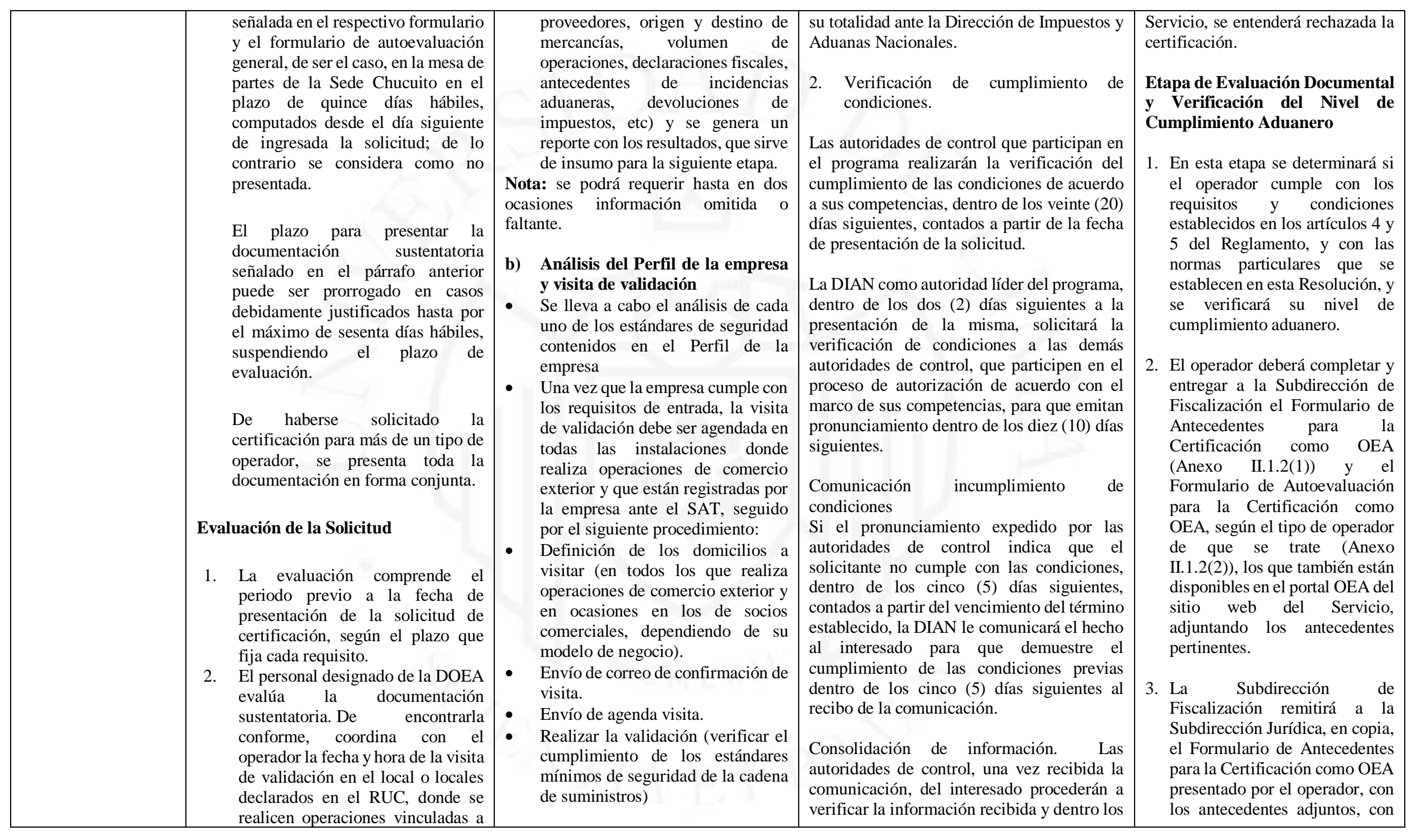




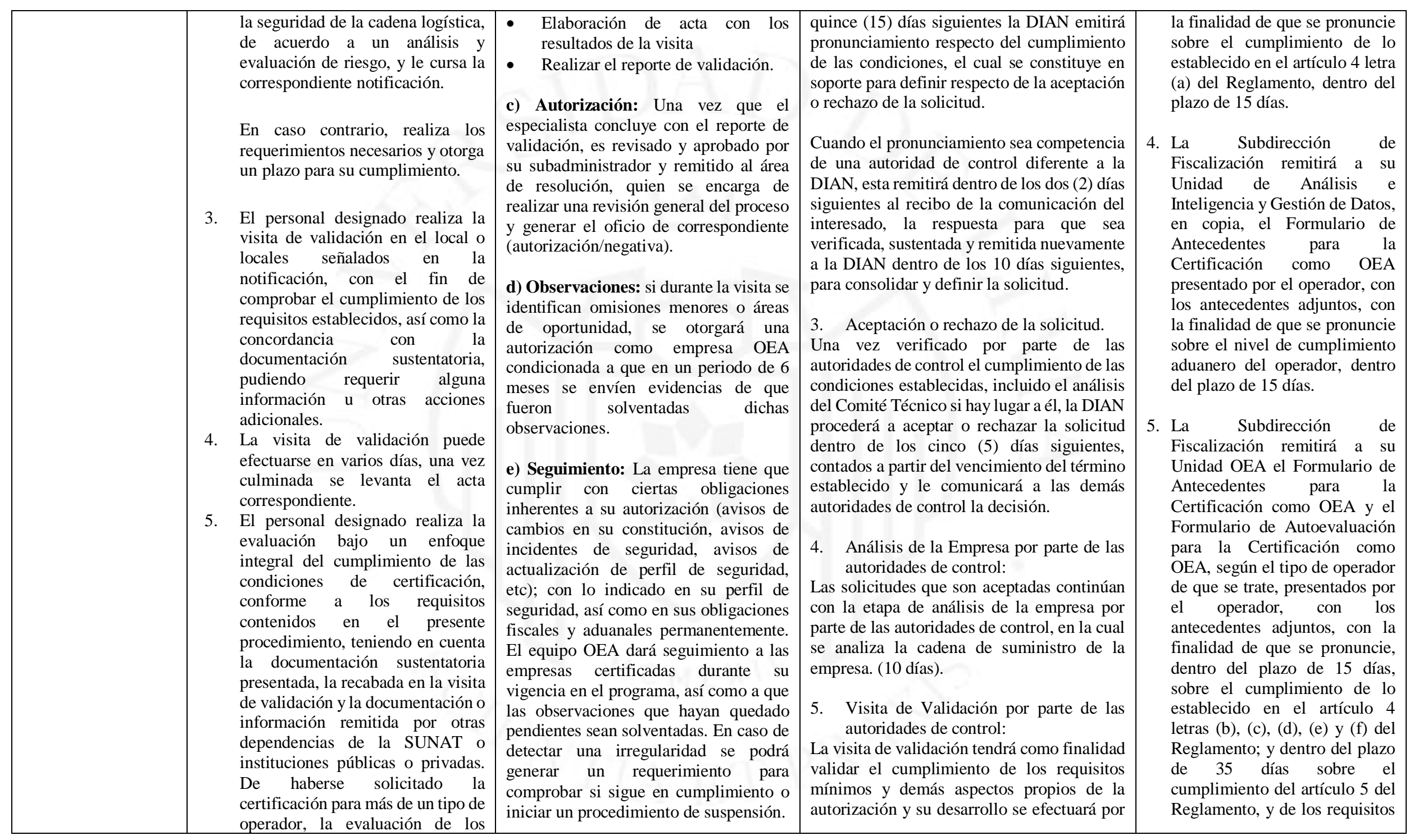




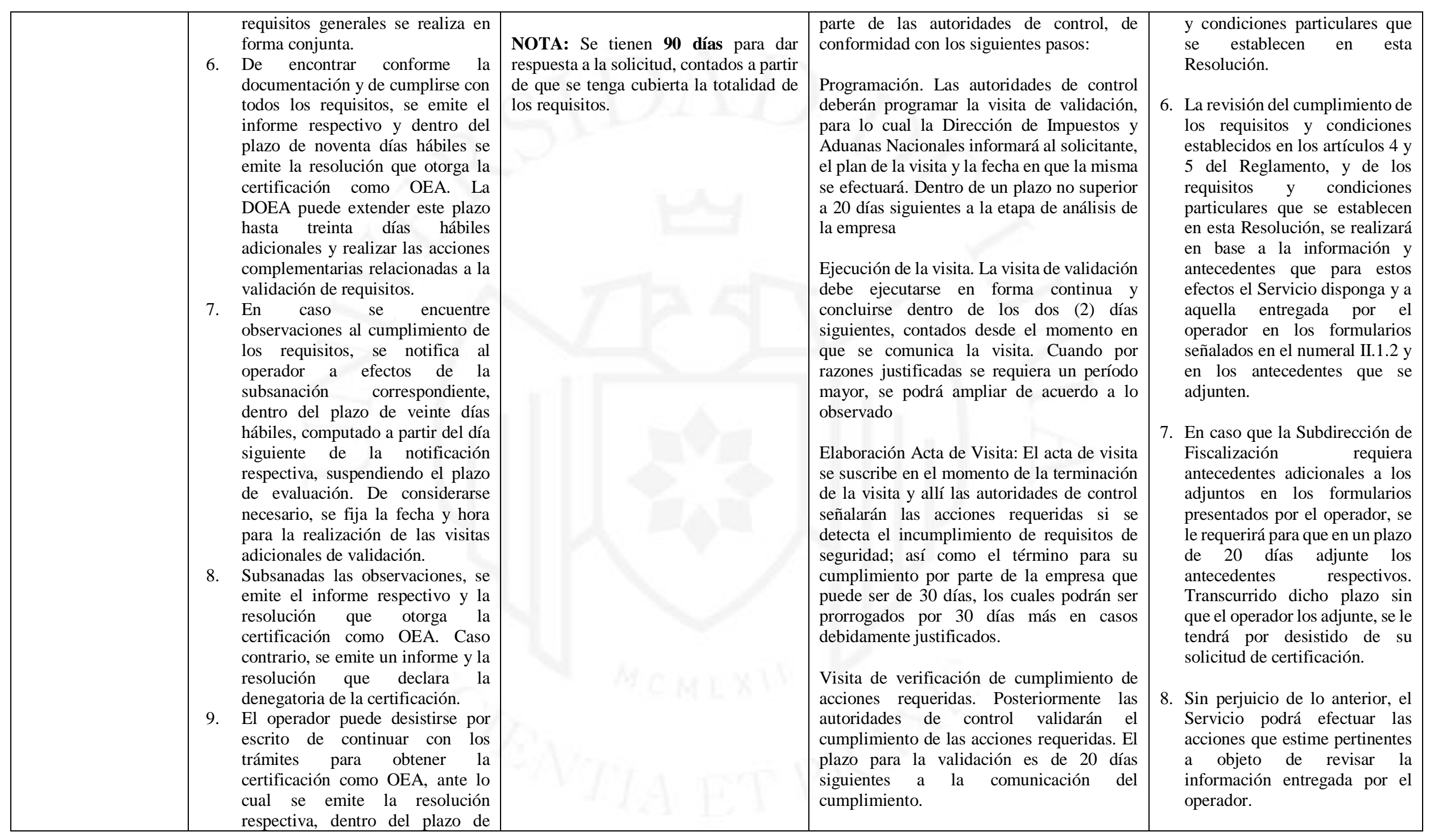




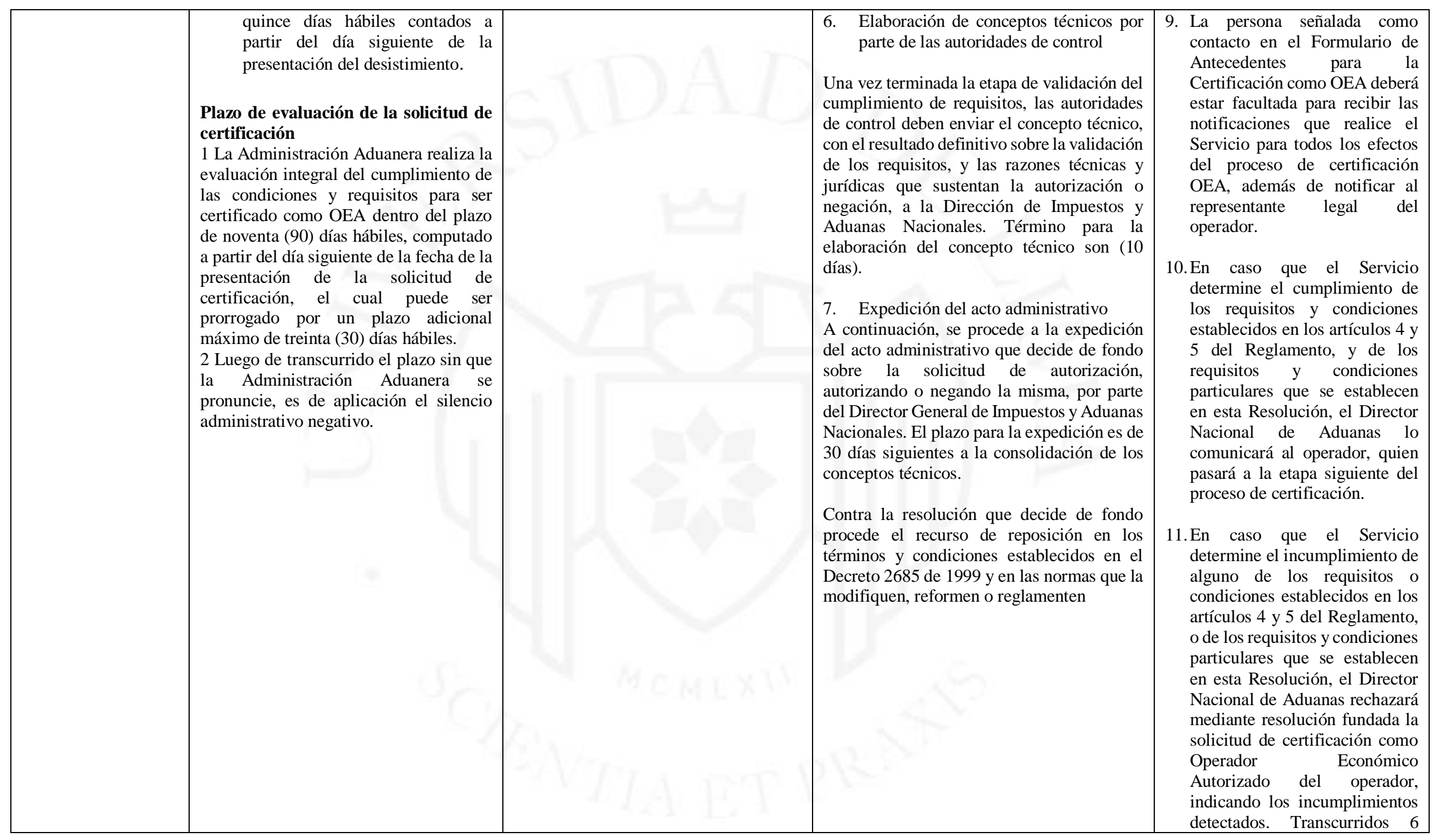




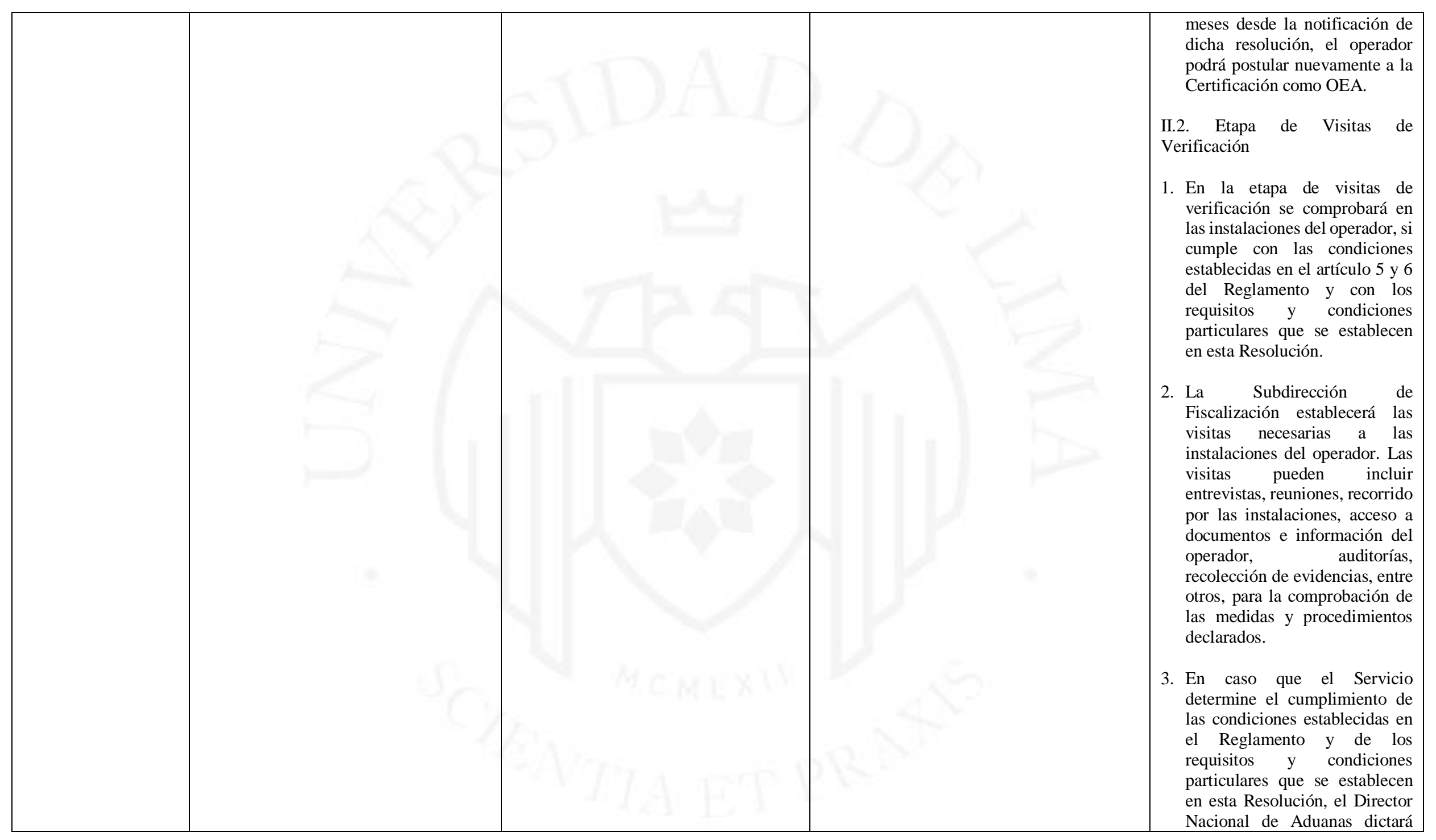




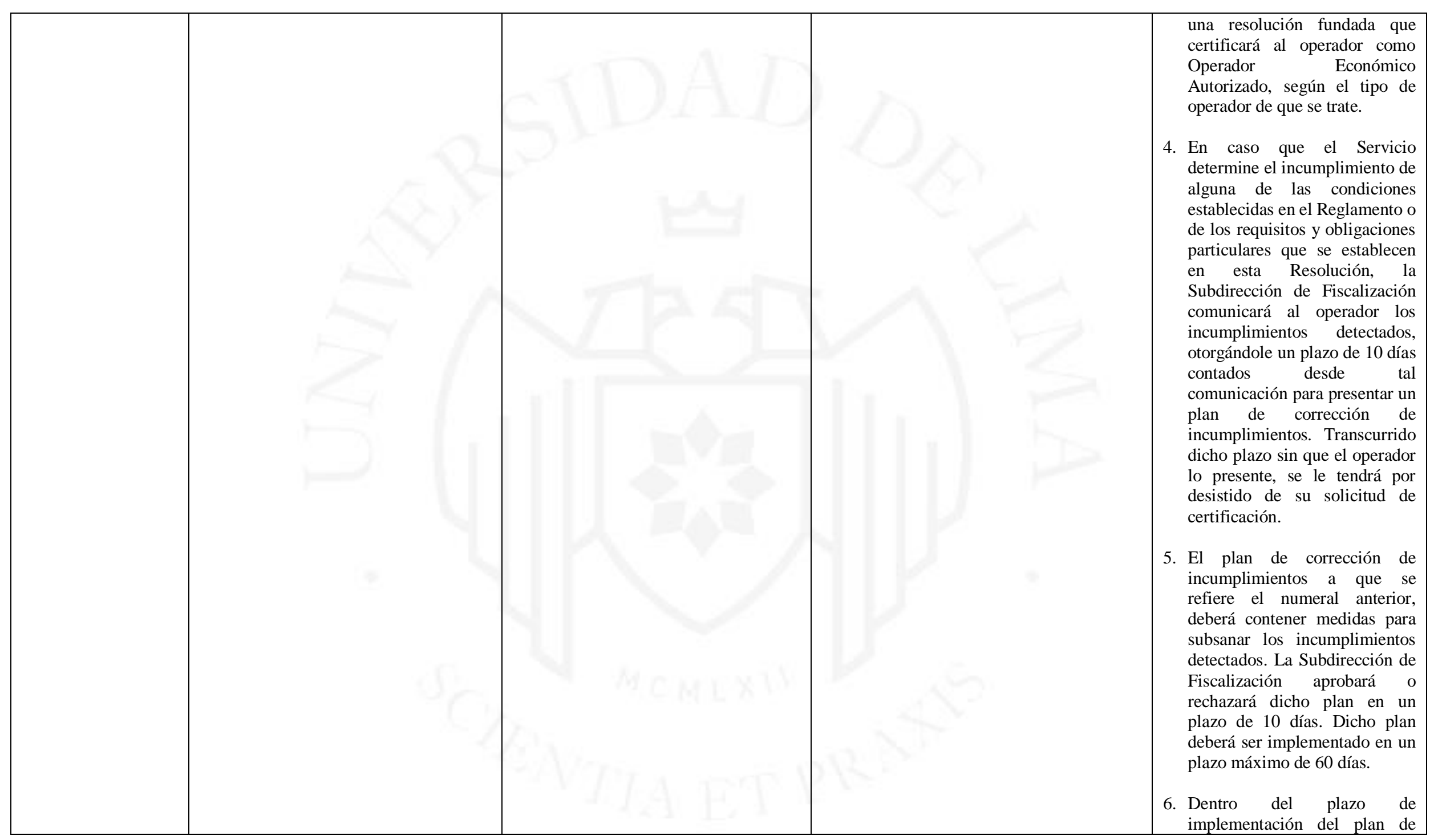




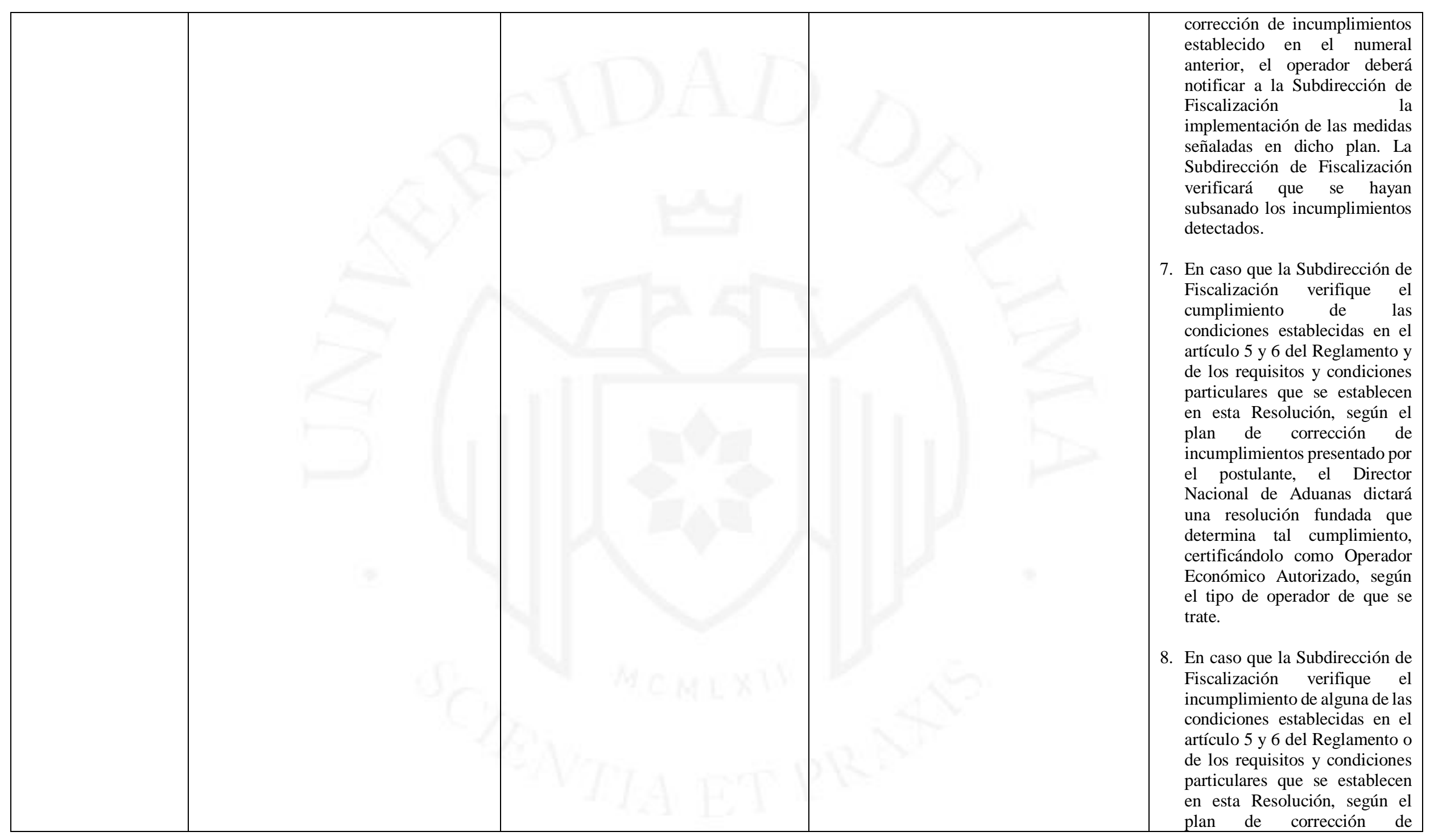




\begin{tabular}{|c|c|c|c|c|}
\hline & & & & $\begin{array}{l}\text { incumplimientos presentado por } \\
\text { el operador, el Director } \\
\text { Nacional de Aduanas dictará } \\
\text { una resolución fundada que } \\
\text { rechaza la solicitud de } \\
\text { certificación como Operador } \\
\text { Económico Autorizado del } \\
\text { operador. } \\
\text { 9. Transcurridos } 12 \text { meses desde la } \\
\text { notificación de la resolución a } \\
\text { que se refiere el numeral } \\
\text { anterior, el operador podrá } \\
\text { iniciar un nuevo proceso de } \\
\text { certificación como OEA. }\end{array}$ \\
\hline $\begin{array}{l}\text { VERIFICACIÓN } \\
\text { DE SEGURIDAD }\end{array}$ & $\begin{array}{l}\text { - El personal designado de la DOEA } \\
\text { evalúa la documentación } \\
\text { sustentatoria. } \\
\text { De encontrarla conforme, coordina } \\
\text { con el operador la fecha y hora de la } \\
\text { visita de validación en el local o } \\
\text { locales declarados en el RUC, donde } \\
\text { se realicen operaciones vinculadas a } \\
\text { la seguridad de la cadena logística, de } \\
\text { acuerdo a un análisis y evaluación de } \\
\text { riesgo, y le cursa la correspondiente } \\
\text { notificación } \\
\text { - En caso contrario, realiza los } \\
\text { requerimientos necesarios y otorga } \\
\text { un plazo para su cumplimiento. } \\
\text { - Visita de validación en el local o } \\
\text { locales señalados en la notificación. } \\
\text { Evaluación de la solicitud (90 días } \\
\text { desde el día siguiente de la } \\
\text { presentación de la solicitud, el cual } \\
\text { puede ser prorrogado por un plazo } \\
\text { adicional de } 30 \text { días hábiles, si se } \\
\text { requieren acciones complementarias } \\
\text { relacionadas a la validación de los } \\
\text { requisitos). }\end{array}$ & $\begin{array}{l}\text { - Los especialistas realizan el análisis } \\
\text { de los estándares en materia de } \\
\text { seguridad, dicha información se } \\
\text { encuentra en el formato de perfil de } \\
\text { seguridad específico para cada tipo } \\
\text { de operador. } \\
\text { - Se revisa que el formato contenga } \\
\text { el disco o medio magnético con los } \\
\text { anexos solicitados en cada estándar } \\
\text { en materia de seguridad. } \\
\text { El especialista realiza e integra al } \\
\text { expediente un "check-list", el cual } \\
\text { incluye el cumplimiento o } \\
\text { incumplimiento documental de } \\
\text { cada sub-estándar en materia de } \\
\text { seguridad. } \\
\text { Si la empresa cumple con todos los } \\
\text { sub-estándares se procede a } \\
\text { programar la visita de inspección o } \\
\text { visita de seguimiento. } \\
\text { Si la empresa no cumple con algún } \\
\text { sub-estándar en materia de } \\
\text { seguridad, se elabora el } \\
\text { requerimiento específico a la } \\
\text { empresa solicitante, información }\end{array}$ & $\begin{array}{l}\text { - Los especialistas de las autoridades de } \\
\text { control que participen en el trámite de la } \\
\text { solicitud realizan la revisión de los } \\
\text { documentos soporte allegados por la } \\
\text { empresa con la solicitud. } \\
\text { - La empresa puede realizar una } \\
\text { presentación general de la cadena de } \\
\text { suministro de su compañía. } \\
\text { - Los especialistas planean y ejecutan la } \\
\text { visita de validación de requisitos de } \\
\text { seguridad. } \\
\text { - Durante la realización de la visita, los } \\
\text { especialistas diligencian la lista de } \\
\text { chequeo de verificación de requisitos de } \\
\text { seguridad, describiendo las situaciones } \\
\text { encontradas que soportan el cumplimiento } \\
\text { o incumplimiento de los requisitos de } \\
\text { seguridad. } \\
\text { - Cuando en la visita se detecta que la } \\
\text { empresa no cumple con algún requisito de } \\
\text { seguridad, se deja la anotación como } \\
\text { acción requerida en el acta con la cual se } \\
\text { cierra la visita. }\end{array}$ & $\begin{array}{l}\text { 1. El proceso es ejecutado por un } \\
\text { equipo de dos (2) Auditores } \\
\text { OEA los que son designados } \\
\text { por el Jefe de la Unidad OEA } \\
\text { (JUO). El Auditor OEA Líder } \\
\text { (AOL) tiene a su cargo el } \\
\text { proceso de verificación y el } \\
\text { Auditor OEA Informante } \\
\text { (AOI), lo apoya en las } \\
\text { funciones de registro y } \\
\text { análisis. } \\
\text { La etapa de evaluación } \\
\text { documental se inicia cuando } \\
\text { el Servicio recepciona los } \\
\text { documentos y formularios de } \\
\text { postulación del operador } \\
\text { interesado en certificar OEA. } \\
\text { El Servicio deberá responder } \\
\text { dentro del plazo de } 40 \text { días } \\
\text { respecto del cumplimiento de } \\
\text { los requisitos establecido en el } \\
\text { artículo } 4 \text { letras y el artículo } 5 \\
\text { del Reglamento OEA. }\end{array}$ \\
\hline
\end{tabular}




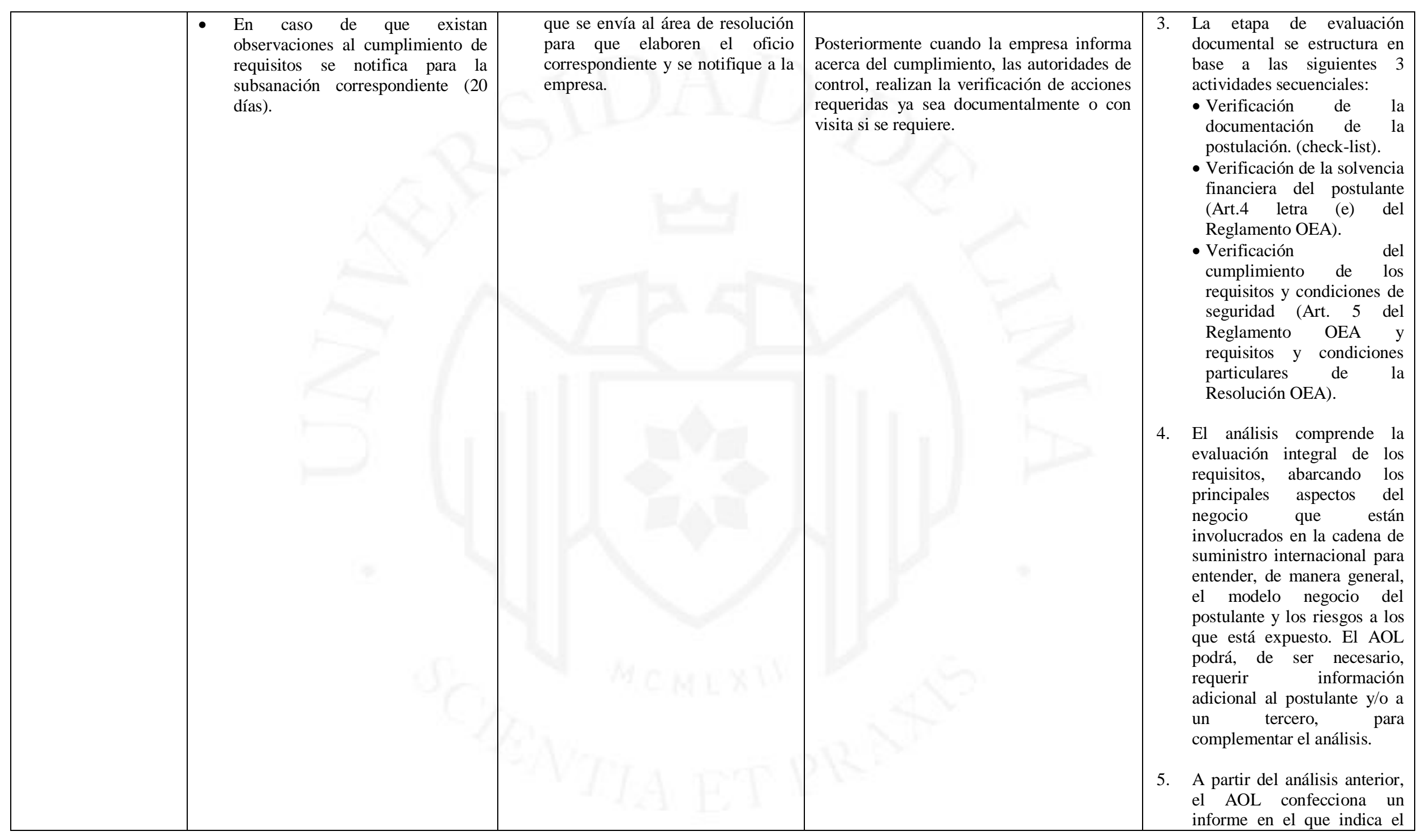




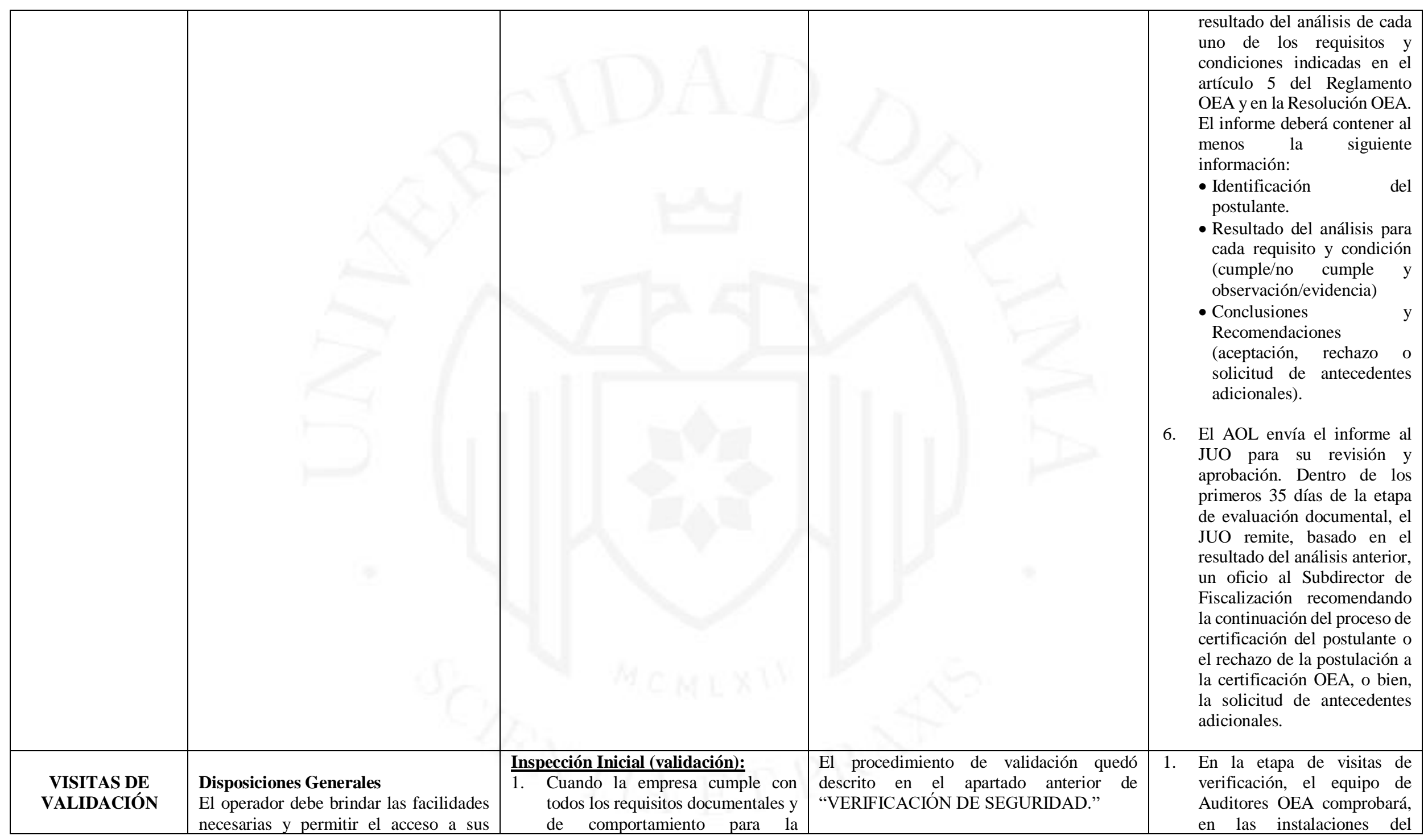




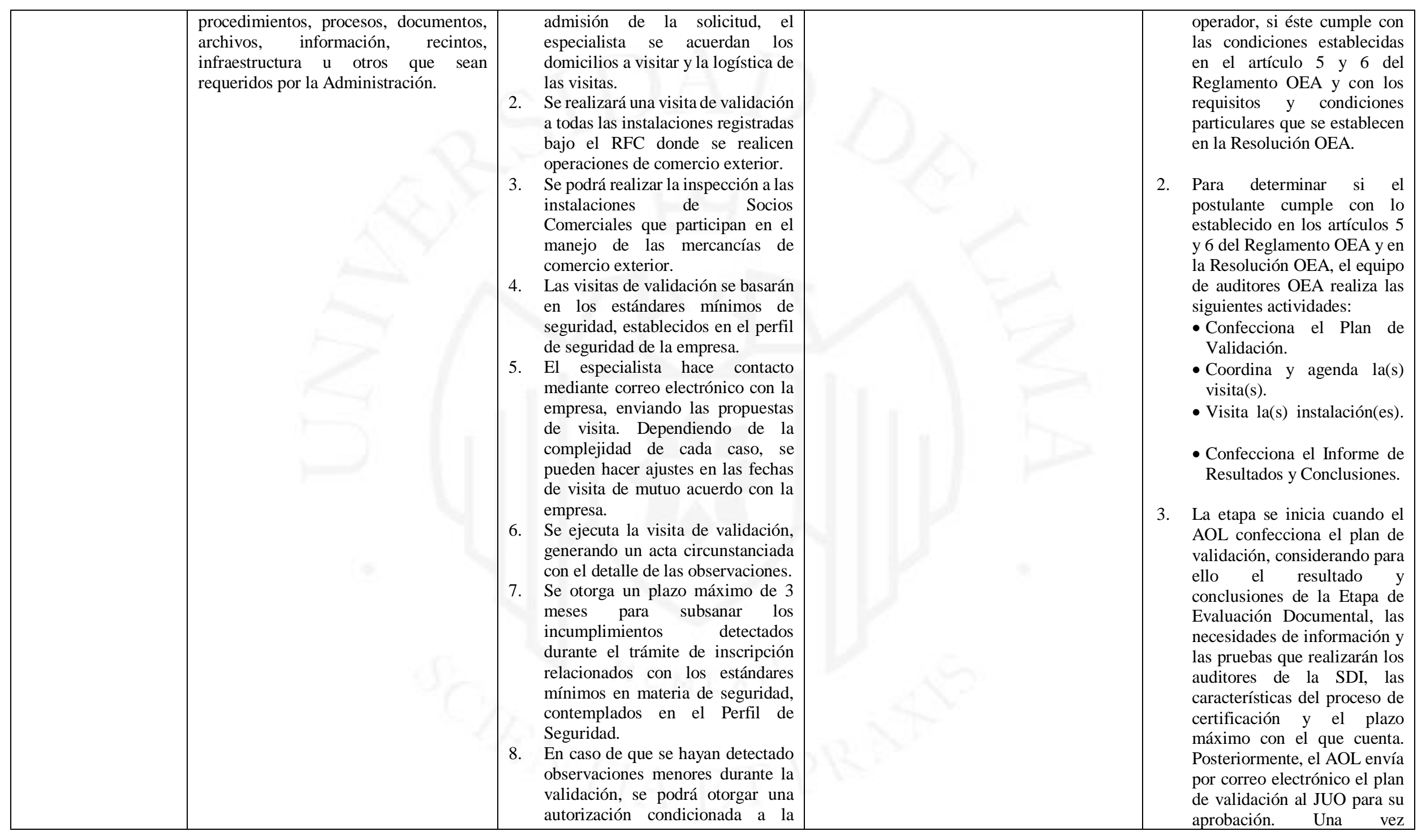




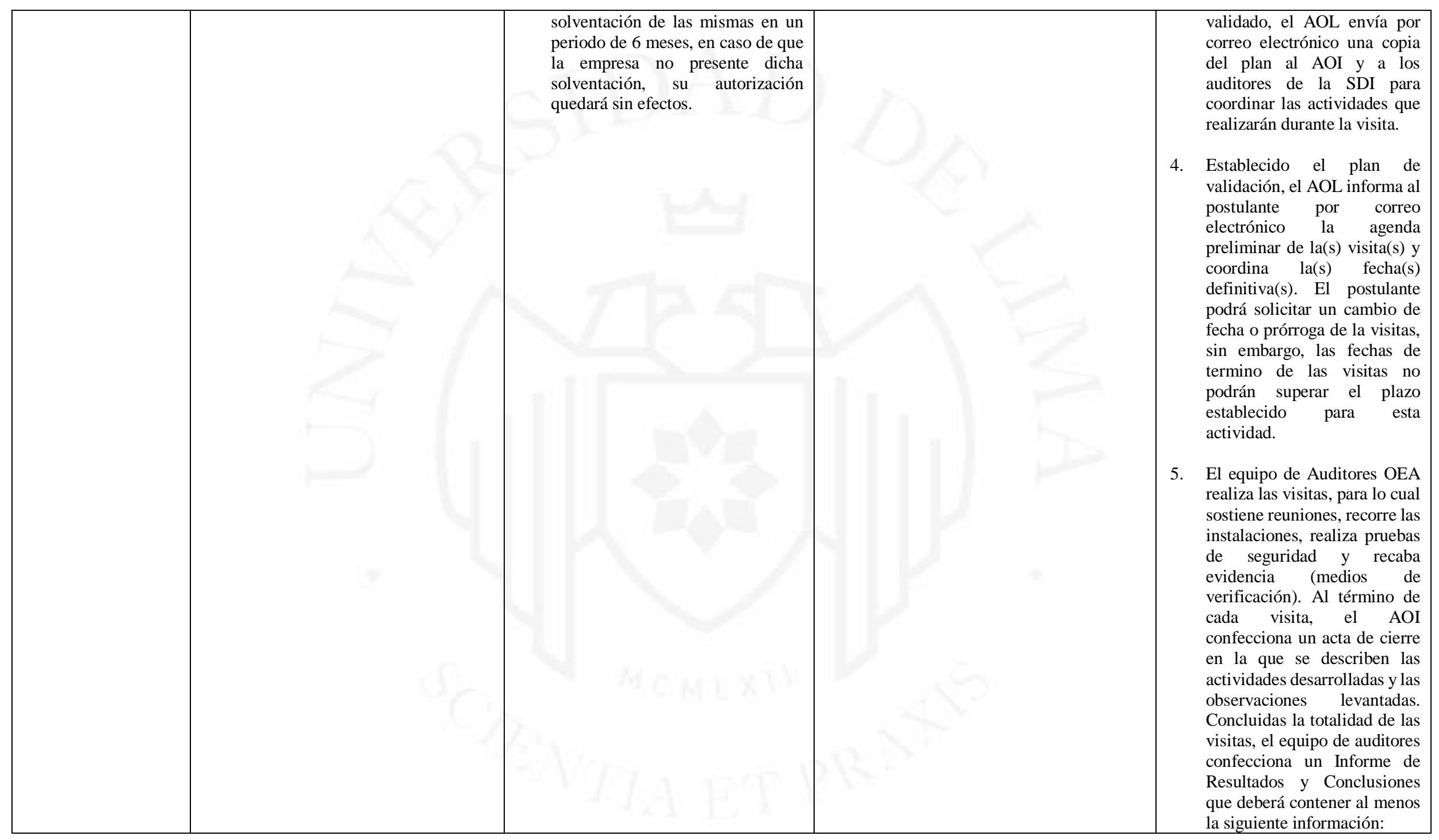




\begin{tabular}{|c|c|c|c|c|}
\hline & & & & $\begin{array}{l}\text { - Identificación del } \\
\text { postulante. } \\
\text { - Resultado del análisis para } \\
\text { cada requisito y condición } \\
\text { (cumple/no cumple y } \\
\text { observación/evidencia) } \\
\text { - Conclusiones } \\
\text { Recomendaciones } \\
\text { (aceptación, rechazo). } \\
\text { 6. Finalmente, el AOL envía el } \\
\text { Informe anterior al JUO para } \\
\text { su revisión quien, una vez } \\
\text { aprobado, lo remite mediante } \\
\text { oficio al Subdirector de } \\
\text { Fiscalización recomendando } \\
\text { la aceptación o rechazo del } \\
\text { postulante a la certificación } \\
\text { OEA. }\end{array}$ \\
\hline RESULTADO & $\begin{array}{l}\text { Emisión de la Certificación } \\
\text { De encontrar conforme la } \\
\text { documentación y de cumplirse con todos } \\
\text { los requisitos, se emite el informe } \\
\text { respectivo y dentro del plazo de noventa } \\
\text { días hábiles se emite la resolución que } \\
\text { otorga la certificación como OEA. } \\
\text { En caso se encuentre observaciones al } \\
\text { cumplimiento de los requisitos, se } \\
\text { notifica al operador a efectos de la } \\
\text { subsanación correspondiente, dentro del } \\
\text { plazo de veinte días hábiles, computado } \\
\text { a partir del día siguiente de la } \\
\text { notificación respectiva, suspendiendo el } \\
\text { plazo de evaluación. De considerarse } \\
\text { necesario, se fija la fecha y hora para la }\end{array}$ & $\begin{array}{l}\text { Autorización } \\
\text { Para las empresas que cumplen con } \\
\text { todos los requisitos anteriores se } \\
\text { entregará un escrito donde se les informa } \\
\text { su autorización como empresa OEA. En } \\
\text { los casos en que el escrito de } \\
\text { autorización incluya observaciones, esta } \\
\text { debe ser resuelta en los } 6 \text { meses } \\
\text { siguientes a su certificación. } \\
\text { La vigencia de la autorización es de } 2 \\
\text { años, sin embargo se podrán homologar } \\
\text { las vigencias de la certificación OEA, a } \\
3 \text { años otorgadas a las empresas } \\
\text { certificadas en materia de IVA y IEPS en } \\
\text { la modalidad AAA; que es otro } \\
\text { programa de certificación enfocado en } \\
\text { cumplimiento fiscal. } \\
\text { En todos los casos, durante los } 30 \text { días } \\
\text { anteriores al fin de vigencia, las }\end{array}$ & $\begin{array}{l}\text { La decisión sobre la autorización o negación } \\
\text { será expedida por el Director General de la } \\
\text { Dirección de Impuestos y Aduanas, mediante } \\
\text { resolución, dentro de los } 30 \text { días siguientes a } \\
\text { la consolidación de los conceptos técnicos. } \\
\text { La vigencia de la autorización es indefinida. } \\
\text { Cuando la decisión es negativa procede el } \\
\text { recurso de reposición en los términos y } \\
\text { condiciones establecidos en el Decreto } 2685 \\
\text { de } 1999 \text { y en las normas que la modifiquen, } \\
\text { reformen o reglamenten }\end{array}$ & $\begin{array}{l}\text { En caso que el Servicio determine } \\
\text { el incumplimiento de alguna de las } \\
\text { condiciones establecidas en el } \\
\text { Reglamento o de los requisitos y } \\
\text { obligaciones particulares que se } \\
\text { establecen en esta Resolución, la } \\
\text { Subdirección de Fiscalización } \\
\text { comunicará al operador los } \\
\text { incumplimientos detectados, } \\
\text { otorgándole un plazo de } 10 \text { días } \\
\text { contados desde tal comunicación } \\
\text { para presentar un plan de } \\
\text { corrección de incumplimientos. } \\
\text { Transcurrido dicho plazo sin que el } \\
\text { operador lo presente, se le tendrá } \\
\text { por desistido de su solicitud de } \\
\text { certificación. } \\
\text { El plan de corrección de } \\
\text { incumplimientos a que se refiere el } \\
\text { numeral anterior, deberá contener }\end{array}$ \\
\hline
\end{tabular}




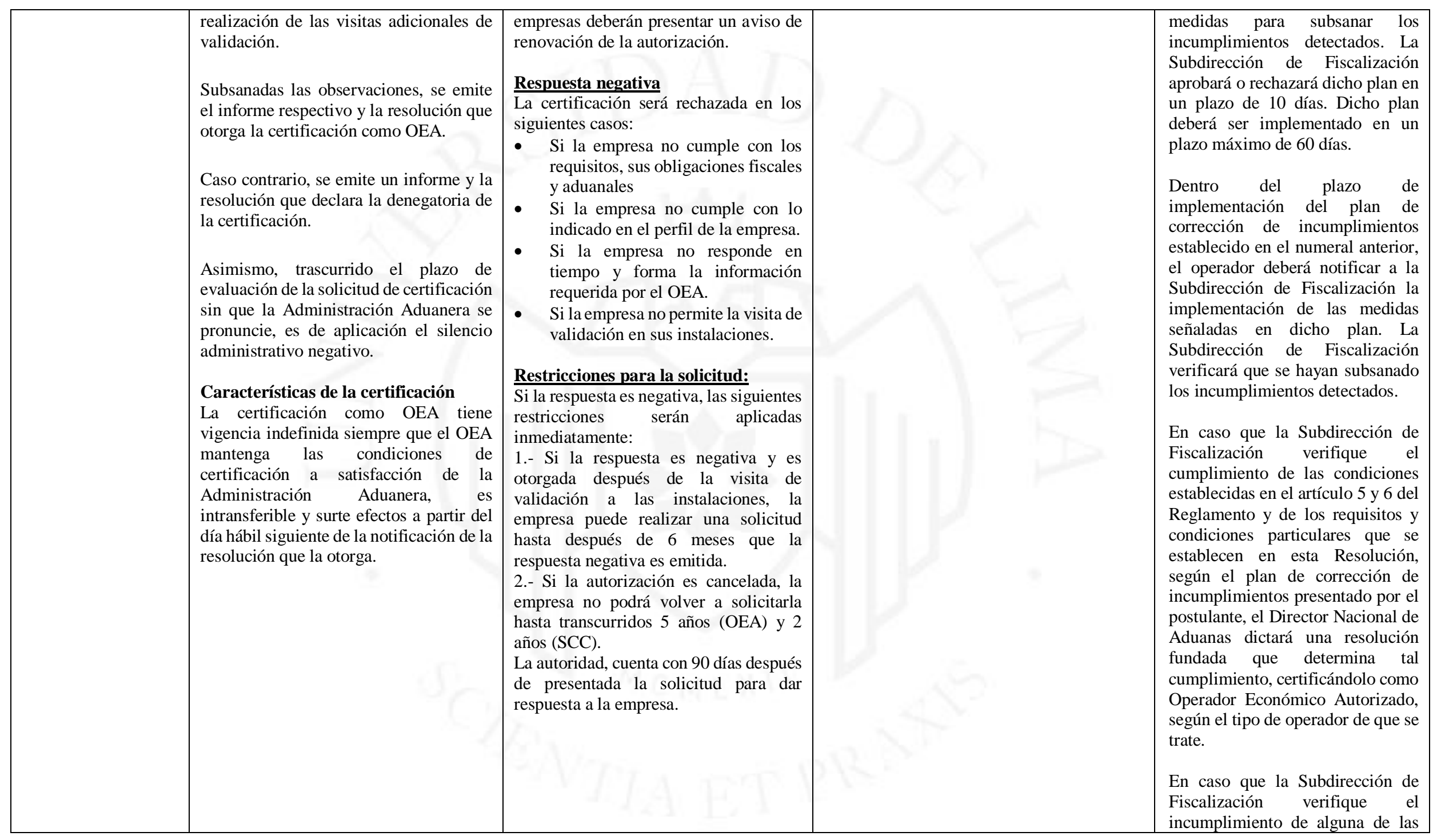




\begin{tabular}{|c|c|c|c|c|}
\hline & & & & $\begin{array}{l}\text { condiciones establecidas en el } \\
\text { artículo } 5 \text { y } 6 \text { del Reglamento o de } \\
\text { los requisitos y condiciones } \\
\text { particulares que se establecen en } \\
\text { esta Resolución, según el plan de } \\
\text { corrección de incumplimientos } \\
\text { presentado por el operador, el } \\
\text { Director Nacional de Aduanas } \\
\text { dictará una resolución fundada que } \\
\text { rechaza la solicitud de certificación } \\
\text { como Operador Económico } \\
\text { Autorizado del operador. }\end{array}$ \\
\hline RENOVACION & No aplica & $\begin{array}{l}\text { La renovación de la certificación OEA } \\
\text { puede realizarse a través de VUCEM; } \\
\text { siempre que las empresas no se } \\
\text { encuentren sujetas al proceso de } \\
\text { cancelación de dicha certificación. } \\
\text { El registro se tendrá por renovado al día } \\
\text { hábil siguiente a la fecha de acuse de } \\
\text { recepción del formato de aviso de } \\
\text { renovación, cuya vigencia se computará } \\
\text { a partir del día siguiente en que concluya } \\
\text { la vigencia inmediata anterior. } \\
\text { La autoridad podrá requerir en cualquier } \\
\text { momento, cuando con posterioridad a la } \\
\text { renovación, detecte que la empresa ha } \\
\text { dejado de cumplir con alguno de los } \\
\text { requisitos necesarios para la obtención } \\
\text { de su certificación. } \\
\text { La autoridad realizará el monitoreo } \\
\text { permanente con el objetivo de revisar si } \\
\text { las empresas siguen cumpliendo con sus } \\
\text { obligaciones fiscales y aduaneras y con } \\
\text { la información indicada en el "Perfil" } \\
\text { correspondiente. }\end{array}$ & No aplica. & $\begin{array}{l}\text { El OEA interesado en renovar su } \\
\text { certificación, deberá iniciar un } \\
\text { nuevo proceso de certificación, } \\
\text { según se establece en el numeral II } \\
\text { de la Resolución } \mathrm{N}^{\circ} 246 \text {, con al } \\
\text { menos } 6 \text { meses de anticipación al } \\
\text { término del período de su } \\
\text { certificación vigente. } \\
\text { El OEA que tenga vigente una } \\
\text { suspensión de beneficios, según se } \\
\text { establece en los Títulos V y VI del } \\
\text { Reglamento, no podrá solicitar la } \\
\text { renovación de su certificación } \\
\text { hasta cumplido el plazo de la } \\
\text { suspensión. }\end{array}$ \\
\hline REVALIDACION & Evaluación periódica de Validación & Visitas de seguimiento (revalidación): & $\begin{array}{l}\text { La revalidación es la actividad que } \\
\text { desarrollan las autoridades de control, con el }\end{array}$ & $\begin{array}{l}\text { Seguimiento de la Certificación } \\
\text { como OEA }\end{array}$ \\
\hline
\end{tabular}




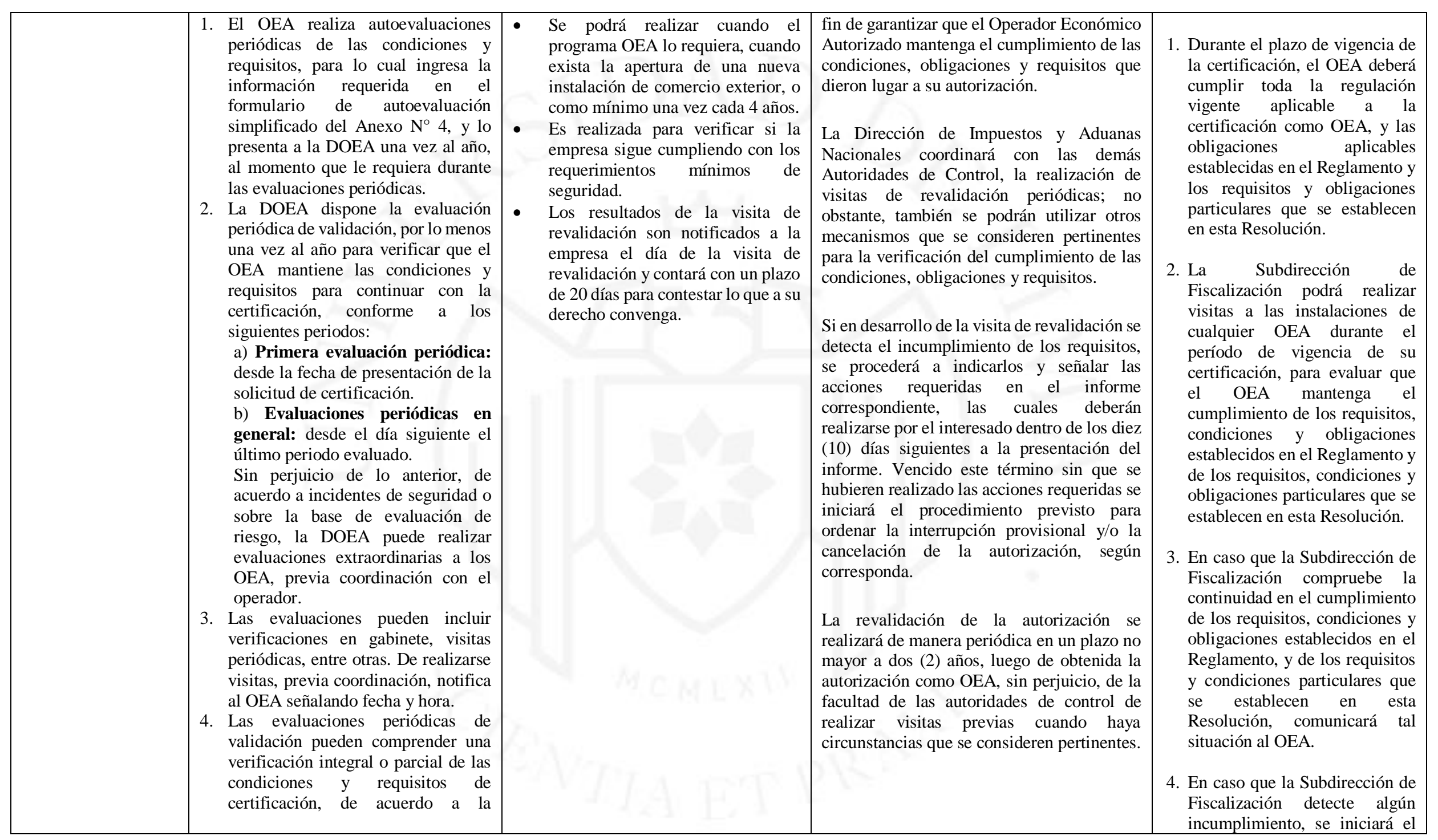




\begin{tabular}{|c|c|c|c|c|}
\hline & $\begin{array}{l}\text { evaluación de riesgos que realice la } \\
\text { DOEA } \\
\text { 5. El resultado de la evaluación } \\
\text { periódica de validación o de } \\
\text { mantenimiento puede ser: } \\
\text { a) Conforme: Cuando se mantengan } \\
\text { las condiciones y requisitos de la } \\
\text { certificación. } \\
\text { b) Con observaciones: Cuando se } \\
\text { detecten observaciones subsanables } \\
\text { al cumplimiento de las condiciones y } \\
\text { requisitos de la certificación. } \\
\text { c) No conforme: Cuando se detecte } \\
\text { el incumplimiento de las condiciones } \\
\text { y requisitos de la certificación. } \\
\text { 6. De configurarse el supuesto b), la } \\
\text { DOEA notifica al OEA las } \\
\text { recomendaciones o acciones } \\
\text { requeridas, otorgándole un plazo } \\
\text { máximo de veinte días hábiles para } \\
\text { su subsanación. Vencido este plazo } \\
\text { sin que el OEA comunique el } \\
\text { cumplimiento de lo requerido se } \\
\text { inicia el procedimiento de } \\
\text { suspensión. } \\
\text { 7. De configurarse el supuesto c), se } \\
\text { inicia del procedimiento de } \\
\text { suspensión. }\end{array}$ & & $\begin{array}{l}\text { A la fecha Colombia no ha realizado visitas } \\
\text { de revalidación, las mismas se empezarán a } \\
\text { efectuar en el año } 2017 \text {. }\end{array}$ & $\begin{array}{l}\text { procedimiento establecido en el } \\
\text { Título VI del Reglamento. }\end{array}$ \\
\hline $\begin{array}{l}\text { CAUSALES DE } \\
\text { SUSPENSIÓN Y } \\
\text { CANCELACIÓN }\end{array}$ & $\begin{array}{l}\text { Causales de suspensión: } \\
\text { 1.No otorgar las facilidades a la } \\
\text { Administración Aduanera para que } \\
\text { verifique el cumplimiento de las } \\
\text { condiciones y requisitos como OEA. } \\
\text { 2. Incumplir las condiciones y requisitos } \\
\text { para mantener la certificación como } \\
\text { OEA. } \\
\text { 3. Usar indebidamente la certificación o } \\
\text { las facilidades obtenidas como OEA. }\end{array}$ & $\begin{array}{l}\text { La cancelación de la autorización podrá } \\
\text { ser en los siguientes casos: } \\
\text { - Cuando no desvirtúen } \\
\text { inconsistencias que hayan generado } \\
\text { un requerimiento (cumplimiento } \\
\text { fiscal y aduanero). } \\
\text { Cuando dejen de cumplir con los } \\
\text { requisitos previstos para la } \\
\text { autorización o la renovación. }\end{array}$ & $\begin{array}{l}\text { Causales de interrupción: } \\
\text { - El incumplimiento de las condiciones, } \\
\text { obligaciones o requisitos en virtud de } \\
\text { los cuales se otorgó la autorización. } \\
\text { - La ocurrencia de un incidente en el que } \\
\text { se vea comprometida su } \\
\text { responsabilidad. } \\
\text { La pérdida o cancelación de las } \\
\text { calidades que le hayan sido otorgadas } \\
\text { por parte de las Autoridades de Control. }\end{array}$ & $\begin{array}{l}\begin{array}{l}\text { Causales de suspensión y } \\
\text { revocación: }\end{array} \\
\begin{array}{l}\text { Son causales de suspensión el } \\
\text { incumplimiento de las } \\
\text { obligaciones establecidas en el } \\
\text { Reglamento. } \\
\text { Son causales de revocación: } \\
\text { a) El incumplimiento reiterado de } \\
\text { las obligaciones establecidas en }\end{array}\end{array}$ \\
\hline
\end{tabular}




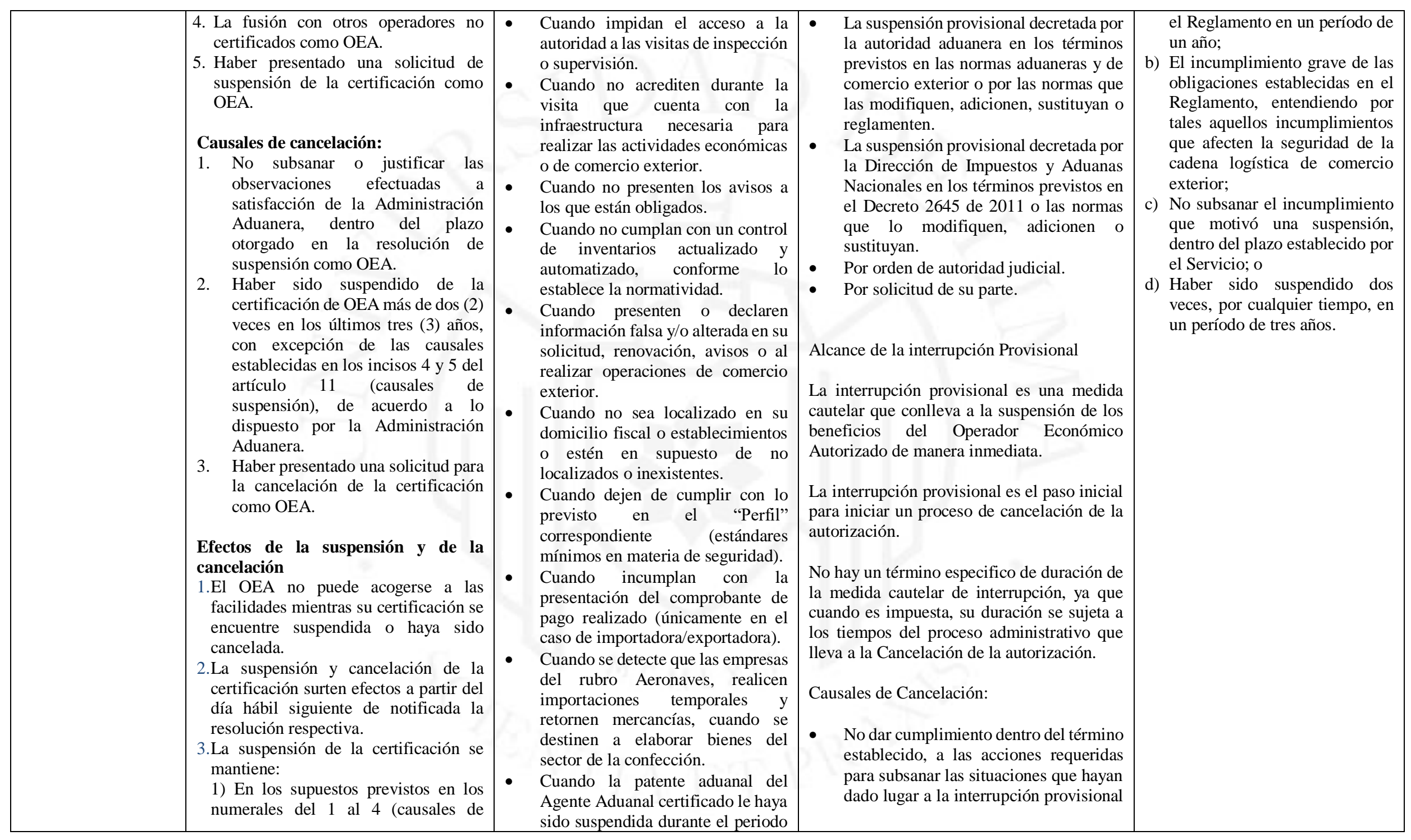




\begin{tabular}{|c|c|c|c|}
\hline & $\begin{array}{l}\text { suspensión), hasta la notificación de la } \\
\text { resolución que deje sin efecto la } \\
\text { suspensión, al haberse subsanado o } \\
\text { justificado las observaciones a } \\
\text { satisfacción de la Administración } \\
\text { Aduanera, o que determine la } \\
\text { cancelación de la certificación. } \\
\text { 2) En el supuesto previsto en el } \\
\text { numeral } 5 \text { (causales de suspensión), } \\
\text { hasta el vencimiento del plazo } \\
\text { otorgado en la resolución de } \\
\text { suspensión. Este plazo puede ser de } \\
\text { hasta seis (06) meses, prorrogables en } \\
\text { casos debidamente justificados. } \\
\text { La Administración Aduanera emitirá } \\
\text { las referidas resoluciones dentro de los } \\
\text { plazos establecidos en el } \\
\text { procedimiento de suspensión y } \\
\text { cancelación de la certificación como } \\
\text { OEA. } \\
\text { 4.La cancelación inhabilita al operador a } \\
\text { solicitar la certificación como OEA, } \\
\text { durante dos (2) años contados a partir } \\
\text { del día hábil siguiente de notificada la } \\
\text { resolución respectiva. }\end{array}$ & $\begin{array}{l}\text { de vigencia de su inscripción, o le } \\
\text { haya sido cancelada. } \\
\text { Cuando la autorización como } \\
\text { Recinto Fiscalizado certificado, sea } \\
\text { cancelada definitivamente. } \\
\text { Cuando la autorización como } \\
\text { Recinto Fiscalizado Estratégico } \\
\text { certificado, sea cancelada } \\
\text { definitivamente. } \\
\text { Cuando el RFC del OEA ó del Auto } \\
\text { Transportista Terrestre, Agente } \\
\text { Aduanal, Transporte Ferroviario, } \\
\text { Parques Industriales, Recinto } \\
\text { Fiscalizado y, Mensajería y } \\
\text { paquetería, no se encuentre activo, } \\
\text { se procederá a la suspensión } \\
\text { inmediata. } \\
\text { Cuando una vez agotados los } \\
\text { plazos, no se presenten la } \\
\text { solventación de requerimientos } \\
\text { específicos que deriven de la } \\
\text { certificación o de las visitas. } \\
\text { Cuando Secretaría de Economía } \\
\text { haya suspendido el Programa } \\
\text { IMMEX a los OEA rubros de } \\
\text { Controladora, Aeronaves, SECIIT } \\
\text { o Textil, se procederá a notificar la } \\
\text { suspensión, la cual subsistirá hasta } \\
\text { en tanto la Secretaría de Economía } \\
\text { deje sin efectos la suspensión del } \\
\text { Programa IMMEX (este programa } \\
\text { es un facilidad que se brinda a estos } \\
\text { sectores siempre que cumplan con } \\
\text { criterios establecidos por la } \\
\text { Secretaría de Economía) } \\
\text { La cancelación durará } 5 \text { años para las } \\
\text { empresas importadoras/exportadoras y } 2 \\
\text { años en los demás casos. }\end{array}$ & $\begin{array}{l}\text { de la autorización como Operador } \\
\text { Económico Autorizado. } \\
\text { - Cuando el resultado de la investigación } \\
\text { de un incidente por parte de las } \\
\text { autoridades competentes, determine la } \\
\text { responsabilidad del Operador } \\
\text { Económico Autorizado. } \\
\text { - Haber obtenido la autorización como } \\
\text { Operador Económico Autorizado, a } \\
\text { través de la utilización de medios } \\
\text { irregulares o fraudulentos debidamente } \\
\text { comprobados por las autoridades } \\
\text { competentes. } \\
\text { - La pérdida de la calidad o calidades que } \\
\text { le fueron concedidas por parte de las } \\
\text { Autoridades de Control. } \\
\text { Por orden de autoridad judicial. } \\
\text { Alcance de la Cancelación } \\
\text { Es la pérdida definitiva de la autorización } \\
\text { como Operador Económico Autorizado. } \\
\text { Una vez se adopta la decisión de cancelación, } \\
\text { la empresa queda inhabilitada para presentar } \\
\text { una nueva solicitud de autorización como } \\
\text { Operador Económico Autorizado durante } 5 \\
\text { años. }\end{array}$ \\
\hline
\end{tabular}




\begin{tabular}{|c|c|c|c|c|}
\hline $\begin{array}{l}\text { PROCEDIMIENTO } \\
\text { DE SUSPENSIÓN } \\
\text { Y CANCELACION }\end{array}$ & $\begin{array}{l}\text { SUSPENSIÓN } \\
\text { 1. El OEA puede solicitar la suspensión } \\
\text { de su certificación, para lo cual debe } \\
\text { indicar los motivos y el plazo de } \\
\text { duración, y adjuntar los documentos } \\
\text { sustentatorios. La suspensión puede } \\
\text { solicitarse por un plazo de hasta seis } \\
\text { meses, prorrogable en casos } \\
\text { debidamente justificados. } \\
\text { 2. La Administración Aduanera puede } \\
\text { declarar procedente la solicitud de } \\
\text { suspensión, sin perjuicio de tomar las } \\
\text { acciones de control que se deriven } \\
\text { del análisis efectuado. La resolución } \\
\text { debe ser emitida dentro del plazo de } \\
\text { quince días hábiles computado desde } \\
\text { la presentación de la solicitud y } \\
\text { señalar el plazo de la suspensión. } \\
\text { 3. Administración Aduanera } \\
\text { saspende de oficio al operador como } \\
\text { OEA, por incurrir en una o más } \\
\text { causales previstas en los incisos } 1 \text { al } \\
4 \text { del artículo } 11 \text { del Reglamento, } \\
\text { para lo cual debe emitir y notificar la } \\
\text { resolución correspondiente. } \\
\text { 4. El operador puede presentar los } \\
\text { descargos correspondientes dentro } \\
\text { del plazo de veinte días hábiles, } \\
\text { tratándose de las causales previstas } \\
\text { en los incisos } 1,2 \text { y } 3 \text { del artículo } 11 \\
\text { del Reglamento y dentro del plazo de } \\
\text { ciento ochenta días hábiles cuando se } \\
\text { trate de la causal señalada en el inciso } \\
4 \text { del citado artículo. Estos plazos se } \\
\text { computan a partir del día siguiente de } \\
\text { la notificación de la resolución de } \\
\text { suspensión. } \\
\text { De aceptarse los descargos, dentro de } \\
\text { los veinte días hábiles siguientes a su } \\
\text { presentación, se emite la resolución }\end{array}$ & $\begin{array}{l}\text { - La autoridad aduanera emitirá un } \\
\text { oficio en el que determina el inicio } \\
\text { del procedimiento de cancelación, } \\
\text { señalando las causas que lo } \\
\text { motivan, una vez que se notifica a } \\
\text { la empresa, se ordena la suspensión } \\
\text { de goce de beneficios y se le otorga } \\
\text { un plazo de } 10 \text { días para subsanar } \\
\text { las razones que motivaron el inicio } \\
\text { de cancelación. } \\
\text { La autoridad cuenta con un plazo } \\
\text { que no excederá de cuatro meses a } \\
\text { partir de la notificación del inicio } \\
\text { del procedimiento, y la empresa } \\
\text { sigue suspendida del goce de } \\
\text { beneficios hasta que se notifique la } \\
\text { resolución que determina la } \\
\text { reactivación de beneficios o la } \\
\text { cancelación. } \\
\text { Transcurridos cuatro meses sin que } \\
\text { se notifique una resolución se } \\
\text { considerará cancelada la } \\
\text { autorización, para lo cual la } \\
\text { empresa podrá interponer los } \\
\text { medios de defensa en cualquier } \\
\text { tiempo ante las instancias jurídicas } \\
\text { competentes.* } \\
\text { *Las instancias jurídicas a las cuales } \\
\text { puede acudir la empresa son: } \\
\text { Ante el SAT (Administración } \\
\text { General Jurídica), es opcional y } \\
\text { mediante un recurso de revocación } \\
\text { de la resolución. } \\
\text { Ante el Tribunal Federal de Justicia } \\
\text { Penal y Administrativa, a través de } \\
\text { un juicio de nulidad, toda vez que } \\
\text { se considera ilegal o transgrede los } \\
\text { derechos del contribuyente. }\end{array}$ & $\begin{array}{l}\text { El procedimiento de interrupción y } \\
\text { cancelación se encuentra previsto en el } \\
\text { artículo } 14 \text { del Decreto } 3568 \text { de } 2011 \text { y } \\
\text { consiste en: } \\
\text { 1. Acto que ordena la interrupción } \\
\text { provisional. Dentro de los cinco (5) días } \\
\text { siguientes a que se tenga conocimiento de la } \\
\text { ocurrencia de los hechos que son causal de } \\
\text { interrupción, el funcionario competente de } \\
\text { las autoridades de control comunicará el } \\
\text { hecho al Comité Técnico del Operador } \\
\text { Económico Autorizado de que trata el } \\
\text { artículo 19 del presente decreto, quien deberá } \\
\text { decidir sobre la adopción o no de la medida, } \\
\text { dentro del término máximo de cinco (5) días } \\
\text { siguientes al recibo de la comunicación. } \\
\text { Adoptada la decisión respecto de la medida } \\
\text { cautelar dentro de los cinco (5) días } \\
\text { siguientes, el funcionario competente de la } \\
\text { Dirección de Impuestos y Aduanas } \\
\text { Nacionales deberá proferir el acto en el que } \\
\text { se ordene la interrupción provisional de la } \\
\text { autorización de Operador Económico } \\
\text { Autorizado, indicando los hechos que } \\
\text { originan la adopción de la medida, el } \\
\text { fundamento jurídico, las pruebas que la } \\
\text { soportan, y el término máximo definido por } \\
\text { las autoridades de control para que el } \\
\text { Operador Económico Autorizado subsane las } \\
\text { situaciones que generaron la interrupción } \\
\text { provisional o demuestre el cumplimiento de } \\
\text { las acciones requeridas cuando a ello hubiere } \\
\text { lugar, con excepción de las situaciones } \\
\text { calificadas como incidentes o suspensión } \\
\text { provisional decretada por la autoridad } \\
\text { aduanera, las cuales no son subsanables. } \\
\text { El acto de interrupción provisional es una } \\
\text { medida cautelar no susceptible de recurso } \\
\text { alguno. }\end{array}$ & 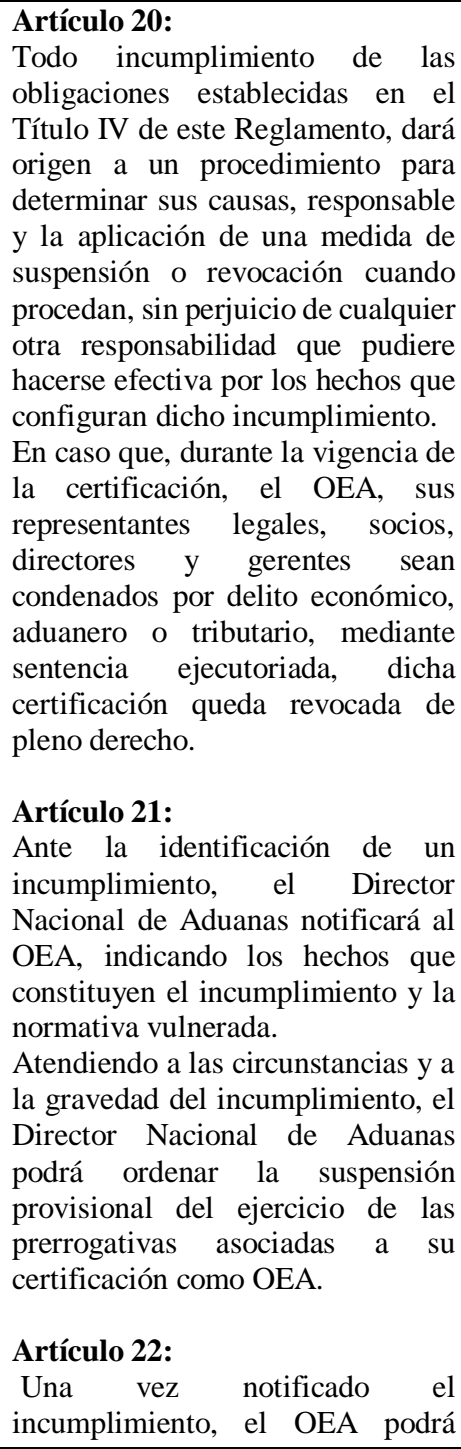 \\
\hline
\end{tabular}




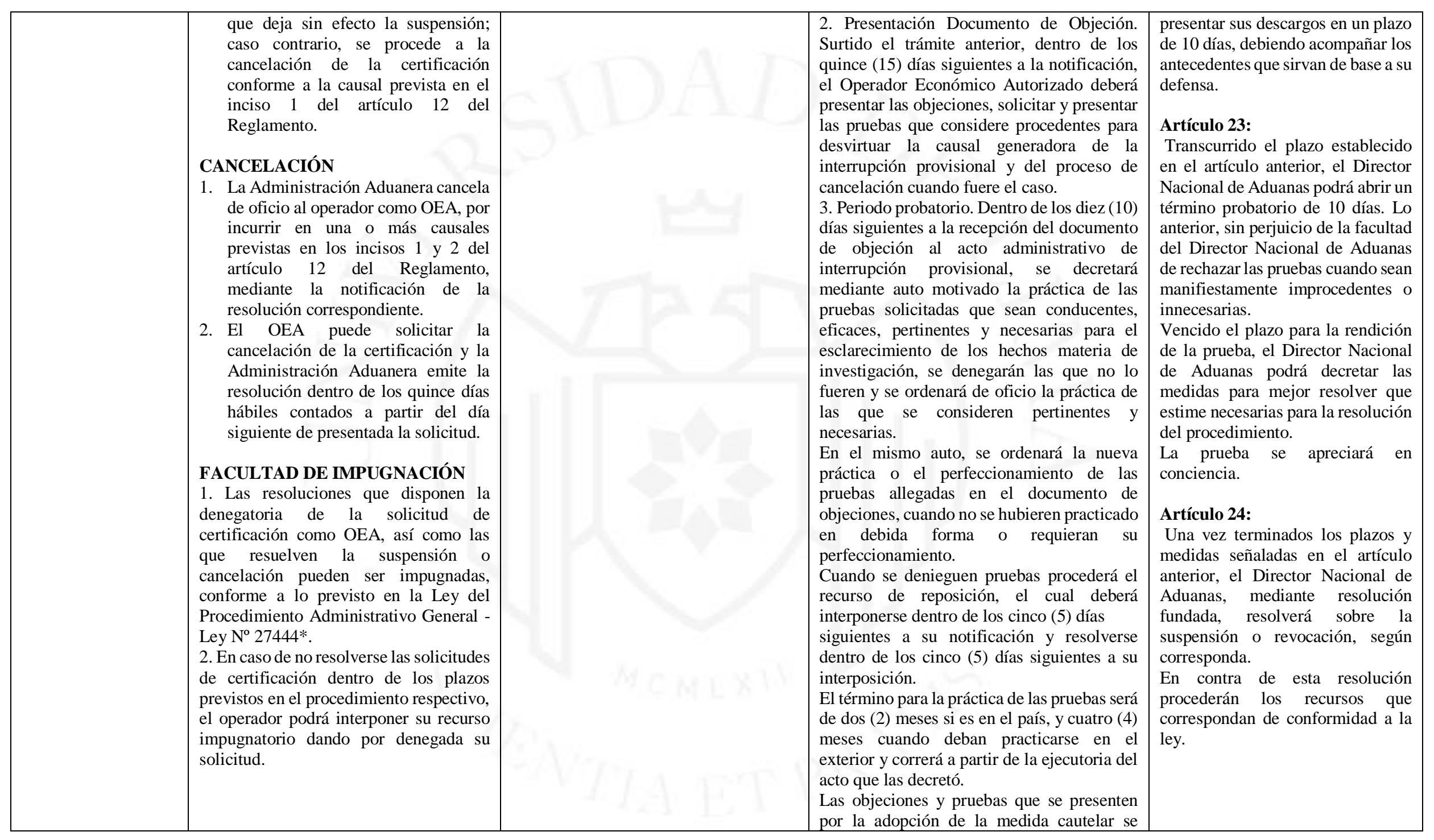




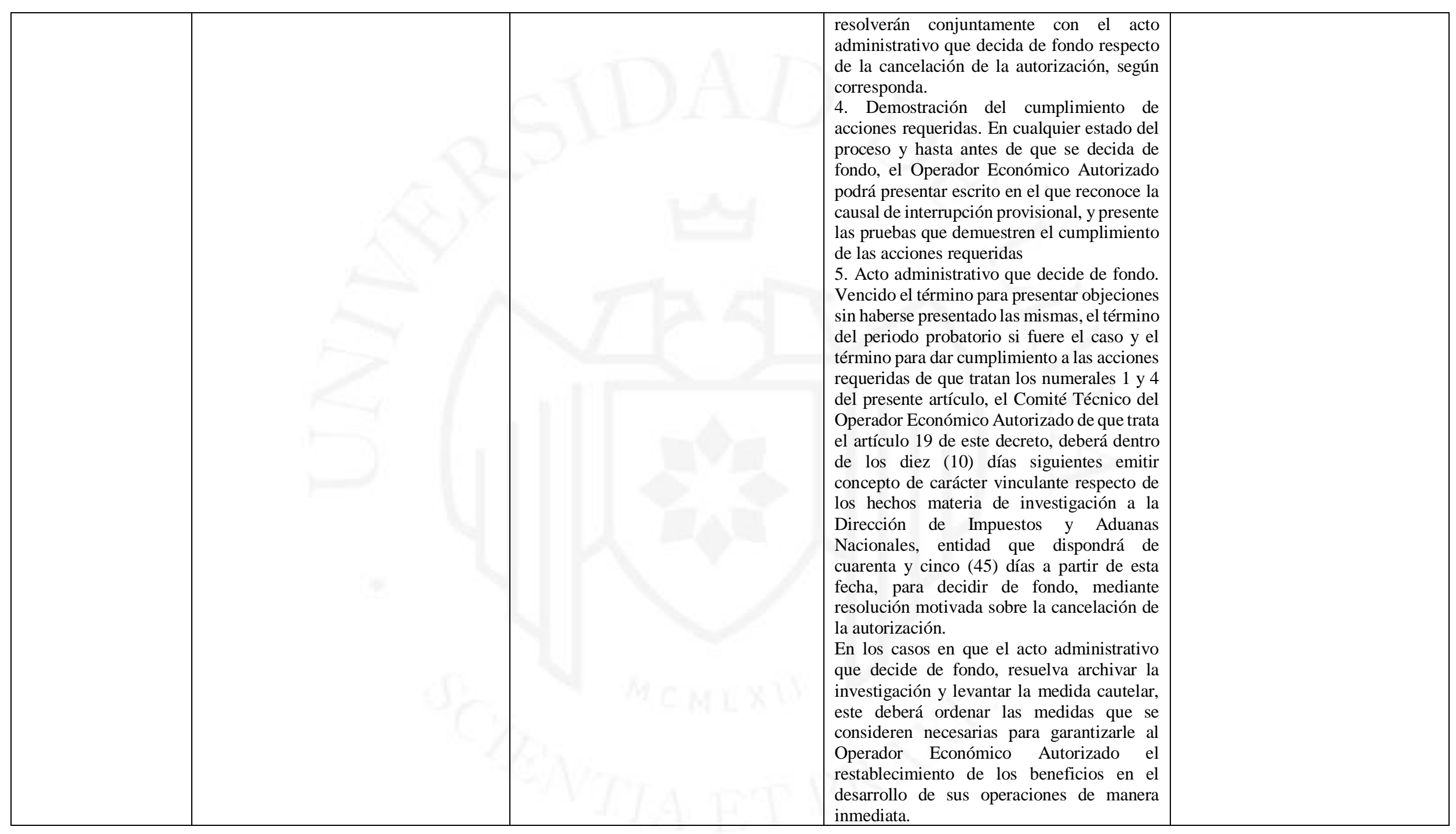




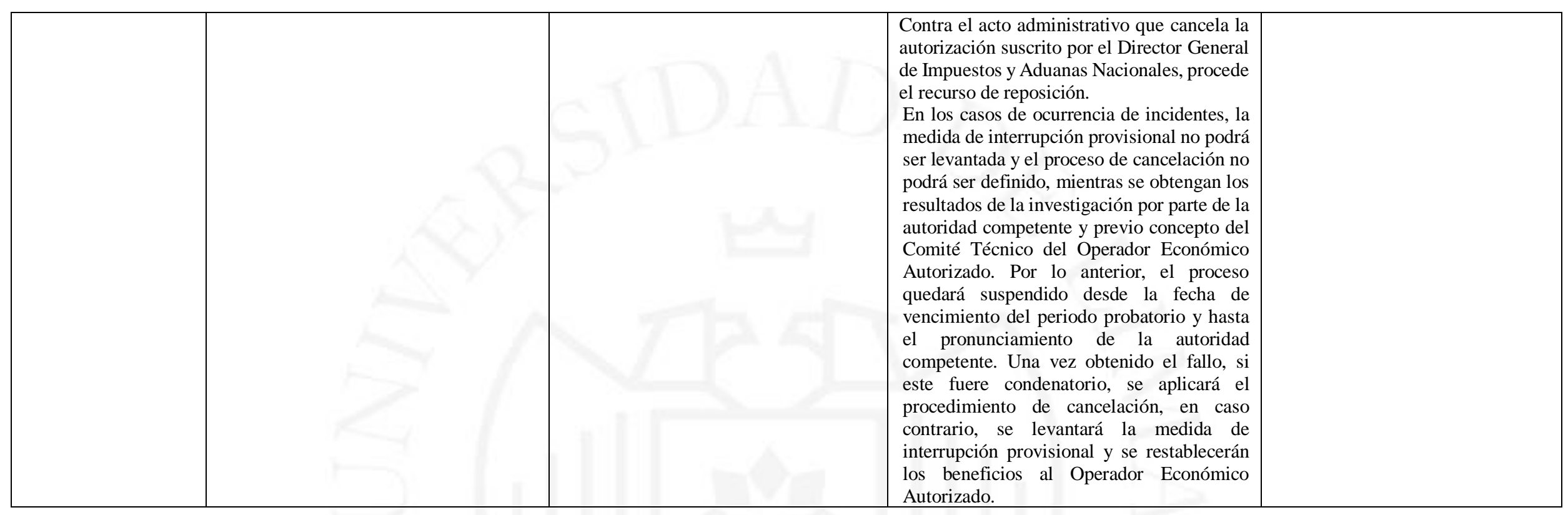


ANEXO 2: Cuadro comparativo de los beneficios otorgados en los programas OEA de los países miembros de la Alianza del Pacifico

\begin{tabular}{|c|c|c|c|c|}
\hline $\begin{array}{c}\text { TIPO DE } \\
\text { BENEFICIO }\end{array}$ & PERÚ & MEXICO & COLOMBIA & CHILE \\
\hline \multirow[t]{5}{*}{$\begin{array}{l}\text { SIMPLIFICACIÓN } \\
\text { DE TRÁMITES } \\
\text { ADUANEROS }\end{array}$} & $\begin{array}{l}\text { Asignación un sectorista } \\
\text { de la DOEA, para la } \\
\text { orientación y asistencia } \\
\text { especializada } \\
\text { procedimientos } \\
\text { vinculados al Programa } \\
\text { OEA y en la coordinación } \\
\text { con las aduanas a nivel } \\
\text { nacional. }\end{array}$ & $\begin{array}{l}\text { Atención por parte de } \\
\text { Especialista en } \\
\text { Seguridad de la } \\
\text { Cadena de Suministro } \\
\text { designado. }\end{array}$ & $\begin{array}{l}\text { - Asignación de un oficial } \\
\text { de operaciones por parte } \\
\text { de cada una de las } \\
\text { autoridades de control } \\
\text { que brindará soporte en } \\
\text { sus operaciones. }\end{array}$ & $\begin{array}{l}\text { - Asignación de un punto de } \\
\text { contacto, para asistir, } \\
\text { atender y coordinar } \\
\text { asuntos aduaneros al } \\
\text { interior del Servicio. }\end{array}$ \\
\hline & $\begin{array}{l}\text { Actuación directa de } \\
\text { exportadores e } \\
\text { importadores como } \\
\text { despachadores de aduana } \\
\text { de sus mercancías ante la } \\
\text { SUNAT, conforme a las } \\
\text { condiciones y requisitos } \\
\text { previstos en el } \\
\text { reglamento de la Ley } \\
\text { General de Aduanas, } \\
\text { siendo que en el caso de } \\
\text { los regímenes de ingreso, } \\
\text { se encuentra exonerado } \\
\text { de presentar garantía para } \\
\text { operar. }\end{array}$ & & $\begin{array}{l}\text { - Actuación directa de } \\
\text { exportadores e } \\
\text { importadores como } \\
\text { declarantes ante la } \\
\text { DIAN en los regímenes } \\
\text { de importación, } \\
\text { exportación y tránsito. }\end{array}$ & \\
\hline & & $\begin{array}{l}\text { Para OEA, } \\
\text { importación de } \\
\text { mercancías utilizando } \\
\text { carriles exclusivos } \\
\text { "Exprés". }\end{array}$ & $\begin{array}{l}\text { - Utilización de canales y } \\
\text { mecanismos especiales } \\
\text { para la realización de las } \\
\text { operaciones de } \\
\text { comercio exterior que } \\
\text { se surtan ante las } \\
\text { Autoridades de Control, } \\
\text { de conformidad con lo } \\
\text { dispuesto en resolución } \\
\text { de carácter general } \\
\text { expedida por las } \\
\text { autoridades } \\
\text { mencionadas. }\end{array}$ & \\
\hline & & & $\begin{array}{l}\text { - Reconocimiento de } \\
\text { mercancías en los } \\
\text { términos señalados en la } \\
\text { legislación aduanera, } \\
\text { para exportadores e } \\
\text { importadores cuando } \\
\text { actúen como } \\
\text { declarantes, y así lo } \\
\text { requieran. }\end{array}$ & \\
\hline & $\begin{array}{l}\text { - Garantía nominal para el } \\
\text { requerimiento previsto } \\
\text { en el artículo } 160^{\circ} \text { de la } \\
\text { Ley, para el despacho de } \\
\text { las mercancías que } \\
\text { solicite bajo el régimen } \\
\text { de importación para el } \\
\text { consumo bajo la } \\
\text { modalidad de despacho } \\
\text { urgente o anticipado, } \\
\text { siempre que no haya }\end{array}$ & & $\begin{array}{l}\text { - Reducción del monto de } \\
\text { las garantías globales } \\
\text { constituidas ante la } \\
\text { Dirección de Impuestos } \\
\text { y Aduanas Nacionales, } \\
\text { en los términos y } \\
\text { condiciones que } \\
\text { establezca la Dirección } \\
\text { de Impuestos y Aduanas } \\
\text { Nacionales. }\end{array}$ & $\begin{array}{l}\text { - las personas acogidas al } \\
\text { beneficio establecido en el } \\
\text { inciso tercero del artículo } \\
64 \text { del decreto ley } \mathrm{N}^{\circ} 825 \text {, } \\
\text { de } 1974, \text { y los importadores } \\
\text { que obtengan la } \\
\text { certificación establecida en } \\
\text { el artículo } 23 \text { bis de esta } \\
\text { Ordenanza (OEA), que } \\
\text { importen mercancías que } \\
\text { no se hayan acogido }\end{array}$ \\
\hline
\end{tabular}




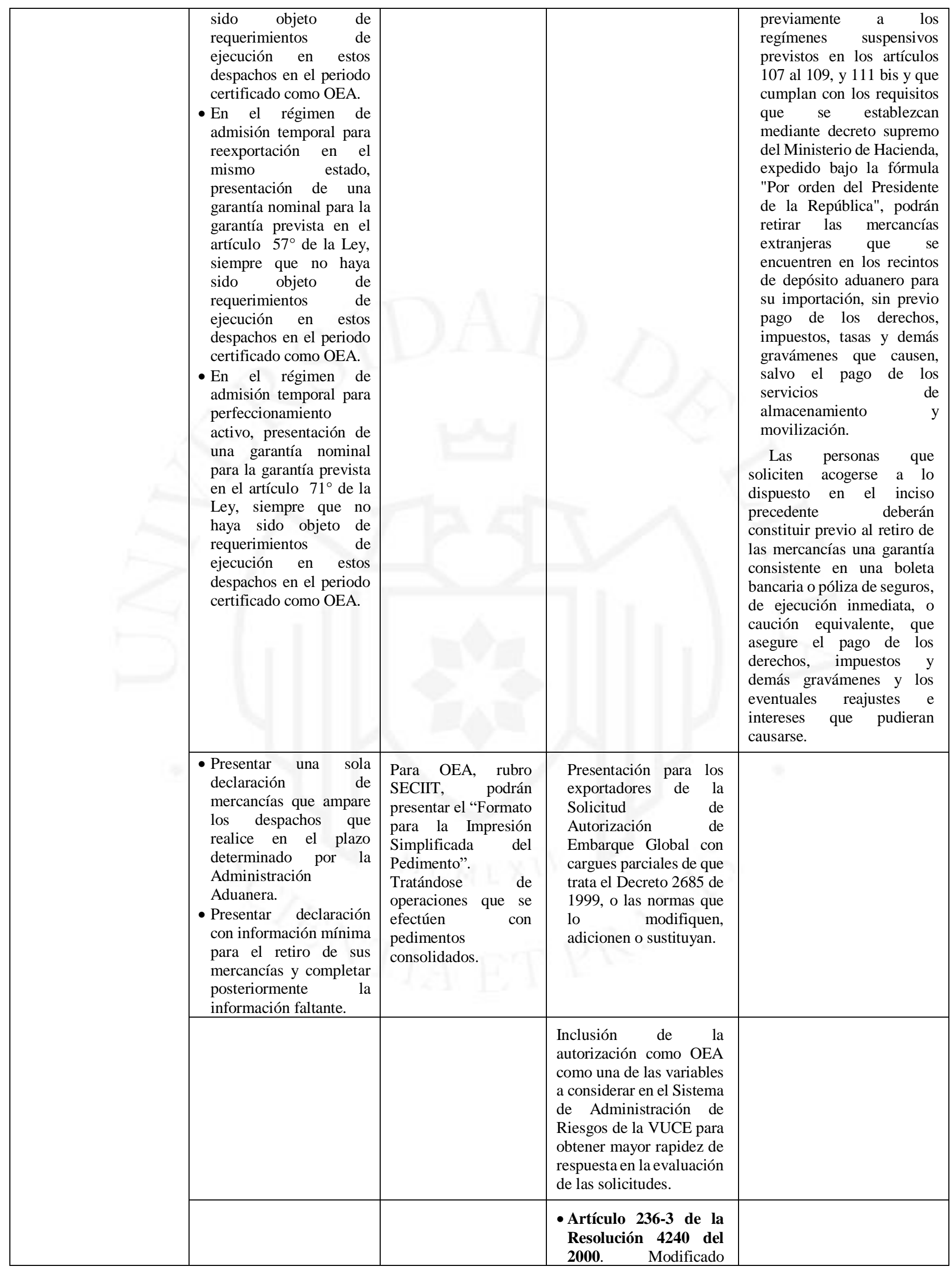




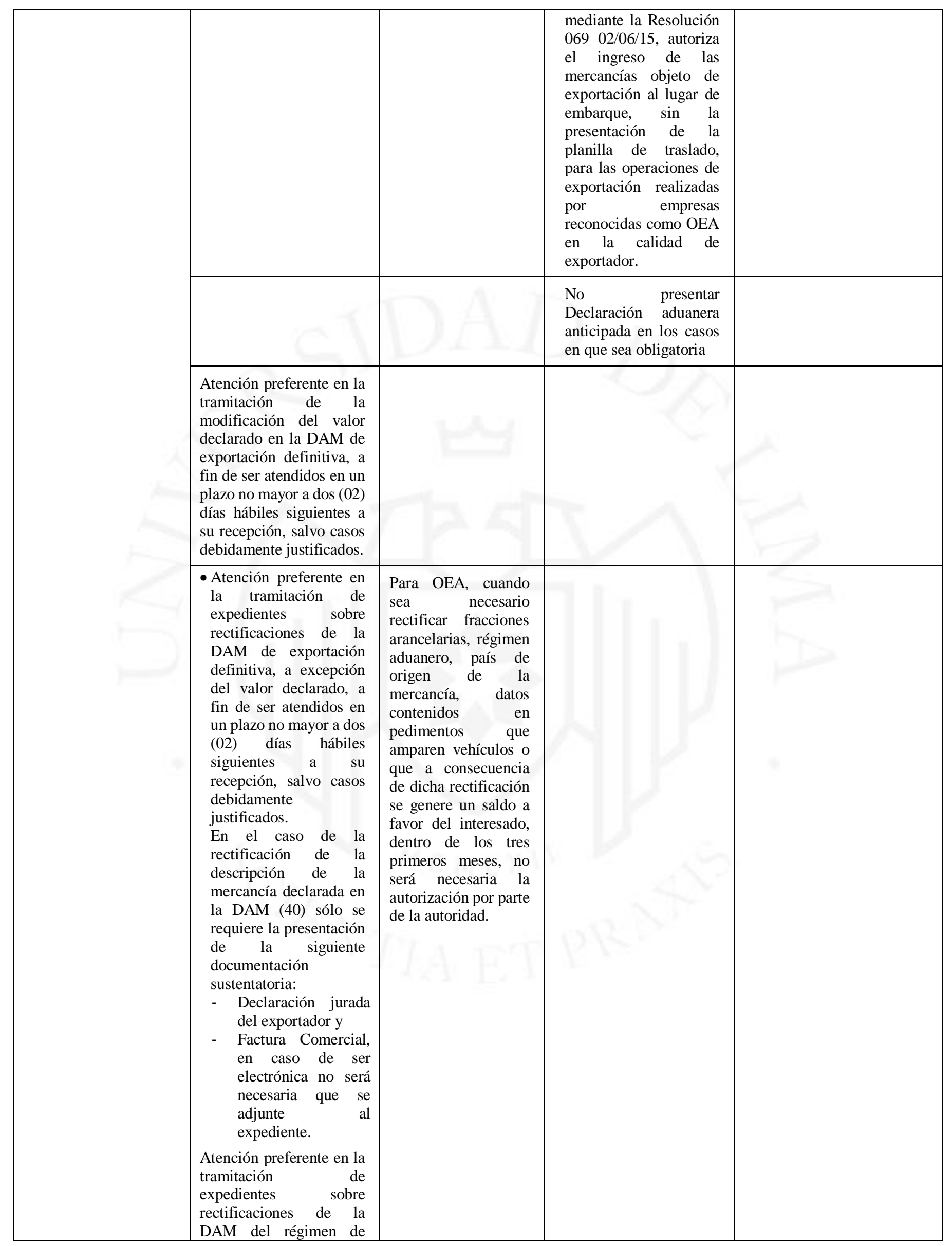




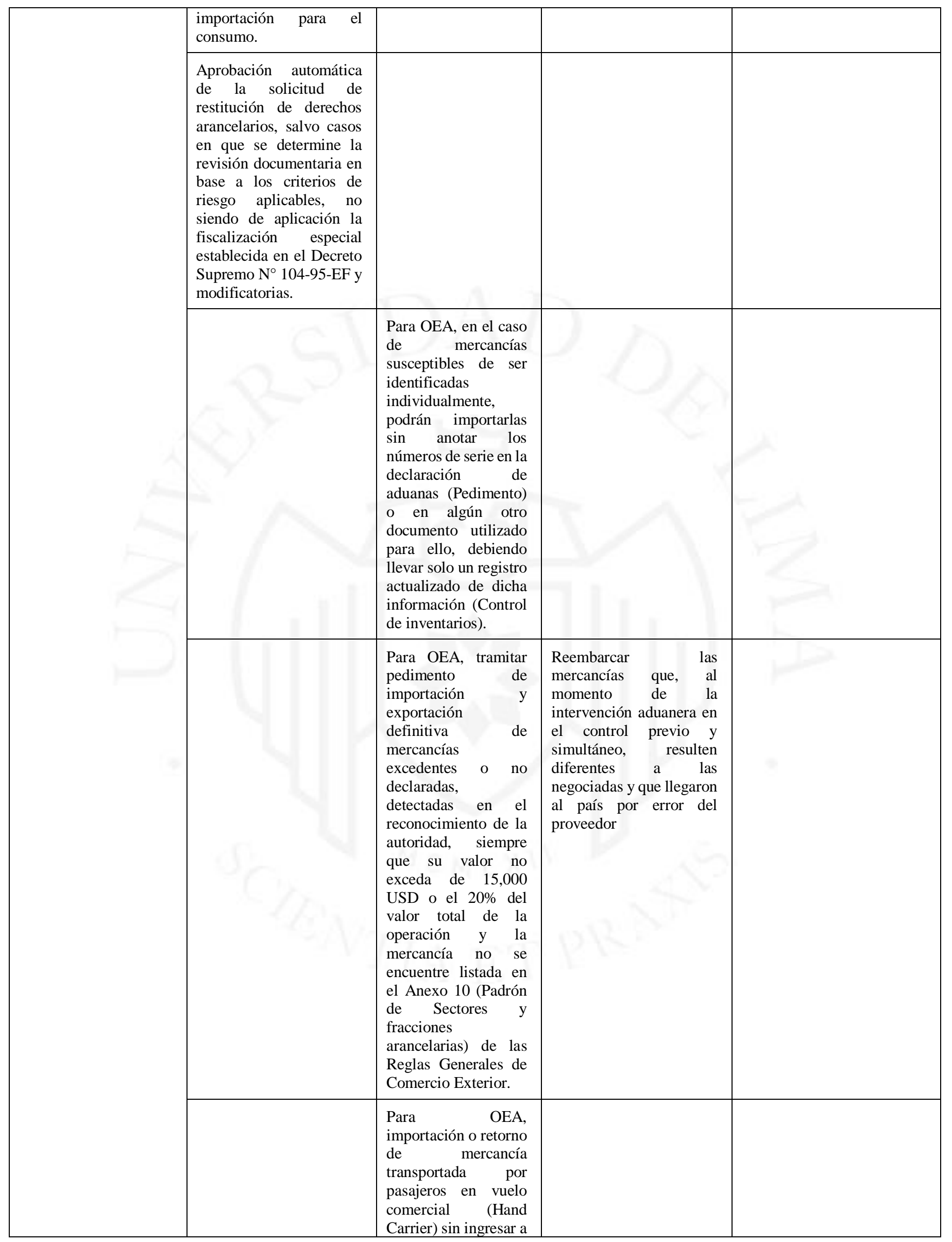




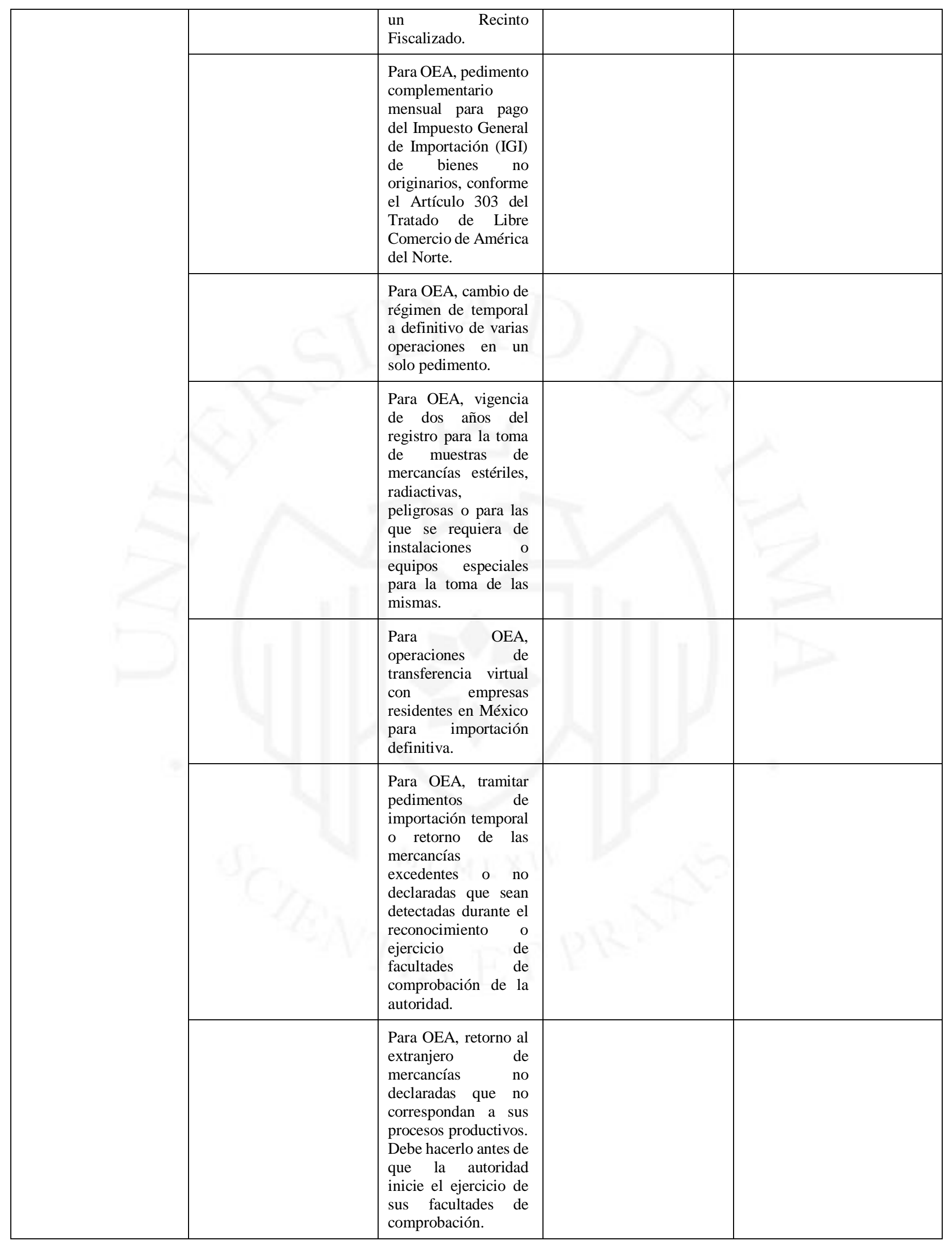




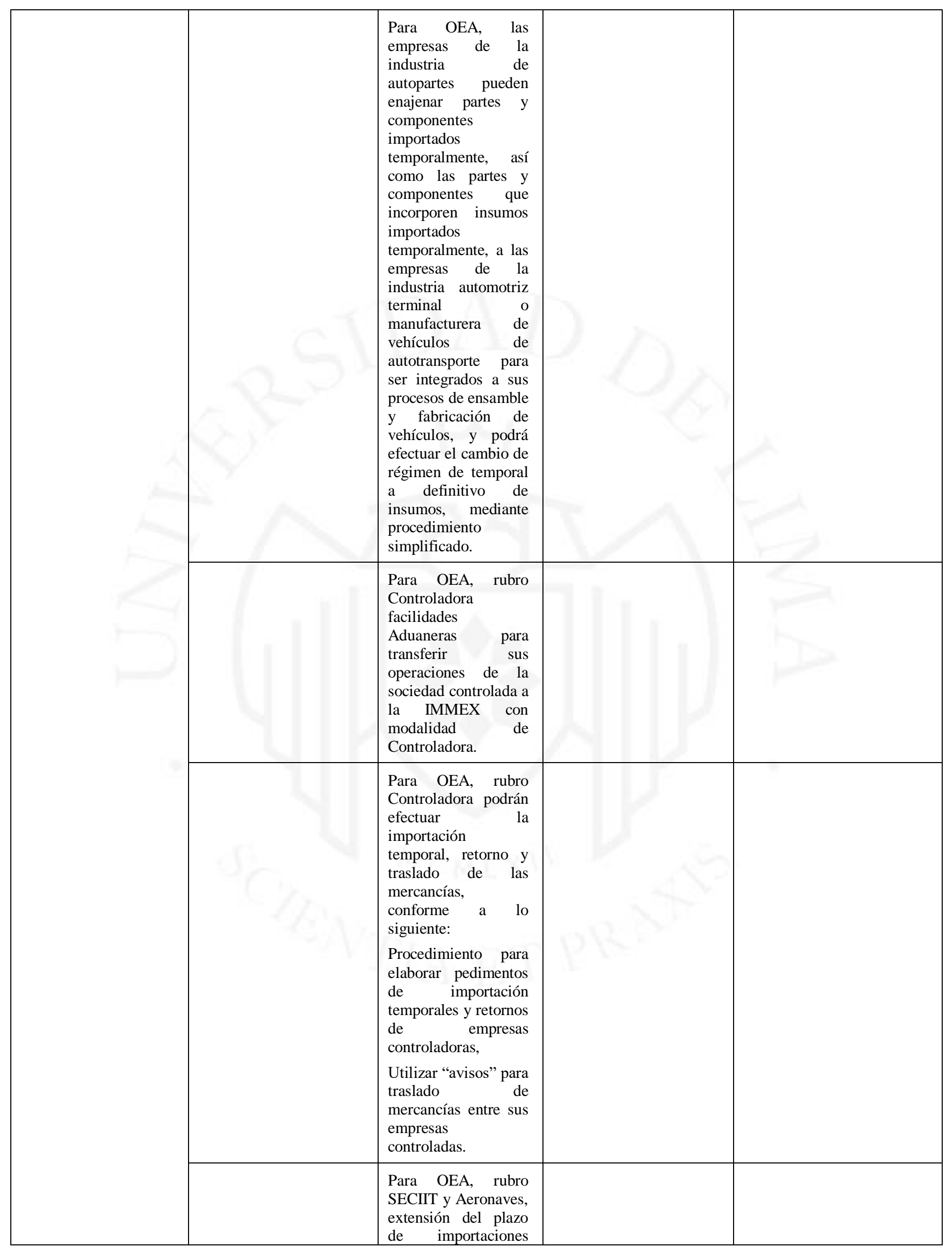




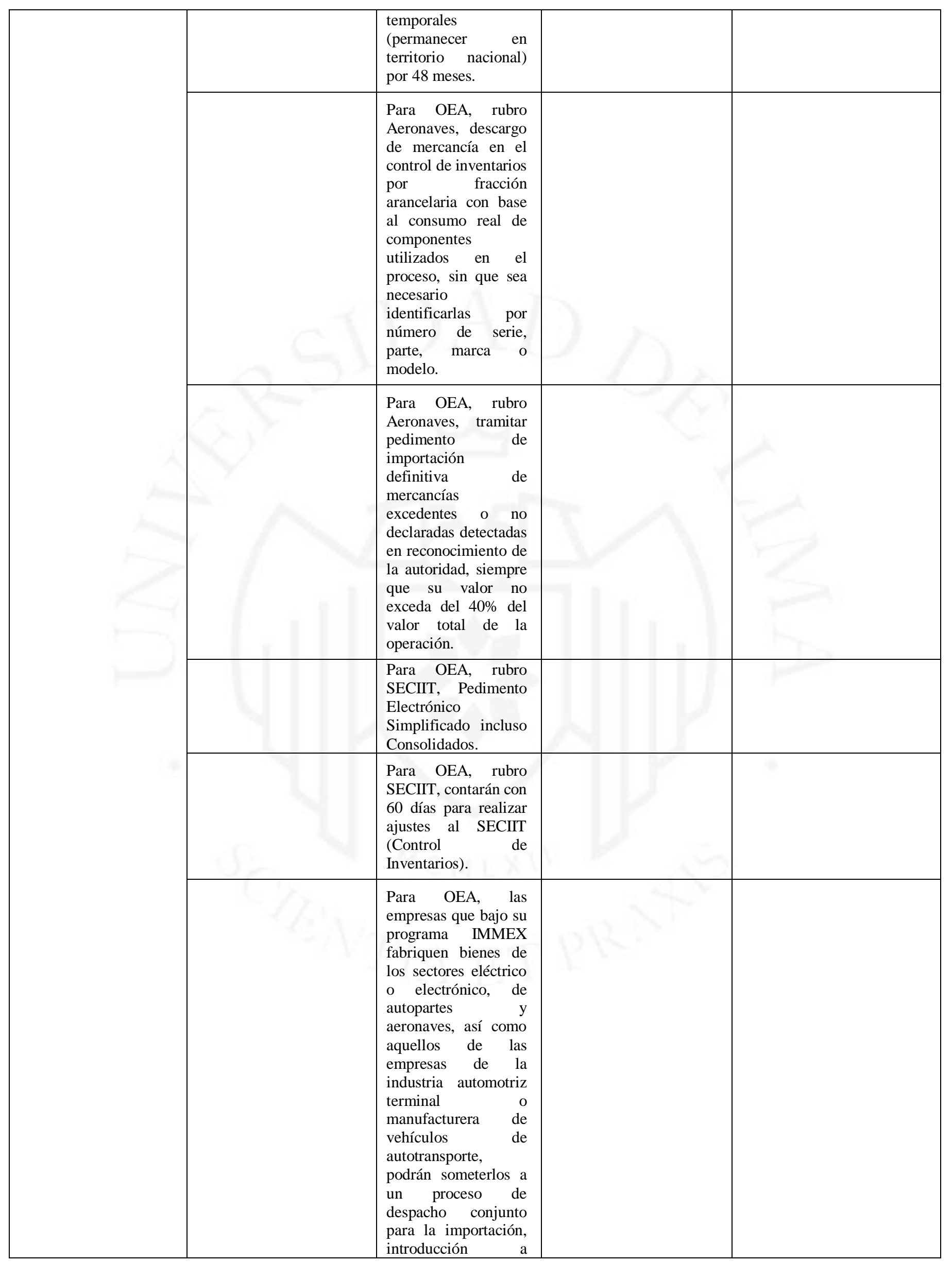




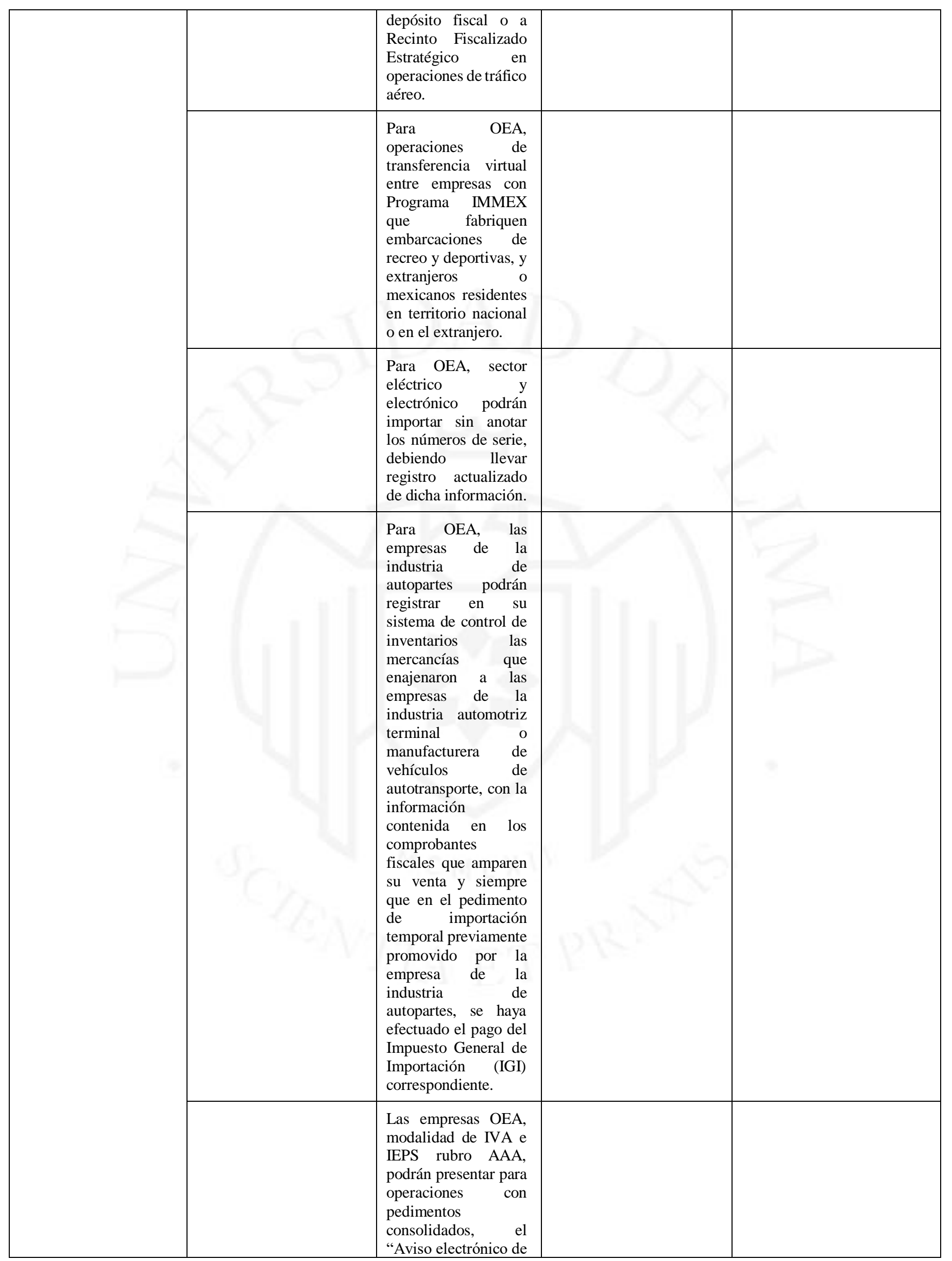




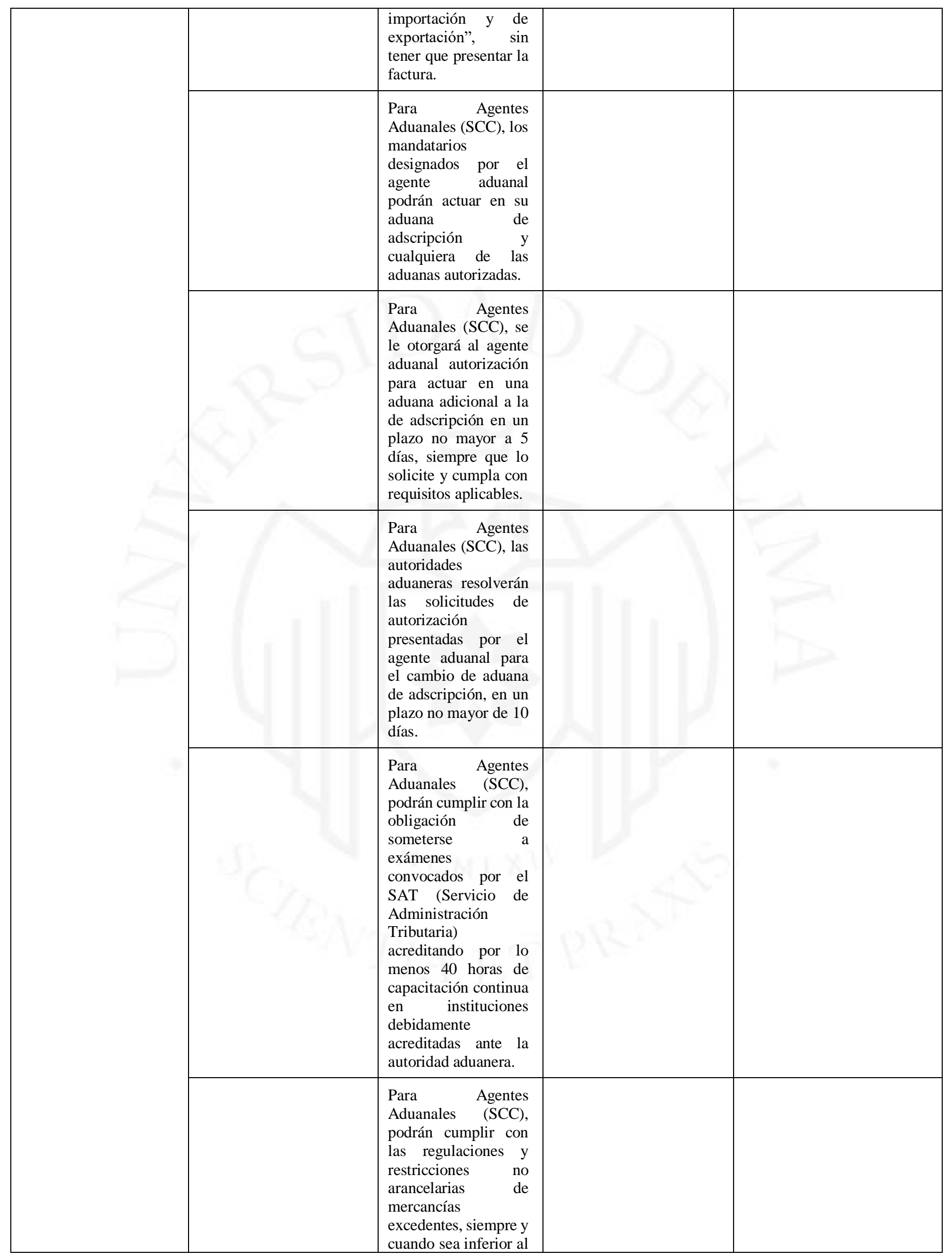




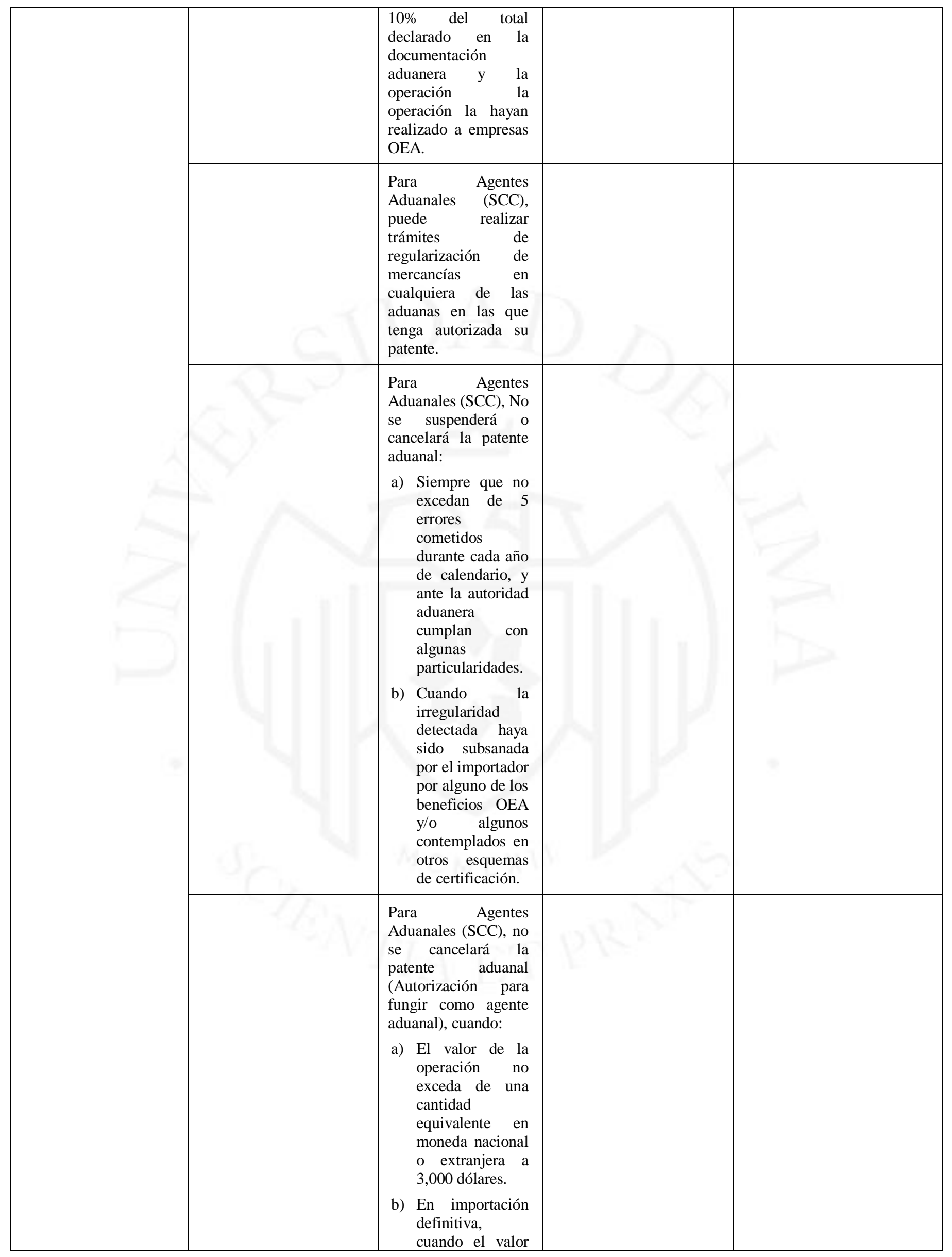




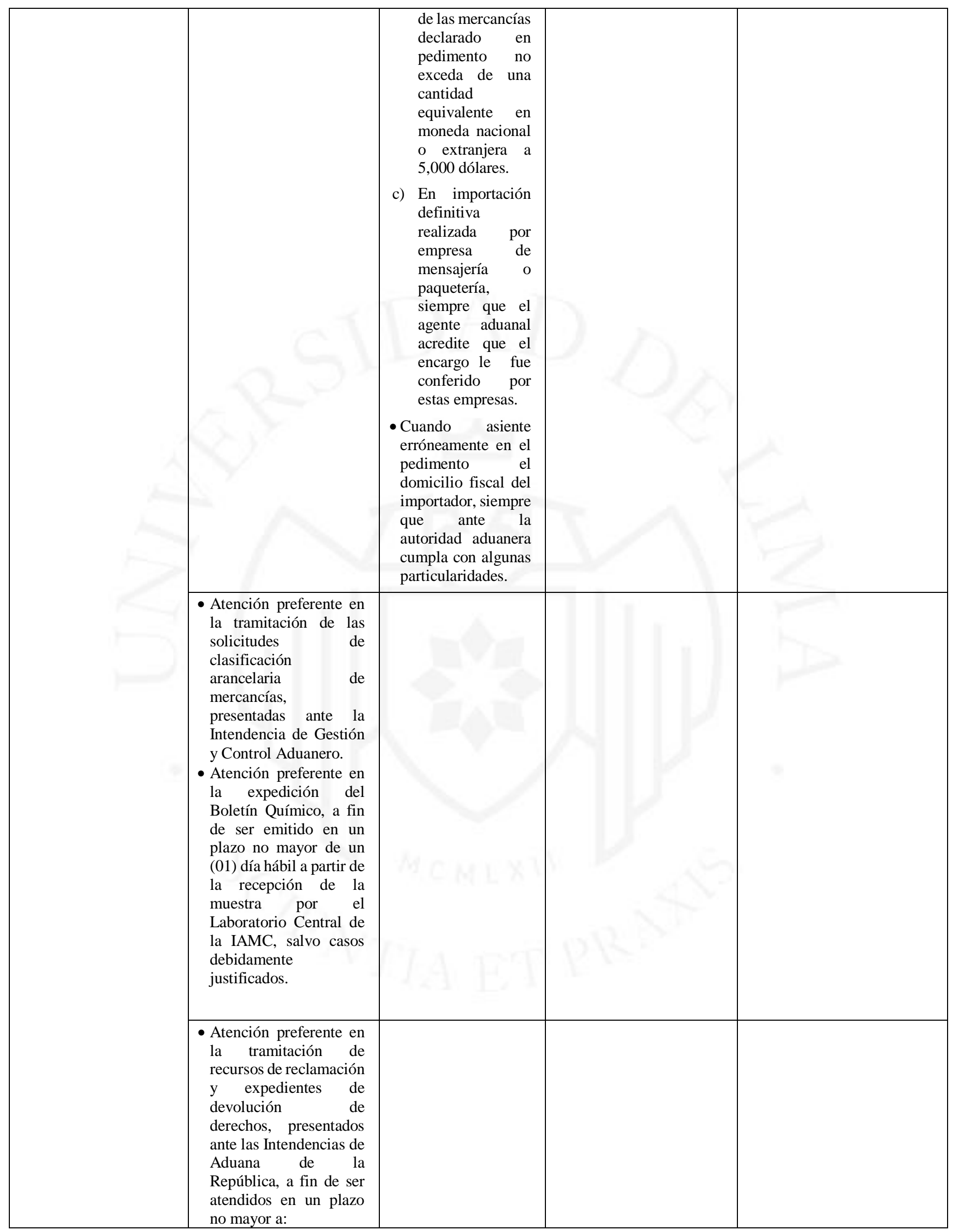




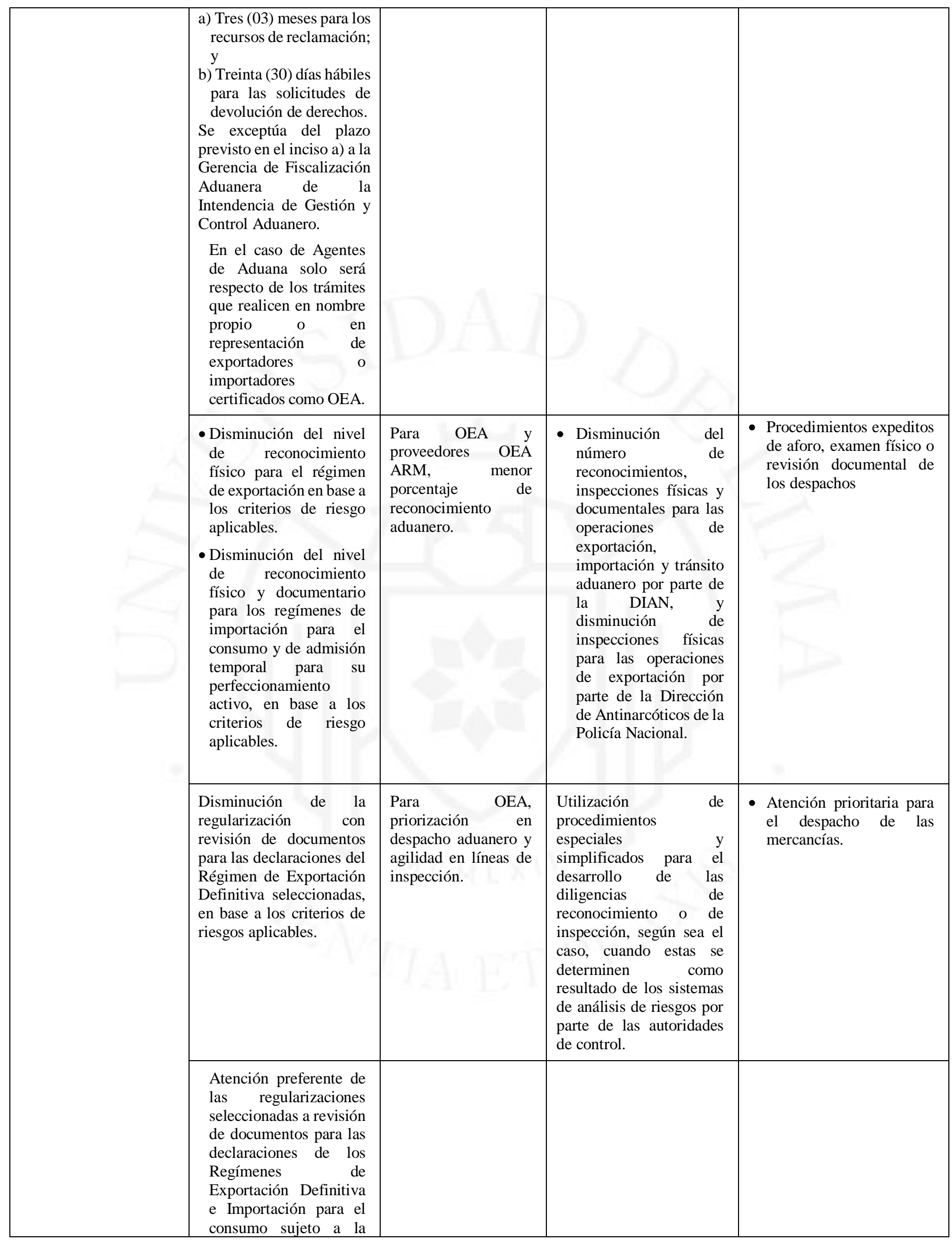




\begin{tabular}{|c|c|c|c|c|}
\hline & $\begin{array}{l}\text { modalidad de despacho } \\
\text { urgente. }\end{array}$ & & & \\
\hline & $\begin{array}{l}\text { Embarque directo desde } \\
\text { el local del exportador de } \\
\text { mercancías acondiciona- } \\
\text { das en contenedores. }\end{array}$ & $\begin{array}{lr}\text { Para } & \text { OEA, } \\
\text { facilidades } & \text { para } \\
\text { tramitar el despacho } \\
\text { de mercancías } \\
\text { medianter } & \text { el } \\
\text { procedimiento de } & \text { devisión en origen a } \\
\text { reven } & \text { los sectores eléctrico, } \\
\text { electrónico, } & \text { de } \\
\text { autopartes r o } & \text { automotriz, siempre } \\
\text { aue se auto regulen. }\end{array}$ & $\begin{array}{l}\text { Autorización para llevar a } \\
\text { cabo la inspección de } \\
\text { mercancías objeto de } \\
\text { exportación ordenada por } \\
\text { la Unidad Administrativa } \\
\text { Especial DIAN, en las } \\
\text { instalaciones y del } \\
\text { exportador y depósito } \\
\text { habilitado, cuando a ello } \\
\text { hubiere lugar. }\end{array}$ & $\begin{array}{l}\text { - Inspección preferente de } \\
\text { las mercancías en sus } \\
\text { instalaciones. }\end{array}$ \\
\hline & & & $\begin{array}{l}\text { Inspección no intrusiva } \\
\text { por parte de la Policía } \\
\text { Nacional de Colombia, } \\
\text { para las operaciones de } \\
\text { exportación, siempre que } \\
\text { el puerto, aeropuerto o } \\
\text { paso de frontera cuente } \\
\text { con las herramientas } \\
\text { tecnológicas para realizar } \\
\text { este control. Sin perjuicio } \\
\text { de la facultad de realizar } \\
\text { inspección física cuando } \\
\text { las circunstancias lo } \\
\text { ameriten. }\end{array}$ & \begin{tabular}{llr}
\multicolumn{3}{c}{ Uso prioritario de tecnología } \\
no invasiva para la \\
fiscalización de & las \\
mercancías. & &
\end{tabular} \\
\hline & & & $\begin{array}{l}\text { Para la categoría OEA } \\
\text { seguridad } \\
\text { facilitación sanitaria } \\
\text { además de los } \\
\text { beneficios anteriores } \\
\text { se tendrán los } \\
\text { siguientes: } \\
\text { a) Autorización para } \\
\text { llevar a cabo la } \\
\text { inspección de de } \\
\text { mercancías objeto de } \\
\text { exportación ordenada } \\
\text { por el ICA y/o el } \\
\text { INVIMA, en las } \\
\text { instalaciones del } \\
\text { exportador y depósito } \\
\text { habilitado, cuando a } \\
\text { ello hubiere lugar. } \\
\text { Disminución del número } \\
\text { de inspecciones físicas } \\
\text { para las operaciones de } \\
\text { exportación por parte del } \\
\text { ICA y/o del INVIMA. }\end{array}$ & \\
\hline $\begin{array}{l}\text { SIMPLIFICACIÓN } \\
\text { Y REDUCCIÓN DE } \\
\text { CONTROLES } \\
\text { ADUANEROS }\end{array}$ & $\begin{array}{l}\text { Atención preferente en } \\
\text { los despachos } \\
\text { sometidos a } \\
\text { reconocimiento físico } \\
\text { en el régimen de } \\
\text { exportación definitiva. }\end{array}$ & & & $\begin{array}{l}\text { - Los beneficios relativos a } \\
\text { control y simplificación } \\
\text { de procesos aduaneros } \\
\text { propios del Servicio. }\end{array}$ \\
\hline & $\begin{array}{l}\text { Atención preferente } \\
\text { en los despachos } \\
\text { sometidos a } \\
\text { reconocimiento a } \\
\text { físico en el Régimen }\end{array}$ & & & \\
\hline
\end{tabular}




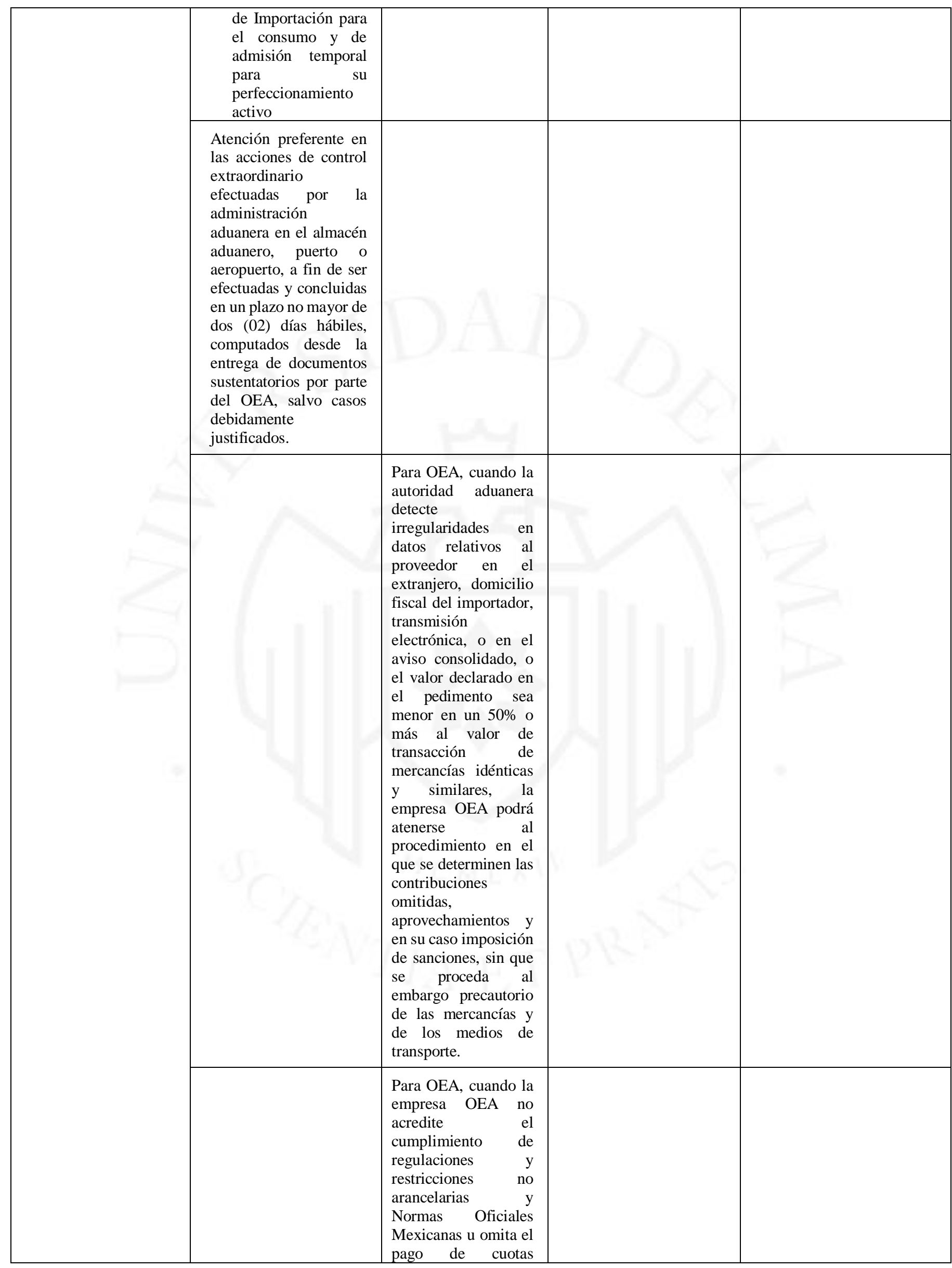




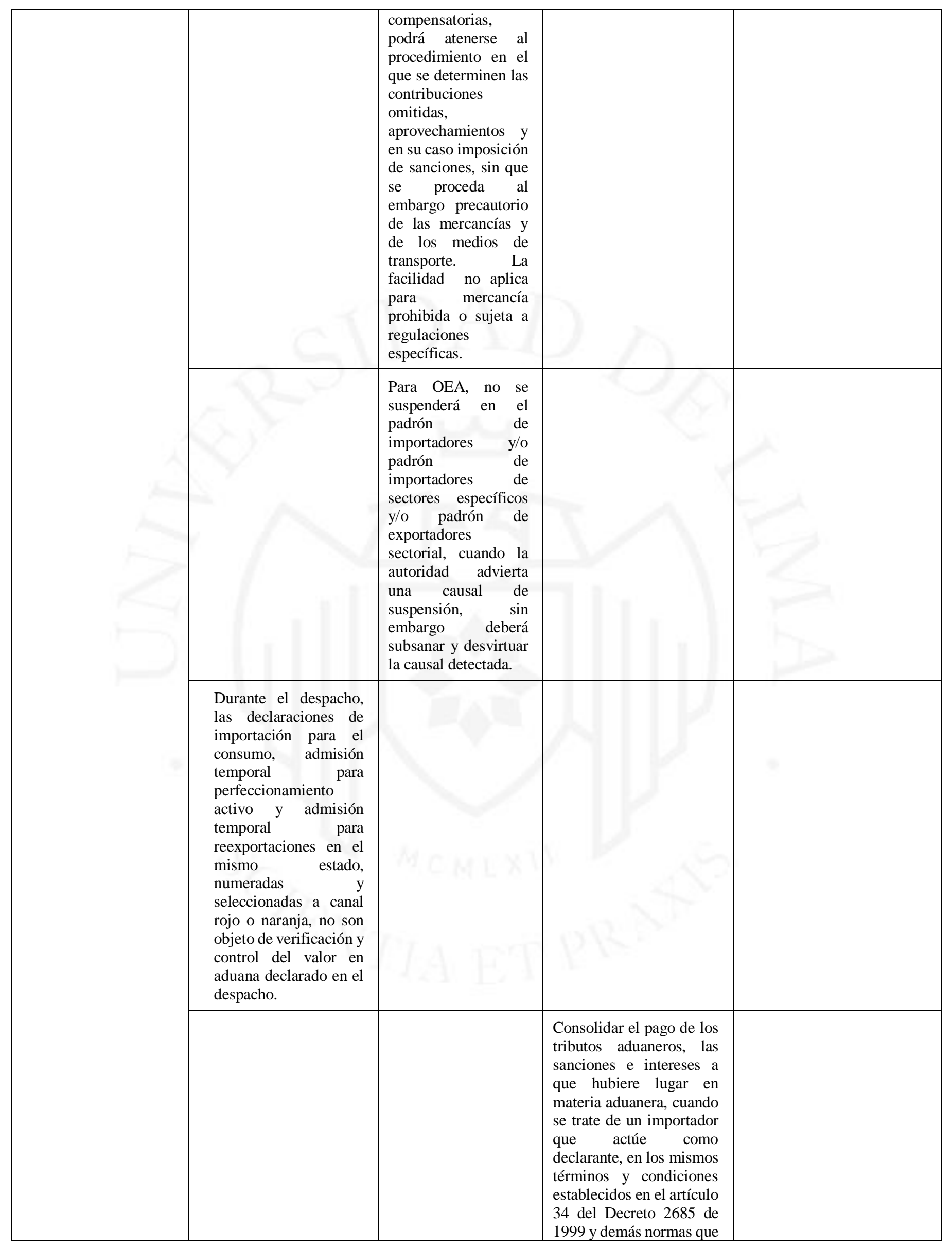




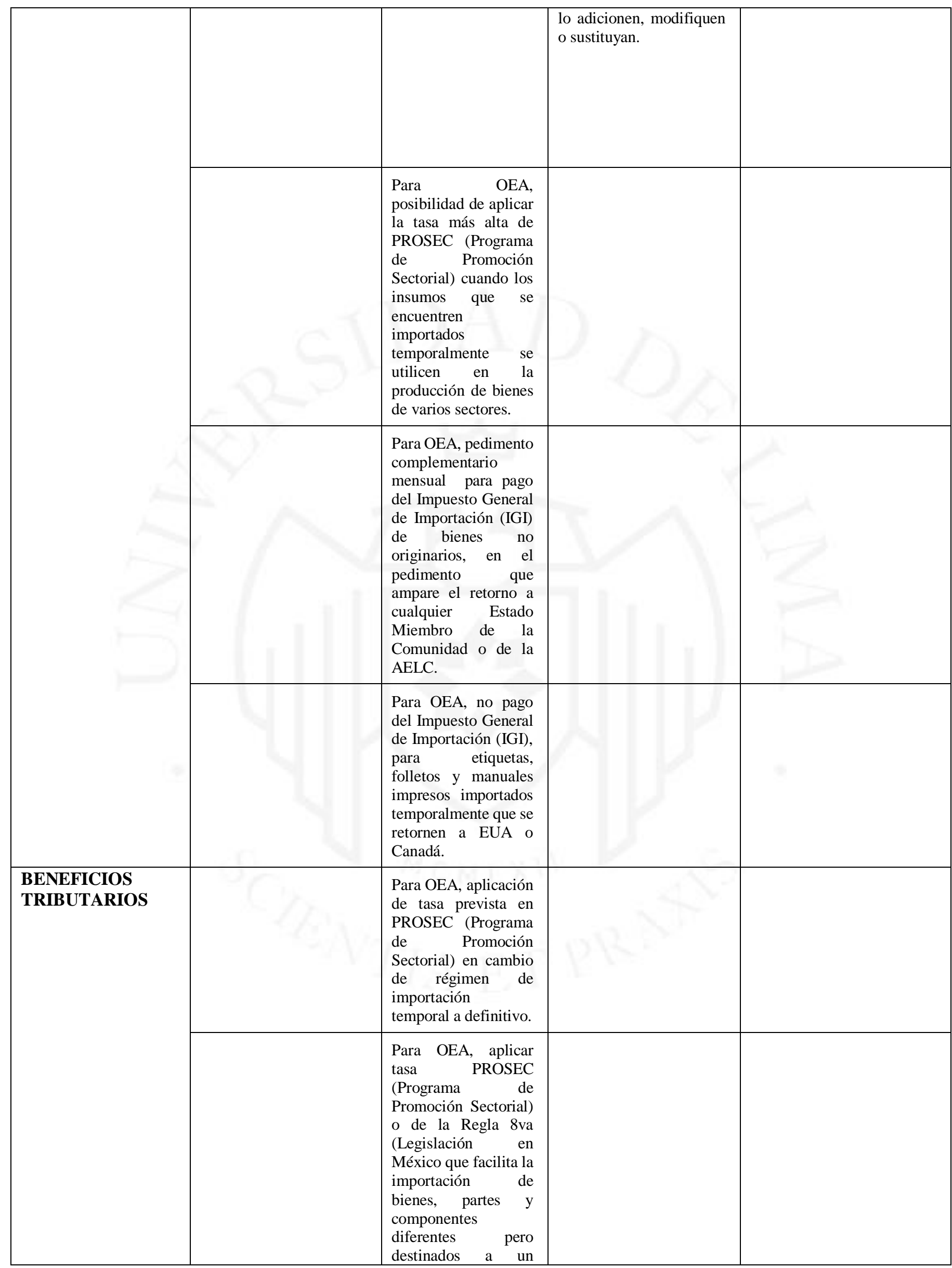




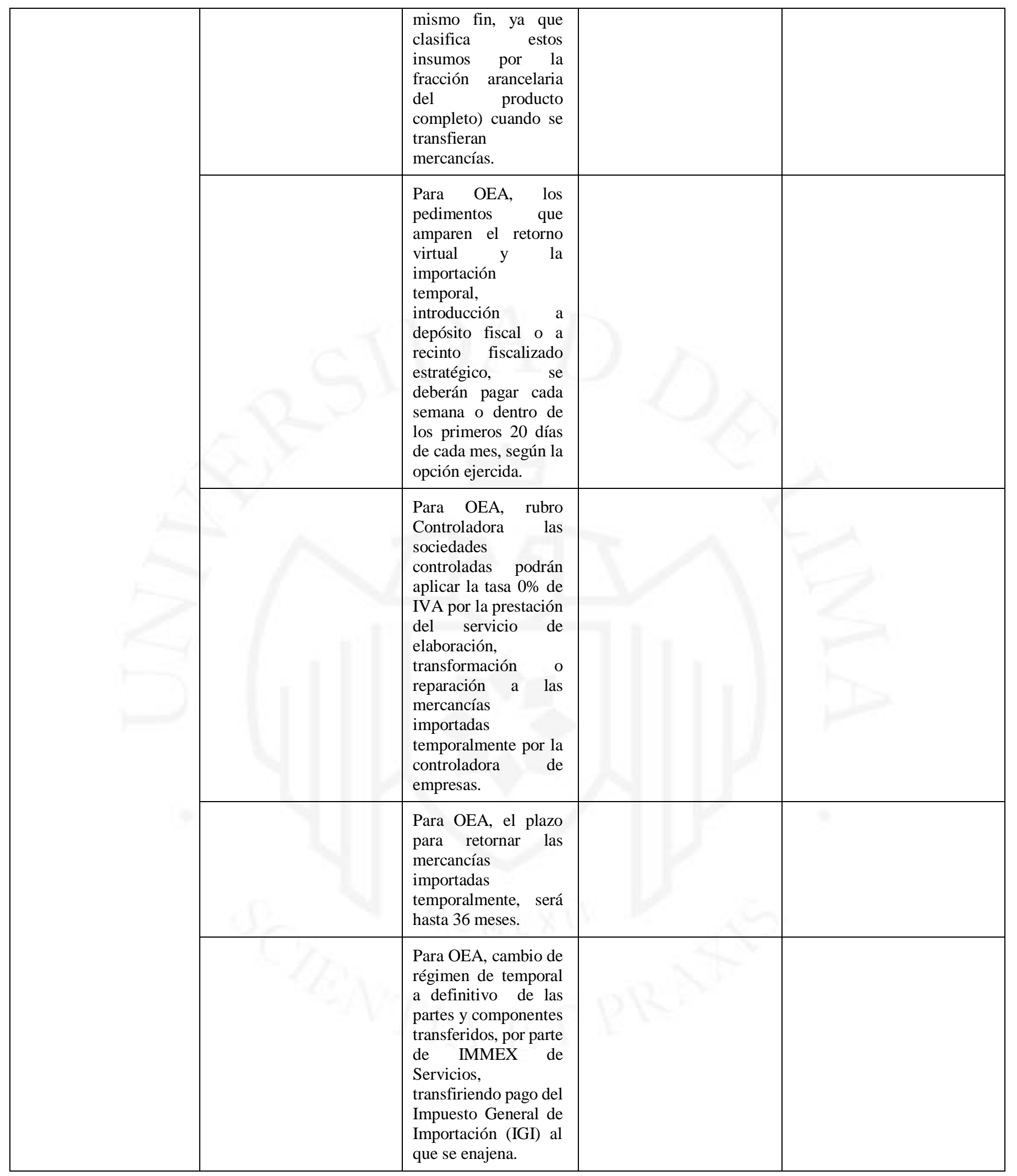




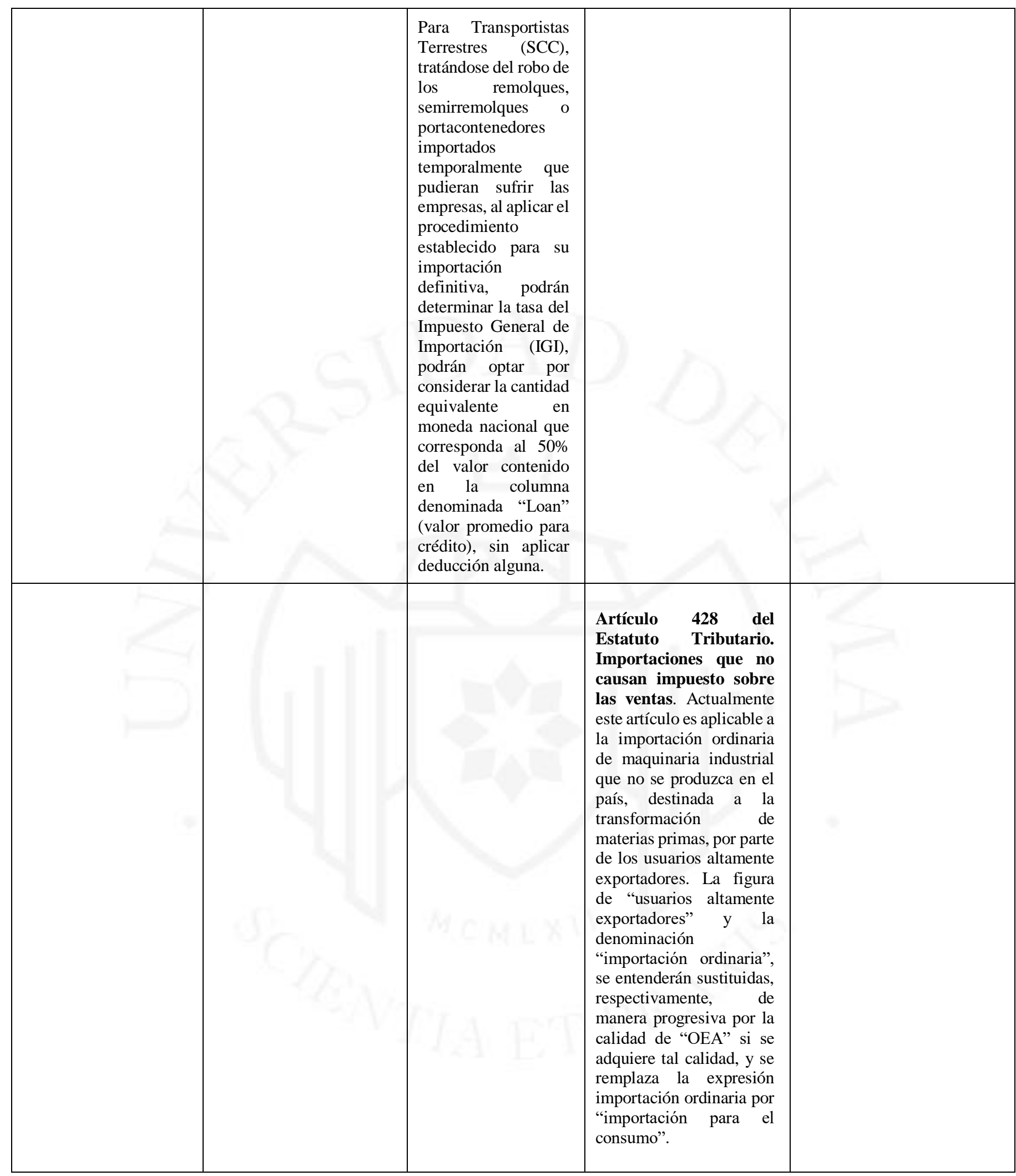




\begin{tabular}{|c|c|c|c|c|}
\hline & & & $\begin{array}{l}\text { Artículo 850, Parágrafo } \\
\mathbf{1} \text { del Estatuto } \\
\text { Tributario (Artículo 66 } \\
\text { de la Ley 1607/ 2012). } \\
\text { Que los responsables del } \\
\text { impuesto sobre las ventas } \\
\text { con derecho a } \\
\text { devolución, que ostenten } \\
\text { la calidad de OEA, } \\
\text { puedan solicitar la } \\
\text { devolución de saldos a } \\
\text { favor en forma bimestral, } \\
\text { independiente que } \\
\text { realicen las operaciones } \\
\text { del artículo } 481 \text { del ET, } \\
\text { sin que tengan que } \\
\text { esperar a la presentación } \\
\text { de la declaración de renta. }\end{array}$ & \\
\hline & & & $\begin{array}{l}\text { Artículo 855, Adición } \\
\text { Parágrafo } 5 \text { del Estatuto } \\
\text { Tributario (Artículo } 68 \\
\text { de la Ley 1607/2012). } \\
\text { Para los responsables del } \\
\text { artículo } 481 \text { del ET, que } \\
\text { sean OEA, el término } \\
\text { para que la DIAN, realice } \\
\text { la devolución es de } 30 \\
\text { días y no en 50 como } \\
\text { quedó para la generalidad } \\
\text { de las empresas. }\end{array}$ & \\
\hline \multirow[t]{5}{*}{$\begin{array}{l}\text { RECONOCIMIEN } \\
\text { TO MUTUO }\end{array}$} & $\begin{array}{l}\text { Reconocimiento Mutuo } \\
\text { con otros países como } \\
\text { empresas seguras y } \\
\text { confiables. }\end{array}$ & $\begin{array}{l}\text { Para } \\
\text { reconocimiento } \\
\text { Mutuo con otros } \\
\text { países como } \\
\text { empresas seguras y } \\
\text { confiables. }\end{array}$ & $\begin{array}{l}\text { Reconocimiento Mutuo } \\
\text { con otros países como } \\
\text { empresas seguras y } \\
\text { confiables. }\end{array}$ & $\begin{array}{l}\text { Reconocimiento Mutuo con } \\
\text { otros países como empresas } \\
\text { seguras y confiables. }\end{array}$ \\
\hline & $\begin{array}{l}\text { Invitación a participar en } \\
\text { sesiones de capacitación } \\
\text { permanente en asuntos } \\
\text { aduaneros, seguridad de } \\
\text { la cadena logística y } \\
\text { eventos vinculados. }\end{array}$ & $\begin{array}{l}\text { Para OEA y SCC, } \\
\text { participación en } \\
\text { talleres, congresos y } \\
\text { seminarios } \\
\text { especialmente } \\
\text { agendados para OEA. }\end{array}$ & $\begin{array}{l}\text { Participación en el } \\
\text { Congreso para OEA y en } \\
\text { las actividades de } \\
\text { capacitación } \\
\text { programadas para los } \\
\text { OEA, por parte de las } \\
\text { autoridades de control en } \\
\text { temas de su competencia. }\end{array}$ & $\begin{array}{l}\text { - Participación de manera } \\
\text { preferente en talleres, } \\
\text { congresos y seminarios } \\
\text { para OEA organizados o } \\
\text { patrocinados por el } \\
\text { Servicio. }\end{array}$ \\
\hline & & $\begin{array}{l}\text { Para OEA, } \\
\text { priorización en } \\
\text { despacho aduanero y } \\
\text { agilidad en líneas de } \\
\text { inspección. }\end{array}$ & & $\begin{array}{l}\text { - Atención prioritaria para } \\
\text { el despacho de las } \\
\text { mercancías. }\end{array}$ \\
\hline & $\begin{array}{l}\text { Atención preferente de } \\
\text { las consultas técnicas en } \\
\text { materia aduanera, según } \\
\text { corresponda. }\end{array}$ & & & \\
\hline & $\begin{array}{l}\text { Atención preferente en } \\
\text { las atenciones de } \\
\text { orientación y asistencia }\end{array}$ & & & \\
\hline
\end{tabular}




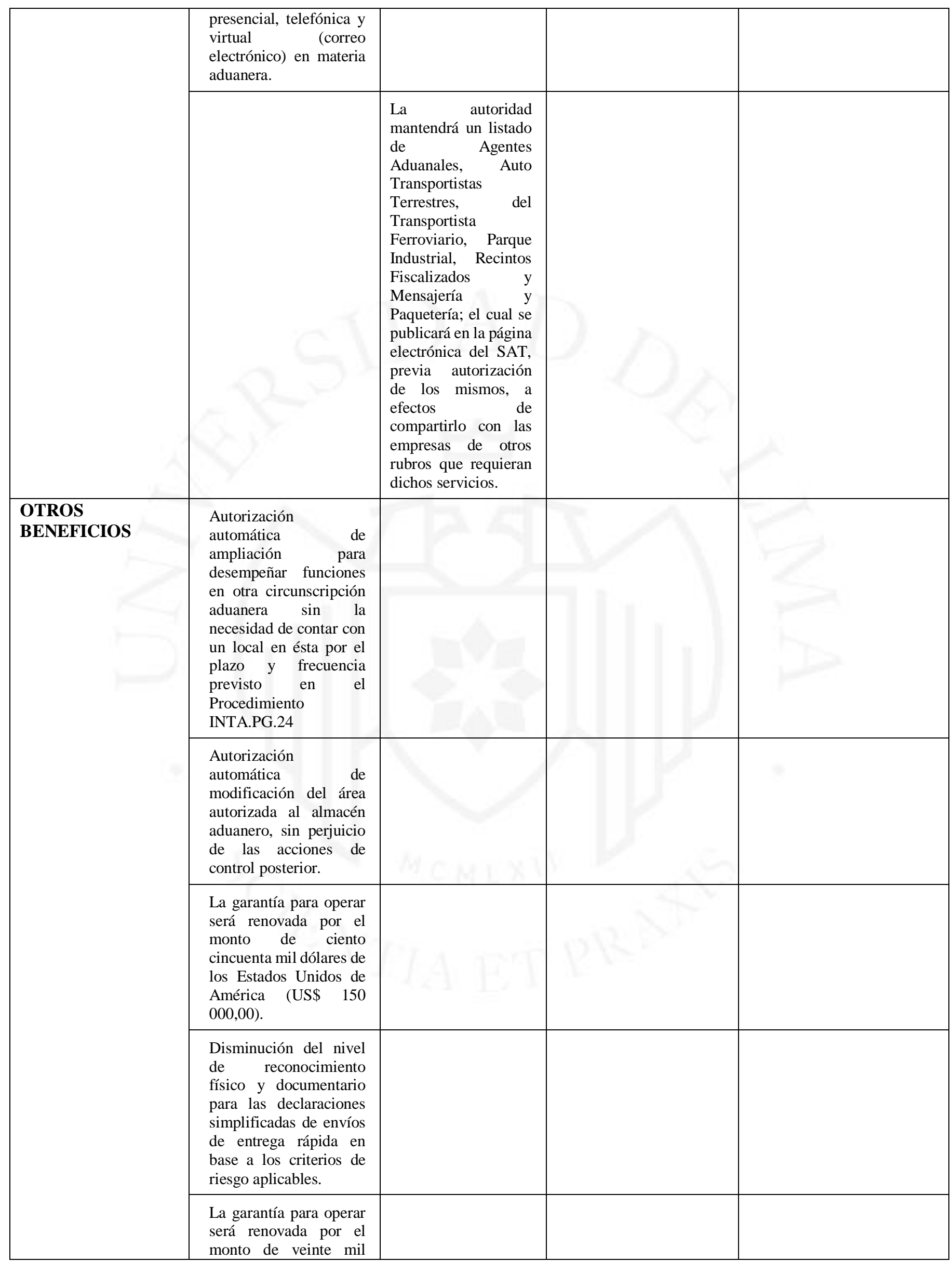




\begin{tabular}{|l|l|l|l|l|}
\hline & $\begin{array}{l}\text { dólares de los Estados } \\
\text { Unidos de América } \\
\text { (US\$20 000,00) }\end{array}$ & & & \\
\hline
\end{tabular}

Fuente: SUNAT 
ANEXO 3:

Beneficios otorgados en el programa OEA del Perú

\begin{tabular}{|c|c|c|c|c|c|c|}
\hline \multirow[b]{2}{*}{ Nro. } & \multirow[b]{2}{*}{ DESCRIPCIÓN } & \multicolumn{5}{|c|}{ Operador } \\
\hline & & Exportador & Importador & $\begin{array}{l}\text { Agente de } \\
\text { Aduana }\end{array}$ & Almacén & $\begin{array}{c}\text { Empresa de } \\
\text { Servicio de } \\
\text { Entrega } \\
\text { Rápida }\end{array}$ \\
\hline 1 & $\begin{array}{l}\text { Atención preferente, durante contingencias o } \\
\text { eventualidades de cierre de puertos y/o aeropuertos. En } \\
\text { el caso de Agentes de Aduana sólo será respecto de los } \\
\text { trámites que realicen en representación de otros OEA. }\end{array}$ & $\mathrm{X}$ & $\mathrm{x}$ & $\mathrm{X}$ & $\mathrm{X}$ & $\mathbf{X}$ \\
\hline 2 & $\begin{array}{l}\text { Atención preferente en la tramitación de recursos de } \\
\text { reclamación y expedientes de devolución de derechos, } \\
\text { presentados ante las Intendencias de Aduana de la } \\
\text { República, a fi n de ser atendidos en un plazo no mayor } \\
\text { a: } \\
\text { a) Tres (03) meses para los recursos de reclamación; } \\
\text { y } \\
\text { b) Treinta (30) días hábiles para las solicitudes de } \\
\text { devolución de derechos. } \\
\text { Se exceptúa del plazo previsto en el inciso a) a la } \\
\text { Gerencia de Fiscalización Aduanera de la Intendencia de } \\
\text { Gestión y Control Aduanero. } \\
\text { En el caso de Agentes de Aduana y las Empresas de } \\
\text { Servicio de Entrega Rápida solo será respecto de los } \\
\text { trámites que realicen en nombre propio o en } \\
\text { representación de exportadores o importadores } \\
\text { certificados como OEA. }\end{array}$ & $\mathrm{X}$ & $\mathrm{X}$ & $\mathrm{X}$ & $\mathrm{X}$ & $\mathbf{X}$ \\
\hline 3 & $\begin{array}{l}\text { Asignación de un sectorista de la DOEA, para la } \\
\text { orientación y asistencia especializada en procedimientos } \\
\text { vinculados al Programa OEA y en la coordinación con } \\
\text { las aduanas a nivel nacional. }\end{array}$ & $\mathrm{X}$ & $\mathrm{X}$ & $\mathrm{X}$ & $\mathrm{X}$ & $\mathbf{X}$ \\
\hline 4 & $\begin{array}{l}\text { Invitación a participar en sesiones de capacitación } \\
\text { permanente en asuntos aduaneros, seguridad de la } \\
\text { cadena logística y eventos vinculados. }\end{array}$ & $\mathrm{X}$ & $\mathrm{X}$ & $\mathrm{X}$ & $\mathrm{X}$ & $\mathbf{X}$ \\
\hline 5 & $\begin{array}{l}\text { Atención preferente de las consultas técnicas en materia } \\
\text { aduanera, según corresponda. }\end{array}$ & $\mathrm{X}$ & $\mathrm{X}$ & $\mathrm{X}$ & $\mathrm{X}$ & $\mathbf{X}$ \\
\hline 6 & $\begin{array}{l}\text { Atención preferente en las atenciones de orientación y } \\
\text { asistencia presencial, telefónica y virtual (correo } \\
\text { electrónico) en materia aduanera. }\end{array}$ & $\mathrm{X}$ & $\mathrm{x}$ & $\mathrm{X}$ & $\mathrm{X}$ & $\mathbf{X}$ \\
\hline 7 & $\begin{array}{l}\text { Disminución del nivel de reconocimiento físico para el } \\
\text { régimen de exportación, en base a los criterios de riesgo } \\
\text { aplicables. }\end{array}$ & $\mathrm{X}$ & & & & \\
\hline 8 & $\begin{array}{l}\text { Disminución del nivel de reconocimiento físico y } \\
\text { documentario para los regímenes de importación para el } \\
\text { consumo y de admisión temporal para su } \\
\text { perfeccionamiento activo, en base a los criterios de } \\
\text { riesgo aplicables. }\end{array}$ & & $\mathrm{x}$ & & & \\
\hline 9 & $\begin{array}{l}\text { Aprobación automática de la solicitud de restitución de } \\
\text { derechos arancelarios, salvo casos en que se determine } \\
\text { la revisión documentaria en base a los criterios de riesgo } \\
\text { aplicables, no siendo de aplicación la fiscalización } \\
\text { especial establecida en el Decreto Supremo Nro. 104- } \\
\text { 95-EF y modificatorias. }\end{array}$ & $\mathrm{X}$ & & & & \\
\hline 10 & $\begin{array}{l}\text { Atención preferente en los despachos sometidos a } \\
\text { reconocimiento físico en el Régimen de Exportación } \\
\text { Definitiva. }\end{array}$ & $\mathrm{X}$ & & & & \\
\hline
\end{tabular}




\begin{tabular}{|c|c|c|c|c|c|c|}
\hline \multirow[b]{2}{*}{ Nro. } & \multirow[b]{2}{*}{ DESCRIPCIÓN } & \multicolumn{5}{|c|}{ Operador } \\
\hline & & Exportador & Importador & $\begin{array}{l}\text { Agente de } \\
\text { Aduana }\end{array}$ & Almacén & $\begin{array}{l}\text { Empresa de } \\
\text { Servicio de } \\
\text { Entrega } \\
\text { Rápida } \\
\end{array}$ \\
\hline 11 & $\begin{array}{l}\text { Atención preferente en los despachos sometidos a } \\
\text { reconocimiento físico en el Régimen de Importación } \\
\text { para el consumo y de admisión temporal para su } \\
\text { perfeccionamiento activo. }\end{array}$ & $\mathrm{x}$ & $\mathrm{X}$ & & & \\
\hline 12 & $\begin{array}{l}\text { Atención preferente en las acciones de control } \\
\text { extraordinario efectuadas por la administración } \\
\text { aduanera en el almacén aduanero, puerto o aeropuerto, a } \\
\text { fi n de ser efectuadas y concluidas en un plazo no mayor } \\
\text { de dos (02) días hábiles, computados desde la entrega de } \\
\text { documentos sustentatorios por parte del OEA, salvo } \\
\text { casos debidamente justificados. }\end{array}$ & $\mathrm{x}$ & $\mathrm{X}$ & & & \\
\hline 13 & $\begin{array}{l}\text { Disminución de la selección a regularización con } \\
\text { revisión de documentos para las declaraciones del } \\
\text { Régimen de Exportación Definitiva seleccionadas, en } \\
\text { base a los criterios de riesgo aplicables. }\end{array}$ & $\mathrm{X}$ & & & & \\
\hline 14 & $\begin{array}{l}\text { Atención preferente de las regularizaciones } \\
\text { seleccionadas a revisión de documentos para las } \\
\text { declaraciones de los Regímenes de Exportación } \\
\text { Definitiva e Importación para el consumo sujeto a la } \\
\text { modalidad de despacho urgente. }\end{array}$ & $\mathrm{x}$ & $\mathrm{X}$ & & & \\
\hline 15 & $\begin{array}{l}\text { Atención preferente en la tramitación de la modificación } \\
\text { del valor declarado en la DAM de exportación } \\
\text { definitiva, a fi n de ser atendidos en un plazo no mayor } \\
\text { de dos (02) días hábiles siguientes a su recepción, salvo } \\
\text { casos debidamente justificados. }\end{array}$ & $\mathrm{X}$ & & & & \\
\hline 16 & $\begin{array}{l}\text { Atención preferente en la tramitación de expedientes } \\
\text { sobre rectificaciones de la DAM de exportación } \\
\text { definitiva, a excepción del valor declarado, a fin de ser } \\
\text { atendidos en un plazo no mayor de dos (02) días hábiles } \\
\text { siguientes a su recepción, salvo casos debidamente } \\
\text { justificados. } \\
\text { En el caso de la rectificación de la descripción de la } \\
\text { mercancía declarada en la DAM (40) sólo se requiere la } \\
\text { presentación de la siguiente documentación } \\
\text { sustentatoria: } \\
\$ \quad \text { Declaración jurada del exportador y } \\
* \quad \text { Factura Comercial, en caso de ser electrónica no } \\
\text { será necesaria que se adjunte al expediente. } \\
\text { La rectificación se solicita según lo establecido en el } \\
\text { Procedimiento de Exportación Definitiva INTA-PG.02 } \\
\text { vigente, con las facilidades referidas en los párrafos } \\
\text { anteriores. }\end{array}$ & $\mathrm{x}$ & & & . & \\
\hline 17 & $\begin{array}{l}\text { Atención preferente en la tramitación de expedientes } \\
\text { sobre rectificaciones de la DAM del régimen de } \\
\text { importación para el consumo. }\end{array}$ & & $\mathrm{x}$ & & & \\
\hline 18 & $\begin{array}{l}\text { Durante el despacho, las declaraciones de importación } \\
\text { para el consumo, admisión temporal para } \\
\text { perfeccionamiento activo y admisión temporal para } \\
\text { reexportaciones en el mismo estado, numeradas y } \\
\text { seleccionadas a canal rojo o naranja, no son objeto de } \\
\text { verificación y control del valor en aduana declarado en } \\
\text { el despacho. }\end{array}$ & $\mathrm{x}$ & $\mathrm{x}$ & & & \\
\hline
\end{tabular}




\begin{tabular}{|c|c|c|c|c|c|c|}
\hline \multirow[b]{2}{*}{ Nro. } & \multirow[b]{2}{*}{ DESCRIPCIÓN } & \multicolumn{5}{|c|}{ Operador } \\
\hline & & Exportador & Importador & $\begin{array}{l}\text { Agente de } \\
\text { Aduana }\end{array}$ & Almacén & $\begin{array}{l}\text { Empresa de } \\
\text { Servicio de } \\
\text { Entrega } \\
\text { Rápida }\end{array}$ \\
\hline 19 & $\begin{array}{l}\text { Actuación directa de exportadores e importadores como } \\
\text { despachadores de aduana de sus mercancías ante la } \\
\text { SUNAT, conforme a las condiciones y requisitos } \\
\text { previstos en el reglamento de la Ley General de } \\
\text { Aduanas, siendo que, en el caso de los regímenes de } \\
\text { ingreso, se encuentra exonerado de presentar garantía } \\
\text { para operar. }\end{array}$ & $\mathrm{x}$ & $\mathrm{x}$ & & & \\
\hline 20 & $\begin{array}{l}\text { Garantía nominal para el requerimiento previsto en el } \\
\text { artículo } 160^{\circ} \text { de la Ley, para el despacho de las } \\
\text { mercancías que solicite bajo el régimen de importación } \\
\text { para el consumo bajo la modalidad de despacho urgente } \\
\text { o anticipado, siempre que no haya sido objeto de } \\
\text { requerimientos de ejecución en estos despachos en el } \\
\text { periodo certificado como OEA. }\end{array}$ & & $\mathrm{x}$ & & & \\
\hline 21 & $\begin{array}{l}\text { En el régimen de admisión temporal para reexportación } \\
\text { en el mismo estado, presentación de una garantía } \\
\text { nominal para la garantía prevista en el artículo } 57^{\circ} \text { de la } \\
\text { Ley, siempre que no haya sido objeto de requerimientos } \\
\text { de ejecución en estos despachos en el periodo certificado } \\
\text { como OEA. }\end{array}$ & $\mathrm{x}$ & $\mathrm{x}$ & & & \\
\hline 22 & $\begin{array}{l}\text { En el régimen de admisión temporal para } \\
\text { perfeccionamiento activo, presentación de una garantía } \\
\text { nominal para la garantía prevista en el artículo } 71^{\circ} \text { de la } \\
\text { Ley, siempre que no haya sido objeto de requerimientos } \\
\text { de ejecución en estos despachos en el periodo certificado } \\
\text { como OEA. }\end{array}$ & $\mathrm{x}$ & $\mathrm{x}$ & & & \\
\hline 23 & $\begin{array}{l}\text { Atención preferente en la tramitación de las solicitudes } \\
\text { de clasificación arancelaria de mercancías, presentadas } \\
\text { ante la Intendencia de Gestión y Control Aduanero. }\end{array}$ & $\mathrm{X}$ & $\mathrm{x}$ & & & \\
\hline 24 & $\begin{array}{l}\text { Atención preferente en la expedición del Boletín } \\
\text { Químico, a fi n de ser emitido en un plazo no mayor de } \\
\text { un (01) día hábil a partir de la recepción de la muestra } \\
\text { por el Laboratorio Central de la IAMC, salvo casos } \\
\text { debidamente justificados. }\end{array}$ & $\mathrm{x}$ & $\mathrm{x}$ & & & \\
\hline 25 & $\begin{array}{l}\text { Embarque directo de las mercancías desde el local } \\
\text { designado por el exportador. }\end{array}$ & $\mathrm{x}$ & & & & \\
\hline 26 & $\begin{array}{l}\text { Ampliación de la autorización para desempeñar } \\
\text { funciones en otra circunscripción aduanera sin la } \\
\text { necesidad de contar con un local en esta. } \\
\text { La ampliación puede ser otorgada por seis meses y hasta } \\
\text { en seis oportunidades en el plazo de cuatro años. } \\
\text { La ampliación correspondiente a una misma } \\
\text { circunscripción aduanera puede ser otorgada hasta en } \\
\text { tres oportunidades en el plazo de cuatro años. } \\
\text { Los OEA pueden numerar el doble de la cantidad de } \\
\text { declaraciones aduaneras de mercancías que figuran en el } \\
\text { numeral 2.A.2 del Anexo } 60 \text { del Procedimiento General } \\
\text { DESPA-PG.24. } \\
\text { La aprobación de la solicitud de ampliación de } \\
\text { autorización es automática. }\end{array}$ & & & $\mathrm{X}$ & & \\
\hline 27 & $\begin{array}{l}\text { Autorización automática de modificación del área } \\
\text { autorizada al almacén aduanero, sin perjuicio de las } \\
\text { acciones de control posterior. }\end{array}$ & & & & $\mathrm{x}$ & \\
\hline
\end{tabular}




\begin{tabular}{|c|c|c|c|c|c|c|}
\hline \multirow[b]{2}{*}{ Nro. } & \multirow[b]{2}{*}{ DESCRIPCIÓN } & \multicolumn{5}{|c|}{ Operador } \\
\hline & & Exportador & Importador & $\begin{array}{l}\text { Agente de } \\
\text { Aduana }\end{array}$ & Almacén & $\begin{array}{c}\text { Empresa de } \\
\text { Servicio de } \\
\text { Entrega } \\
\text { Rápida } \\
\end{array}$ \\
\hline 28 & $\begin{array}{l}\text { Acceso a las facilidades adicionales previstas en los } \\
\text { Acuerdos de Reconocimiento Mutuo, conforme a lo } \\
\text { dispuesto en el mismo. }\end{array}$ & $\mathrm{X}$ & $\mathrm{X}$ & & & \\
\hline 29 & $\begin{array}{l}\text { La garantía para operar será renovada por el monto de } \\
\text { ciento cincuenta mil dólares de los Estados Unidos de } \\
\text { América (US\$150000,00). }\end{array}$ & & & $\mathrm{X}$ & & \\
\hline 30 & $\begin{array}{l}\text { Disminución del nivel de reconocimiento físico y } \\
\text { documentario para las declaraciones simplificadas de } \\
\text { envíos de entrega rápida en base a los criterios de riesgo } \\
\text { aplicables. }\end{array}$ & & & & & $\mathbf{X}$ \\
\hline 31 & $\begin{array}{l}\text { La garantía para operar será renovada por el monto de } \\
\text { veinte mil dólares de los Estados Unidos de América } \\
\text { (US\$ } 20000,00 \text { ) }\end{array}$ & & & & & $\mathbf{X}$ \\
\hline
\end{tabular}

Fuente: SUNAT 